\title{
$\mathrm{M}|\mathrm{R}| \mathrm{S}$ Internet Journal Nitride Semiconductor Research
}

\section{A Review of Dry Etching of GaN and Related Materials}

\author{
S.J. Pearton ${ }^{1}$, R. J. Shul ${ }^{2}$ and Fan Ren ${ }^{3}$ \\ ${ }^{1}$ Department of Materials Science and Engineering, University of Florida, \\ ${ }^{2}$ Sandia National Laboratories/New Mexico, \\ ${ }^{3}$ Department of Chemical Engineering, University of Florida,
}

(Received Wednesday, September 20, 2000; accepted Thursday, November 16, 2000)

The characteristics of dry etching of the AlGaInN materials system in different reactor types and plasma chemistries are reviewed, along with the depth and thermal stability of etch-induced damage. The application to device processing for both electronics and photonics is also discussed.

\section{Introduction}

$\mathrm{GaN}$ and related alloys are finding application for fabrication of blue/green/UV emitters (light-emitting diodes and lasers) and high temperature, high power electronic devices [1] [2] [3] [4]. The emitter technology is relatively mature, with light-emitting diodes being commercially available since 1994 and blue laser diodes also available from Nichia Chemical Industries. Electronic devices such as heterostructure field effect transistors (FETs), heterojunction bipolar transistors (HBTs), metal oxide semiconductor field effect transistors (MOSFETs) and diode rectifiers have all been realized in the AlGaInN system, with very promising high temperature $\left(>300^{\circ} \mathrm{C}\right)$ and high voltage performance. The applications for the emitter devices lies in full color displays, optical data storage, white-light sources and covert communications, while the electronic devices are suited for high power switches and microwave power generation.

Due to limited wet chemical etch results for the group-III nitrides, a significant amount of effort has been devoted to the development of dry etch processing [5] [6]. Dry etch development was initially focused on mesa structures where high etch rates, anisotropic profiles, smooth sidewalls and equirate etching of dissimilar materials were required. For example, commercially available LEDs and laser facets for GaN-based laser diodes were patterned using reactive ion etch (RIE). However, as interest in high power, high temperature electronics increased, etch requirements expanded to include smooth surface morphology, low plasmainduced damage and selective etching of one layer of another occurred. Dry etch development is further complicated by the inert chemical nature and strong bond energies of the group-III nitrides as compared to other compound semiconductors. GaN has a bond energy of $8.92 \mathrm{eV} /$ atom, InN $7.72 \mathrm{eV} /$ atom and AlN $11.52 \mathrm{eV} /$ atom.

\section{Plasma Reactors}

Dry plasma etching has become the dominant patterning technique for the group-III nitrides, due to the shortcomings in wet chemical etching. Plasma etching proceeds by either physical sputtering, chemical reaction, or a combination of the two often referred to as ion-assisted plasma etching, Physical sputtering is dominated by the acceleration of energetic ions formed in the plasma to the substrate surface at relatively high energies, typically $>200 \mathrm{eV}$. Due to the transfer of energy and momentum to the substrate, material is ejected from the surface. This sputter mechanism tends to yield anisotropic profiles; however, it can result in significant damage, rough surface morphology, trenching, poor selectivity and nonstoichiometric surfaces thus minimizing device performance. Pearton and co-workers measured sputter rates for GaN, InN, AlN and $\mathrm{InGaN}$ as a function of $\mathrm{Ar}^{+}$ ion energy [1] [2]. The sputter rates increased with ion energy but were quite slow, $<600 \AA / \mathrm{min}$, due to the high bond energies of the group III-N bond.

Chemically dominated etch mechanisms rely on the formation of reactive species in the plasma which absorb to the surface, form volatile etch products and then desorb from the surface. Since ion energies are relatively low, etch rates in the vertical and lateral direction are often similar thus resulting in isotropic etch profiles and loss of critical dimensions. However, due to the low ion energies used, plasma-induced damage is minimized. Alternatively, ion-assisted plasma etching relies on both chemical reactions and physical sputtering to yield anisotropic profiles at reasonably high etch rates. 
Provided the chemical and physical component of the etch mechanism are balanced, high resolution features with minimal damage can be realized and optimum device performance can be obtained.

\subsection{Reactive ion etching.}

RIE utilizes both the chemical and physical components of an etch mechanism to achieve anisotropic profiles, fast etch rates and dimensional control. RIE plasma are typically generated by applying radio frequency (rf) power of $13.56 \mathrm{MHz}$ between two parallel electrodes in a reactive gas [see Figure 1(a)]. The substrate is placed on the powered electrode where a potential is induced and ion energies, defined as they cross the plasma sheath, are typically a few hundred eV. RIE is operated at low pressures, ranging from a few mTorr up to 200 mTorr, which promotes anisotropic etching due to increased mean free paths and reduced collisional scattering of ions during acceleration in the sheath. Adesida et al. were the first to report RIE of $\mathrm{GaN}$ in $\mathrm{SiCl}_{4}$-based plasmas [6]. Etch rates increased with increasing dc bias, and were $>500 \AA / \mathrm{min}$ at $-400 \mathrm{~V}$. Lin et al., reported similar results for $\mathrm{GaN}$ in $\mathrm{BCl}_{3}$ and $\mathrm{SiCl}_{4}$ plasmas with etch rates of $1050 \AA / \mathrm{min}$ in $\mathrm{BCl}_{3}$ at $150 \mathrm{~W}$ cathode (area $250 \mathrm{in.}^{2}$ ) rf power [1] [2]. Additional RIE results have been reported for $\mathrm{HBr}-$ [1] [2], $\mathrm{CHF}_{3}$ - and $\mathrm{CCl}_{2} \mathrm{~F}_{2}$-based [1] [2] plasmas with etch rates typically $<600 \AA / \mathrm{min}$. The best RIE results for the group-III nitrides have been obtained in chorine-based plasmas under high ion energy conditions where the III-N bond breaking and the sputter desorption of etch products from the surface are most efficient. Under these conditions, plasma damage can occur and degrade both electrical and optical device performance. Lowering the ion energy or increasing the chemical activity in the plasma to minimize the damage often results in slower etch rates or less anisotropic profiles which significantly limits critical dimension. Therefore, it is necessary to pursue alternative etch platforms which combine high quality etch characteristics with low damage.

\subsection{High-density plasmas.}

The use of high-density plasma etch systems including electron cyclotron resonance (ECR), inductively coupled plasma (ICP) and magnetron RIE (MRIE), has resulted in improved etch characteristics for the groupIII nitrides as compared to RIE. This observation is attributed to plasma densities which are 2 to 4 orders of magnitude higher than RIE thus improving the III-N bond breaking efficiency and the sputter desorption of etch products formed on the surface. Additionally, since ion energy and ion density can be more effectively decoupled as compared to RIE, plasma-induced damage is more readily controlled. Figure 1 (b) shows a sche- matic diagram of a typical low profile ECR etch system. High-density ECR plasmas are formed at low pressures with low plasma potentials and ion energies due to magnetic confinement of electrons in the source region. The sample is located downstream from the source to minimize exposure to the plasma and to reduce the physical component of the etch mechanism. Anisotropic etching can be achieved by superimposing an rf bias (13.56 $\mathrm{MHz})$ on the sample and operating at low pressure $(<5$ mTorr) to minimize ion scattering and lateral etching. However, as the rf biasing is increased the potential for damage to the surface increases. Figure 2 shows a schematic of the plasma parameters and sample position in a typical high-density plasma reactor. Pearton and coworkers were the first to report ECR etching of group-III nitride films []]. Etch rates for $\mathrm{GaN}, \mathrm{InN}$ and $\mathrm{AlN}$ increased as either the ion energy (dc bias) or ion flux (ECR source power) increased. Etch rates of $1100 \AA$ / min for AlN and $700 \AA / m i n$ for $\mathrm{GaN}$ at $-150 \mathrm{~V}$ dc bias in a $\mathrm{Cl}_{2} / \mathrm{H}_{2}$ plasma and $350 \AA / \mathrm{min}$ for $\mathrm{InN}$ in a $\mathrm{CH}_{4} / \mathrm{H}_{2} /$ Ar plasma at $-250 \mathrm{~V}$ dc bias were reported. The etched features were anisotropic and the surface remained stoichiometric over a wide range of plasma conditions. $\mathrm{GaN}$ ECR etch data has been reported by several authors with etch rates as high as $1.3 \mu \mathrm{m} / \mathrm{min}$ [1] [2] [5] [6].

ICP offers another high-density plasma etch platform to pattern group-III nitrides. ICP plasmas are formed in a dielectric vessel encircled by an inductive coil into which rf power is applied [see Figure 1 (c)]. The alternating electric field between the coils induces a strong alternating magnetic field trapping electrons in the center of the chamber and generating a high-density plasma. Since ion energy and plasma density can be effectively decoupled, uniform density and energy distributions are transferred to the sample while keeping ion and electron energy low. Thus, ICP etching can produce low damage while maintaining fast etch rates. Anisotropy is achieved by superimposing of $\mathrm{rf}$ bias on the sample. ICP etching is generally believed to have several advantages over ECR including easier scale-up for production, improved plasma uniformity over a wider area and lower cost-of-operation. The first ICP etch results for $\mathrm{GaN}$ were reported in $\mathrm{Cl}_{2} / \mathrm{H}_{2} / \mathrm{Ar}$ ICPgenerated plasma with etch rates as high as $\sim 6875 \AA$ / min [7] . Etch rates increased with increasing dc bias and etch profiles were highly anisotropic with smooth etch morphologies over a wide range of plasma conditions. GaN etching has also been reported in a variety of halogen- and methane-based ICP plasmas [8]. Use of a $\mathrm{Cl}_{2} / \mathrm{Ar} / \mathrm{O}_{2}$ chemistry produced good selectivity for $\mathrm{GaN}$ and $\mathrm{InGaN}$ over $\mathrm{AlGaN}$ (up to $~ 50$ ), due to formation of an oxide on the $\mathrm{AlGaN}$ [8]. 
MRIE is another high-density etch platform which is comparable to RIE. In MRIE, a magnetic field is used to confine electrons close to the sample and minimize electron loss to the wall. Under these conditions, ionization efficiencies are increased and high plasma densities and fast etch rates are achieved at much lower dc biases (less damage) as compared to RIE. GaN etch rates of $\sim 3500 \AA /$ min were reported in $\mathrm{BCl}_{3}$-based plasmas at dc

biases <-100 V. The etch was fairly smooth and anisotropic.

\subsection{Chemically-Assisted Ion Beam Etching.}

Chemically assisted ion beam etching (CAIBE) and reactive ion beam etching (RIBE) have also been used to etch group-III nitride films [6] [7]. In these processes, ions are generated in a high-density plasma source and accelerated by one or more grids to the substrate. In CAIBE, reactive gases are added to the plasma downstream of the acceleration grids thus enhancing the chemical component of the etch mechanism, whereas in RIBE, reactive gases are introduced in the ion source. Both etch platforms rely on relatively energetic ions $(200-2000 \mathrm{eV})$ and low chamber pressures ( $<5 \mathrm{mTorr})$ to achieve anisotropic etch profiles. However, with such high ion energies, the potential for plasma-induced damage exists. Adesida and co-workers reported CAIBE etch rates for $\mathrm{GaN}$ as high as $2100 \AA / \mathrm{min}$ with $500 \mathrm{eV}$ $\mathrm{Ar}^{+}$ions and $\mathrm{Cl}_{2}$ or $\mathrm{HCl}$ ambients [6]. Rates increased with beam current, reactive gas flow rate and substrate temperature. Anisotropic profiles with smooth etch morphologies were observed.

\subsection{Reactive Ion Beam Etching.}

The RIBE removal rates for $\mathrm{GaN}, \mathrm{AlN}$ and $\mathrm{InN}$ are shown in Figure 3 as a function of $\mathrm{Cl}_{2}$ percentage in $\mathrm{Cl}_{2} /$ Ar beams at $400 \mathrm{eV}$ and $100 \mathrm{~mA}$ current. The trend in removal rates basically follows the bond energies of these materials. At fixed $\mathrm{Cl}_{2} / \mathrm{Ar}$ ratio, the rates increased with beam energy. At very high voltages, one would expect the rates to saturate or even decrease due to ion-assisted desorption of the reactive chlorine from the surface of the nitride sample before it can react to form the chloride etch products.

There was relatively little effect of either beam current or sample temperature on the RIBE removal rates of the nitride. The etch profiles are anisotropic with light trenching at the base of the features. This is generally ascribed to ion deflection from the sidewalls causing an increased ion flux at the base of the etched features.

\subsection{Low Energy Electron Enhanced Etching.}

Low energy electron enhanced etching (LE4) of GaN has been reported by Gilllis and co-workers [9]. LE4 is an etch technique which depends on the interaction of low energy electrons $(<15 \mathrm{eV})$ and reactive species at the substrate surface. The etch process results in minimal surface damage since there is negligible momentum transferred from the electrons to the substrate. GaN etch rates of $\sim 500 \AA / m i n$ in a $\mathrm{H}_{2}$-based LE4 plasma and $\sim 2500 \AA / \mathrm{min}$ in a pure $\mathrm{Cl}_{2}$ LE4 plasma have been reported [9]. GaN has also been etched using photoassisted dry etch processes where the substrate is exposed to a reactive gas and ultraviolet laser radiation simultaneously. Vibrational and electronic excitations lead to improved bond breaking and desorption of reactant products. GaN etch rates are compared in Figure 4 for RIE, ECR and ICP $\mathrm{Cl}_{2} / \mathrm{H}_{2} / \mathrm{CH}_{4} / \mathrm{Ar}$ plasmas as well as a RIBE $\mathrm{Cl}_{2} / \mathrm{Ar}$ plasma. $\mathrm{CH}_{4}$ and $\mathrm{H}_{2}$ were removed from the plasma chemistry to eliminate polymer deposition in the RIBE chamber. Etch rates increased as a function of dc bias independent of etch technique. GaN etch rates obtained in the ICP and ECR plasmas were much faster than those obtained in RIE and RIBE. This was attributed to higher plasma densities (1-4 orders of magnitude higher) which resulted in more efficient breaking of the III-N bond and sputter desorption of the etch products. Slower rates observed in the RIBE may also be due to lower operational pressures $(0.3$ mTorr compared to 2 mTorr for the ICP and ECR) and/or lower ion and reactive neutral flux at the GaN surface due to high sourceto-sample separation.

\section{Plasma Chemistries}

\section{$3.1 \mathrm{Cl}_{2}$-Based.}

Etch characteristics are often dependent upon plasma parameters including pressure, ion energy and plasma density. As a function of pressure, plasma conditions including the mean free path and the collisional frequency can change resulting in changes in both ion energy and plasma density. GaN etch rates are shown as a function of pressure for an ICP-generated $\mathrm{BCl}_{3} / \mathrm{Cl}_{2}$ plasma in Figure 5. Etch rates increased as the pressure was increased from 1 to 2 mTorr and then decreased at higher pressures. The initial increase in etch rate suggested a reactant limited regime at low pressure, however at higher pressures the etch rates decreased due either to lower plasma densities (ions or radical neutrals), redeposition or polymer formation on the substrate surface. At pressures $<10 \mathrm{mTorr}, \mathrm{GaN}$ etches were anisotropic and smooth, while at pressure $>10$ mTorr the etch profile was undercut and poorly defined due to a lower mean free path, collisional scattering of the ions and increased lateral etching of the GaN.

$\mathrm{GaN}$ etch rates are plotted as a function of dc bias (which correlates to ion energy) for an ICP-generated $\mathrm{BCl}_{3} / \mathrm{Cl}_{2}$ plasma in Figure 6. The $\mathrm{GaN}$ etch rates increased monotonically as the dc bias or ion energy 
increased. Etch rates increased due to improved sputter desorption of etch products from the surface as well as more efficient breaking of the Ga-N bonds. Etch rates have also been observed to decrease under high ion bombardment energies due to sputter desorption of reactive species from the surface before the reactions occur. This is often referred to as an adsorption limited etch regime. In Figure 7, SEM micrographs are shown for (a) -50 , (b) -150 and (c) $-300 \mathrm{~V}$ dc bias. The etch profile became more anisotropic as the dc bias increased from -50 to $-150 \mathrm{~V}$ dc bias due to the perpendicular path of the ions relative to the substrate surface which maintained straight wall profiles. However, as the dc bias was increased to $-300 \mathrm{~V}$, a tiered etch profile with vertical striations in the sidewall was observed due to erosion of the resist mask edge. The GaN may become rougher at these conditions due to mask redeposition and preferential loss of $\mathrm{N}_{2}$.

In Figure 8, GaN etch rates are shown as a function of ICP-source power while the dc bias was held constant at $-250 \mathrm{~V}$. GaN etch rates increased as the ICP source power increased due to higher concentrations of reactive species which increases the chemical component of the etch mechanism and/or higher ion flux which increases the bond breaking and sputter desorption efficiency of the etch. Etch rates have also been observed to stabilize or decrease under high plasma flux conditions due either to saturation of reactive species at the surface or sputter desorption of reactive species from the surface before the reactions occur. The etch profile was anisotropic and smooth up to $1000 \mathrm{~W}$ ICP power where the feature dimensions were lost and sidewall morphology was rough due to erosion of the mask edge under high plasma flux conditions. In addition to etch rates, etch selectivity or the ability to etch one film at higher rates than another can be very important in device fabrication. For example, optimization of etch selectivity is critical to control threshold voltage uniformity for high electron mobility transistors (HEMTs), to accurately stop on either the emitter or collector regions for metal contacts for heterojunction bipolar transistors (HBTs), and for low resistivity $n$-ohmic contacts on InN layers. Several studies have recently reported etch selectivity for the group-III nitrides [6] [7] [8]. For example, Figure 9 shows GaN, InN and AlN etch rates and etch selectivities as a function of cathode rf power in an ICP-generated $\mathrm{Cl}_{2} / \mathrm{Ar}$ plasma. Etch rates for all three films increased with increasing cathode $\mathrm{rf}$ power or dc bias due to improved breaking of the III-N bonds and more efficient sputter desorption of the etch products. Increasing $\mathrm{InN}$ etch rates were especially significant since $\mathrm{InCl}_{3}$, the primary In etch product in a $\mathrm{Cl}$-based plasma, has a relatively low volatility. However, under high dc-bias conditions, desorption of the $\mathrm{InCl}_{3}$ etch products occurred prior to coverage of the etch surface. The GaN:InN and GaN:AlN etch selectivities were <8:1 and decreased as the cathode rf power or ion energy increased. Smith and co-workers reported similar results in a $\mathrm{Cl}_{2}$-Ar ICP plasma where GaN:AlN and GaN:AlGaN selectivities decreased as dc bias increased. At $-20 \mathrm{~V}$ dc bias, etch selectivities of $\sim 39: 1$ were reported for GaN:AlN and $\sim 10: 1$ for GaN:AlGaN. Temperature dependent etching of the group-III nitrides have been reported in ECR and ICP etch systems [5]. Etch rates are often influenced by the substrate temperature which can effect the desorption rate of etch produce, the gas-surface reaction kinetics and the surface mobility of reactants. Substrate temperature can be controlled and maintained during the etch process by a variety of clamping and backside heating or cooling procedures. GaN and $\mathrm{InN}$ etch rates are shown in Figure 10 as a function of temperature in $\mathrm{Cl}_{2} / \mathrm{H}_{2} / \mathrm{Ar}$ ICP plasma. GaN etch rates were much faster than $\mathrm{InN}$ due to higher volatility of the $\mathrm{GaCl}_{3}$ etch products as compared to $\mathrm{InCl}_{3}$ and showed little dependence on temperature. However, the $\mathrm{InN}$ etch rates showed a considerable temperature dependence increasing at $150^{\circ} \mathrm{C}$ due to higher volatilities of the $\mathrm{InCl}_{3}$ etch products at higher substrate temperatures.

Several different plasma chemistries have been used to etch the group-III nitrides. As established above, etch rates and profiles can be strongly affected by the volatility of the etch products formed. Table I shows the boiling points of possible etch products for the group-III nitrides exposed to halogen- and hydrocarbon-based plasmas. For halogen-based plasmas, etch rates are often limited by the volatility of the group-III halogen etch product. For Ga- and Al-containing films, chlorine-based plasmas typically yield fast rates with anisotropic, smooth etch profiles. $\mathrm{CH}_{4} / \mathrm{H}_{2}$-based plasma chemistries have also yielded smooth, anisotropic profiles for Ga-containing films, however at much slower rates. Based only on a comparison of etch product volatility, slower etch rates in $\mathrm{CH}_{4}$-based plasmas is unexpected since the $\left(\mathrm{CH}_{3}\right)_{3} \mathrm{Ga}$ etch product has a much lower boiling point than $\mathrm{GaCl}_{3}$. This observation demonstrates the complexity of the etch process where redeposition, polymer formation, and gas-phase kinetics can influence the results. As shown above, etch rates for Incontaining films obtained in room temperature chlorinebased plasmas tend to be slow with rough surface morphology and overcut profiles due to the low volatility of the $\mathrm{InCl}_{3}$ and preferential loss of the group- $\mathrm{V}$ etch products. However, at elevated temperatures $\left(>130^{\circ} \mathrm{C}\right)$, the $\mathrm{InCl}_{3}$ volatility increases and the etch rates and surface 
morphology improve. Significantly better room temperature etch results are obtained in $\mathrm{CH}_{4} / \mathrm{H}_{2}$-based plasmas due to the formation of more volatile $\left(\mathrm{CH}_{3}\right)_{3} \mathrm{In}$ etch products. Another example of plasma chemistry dependent etching of $\mathrm{GaN}$ is shown in Figure 13 for $\mathrm{Cl}_{2} / \mathrm{N}_{2} /$ $\mathrm{Ar}$ and $\mathrm{BCl}_{3} / \mathrm{N}_{2} / \mathrm{Ar} \mathrm{ICP}$-generated plasmas. In the $\mathrm{Cl}_{2}$ based plasma, $\mathrm{GaN}$ etch rates decreased as the $\% \mathrm{~N}_{2}$ increased, presumable due to a reduction in reactive $\mathrm{Cl}$. In the $\mathrm{BCl}$-based plasma $\mathrm{GaN}$ etch rates increased up to $40 \% \mathrm{~N}_{2}$ and then decreased at higher $\mathrm{N}_{2}$ concentration. This observation has also been reported for ECR and ICP etching of GaAs, GaP and In-containing films [8]. Ren and co-workers first observed maximum etch rates for In-containing films ( $\mathrm{InGaN}$ and $\mathrm{InGaP}$ ) in an ECR discharge at a gas ratio of $75 / 25$ for $\mathrm{BCl}_{3} / \mathrm{N}_{2}$ [10]. Using optical emission spectroscopy (OES), Ren reported maximum emission intensity for atomic and molecular $\mathrm{Cl}$ at $75 \% \mathrm{BCl}_{3}$ as well as a decrease in the $\mathrm{BCl}_{3}$ intensity and the appearance of a $\mathrm{BN}$ emission line. The authors speculated that $\mathrm{N}_{2}$ enhanced the dissociation of $\mathrm{BCl}_{3}$ resulting in higher concentrations of reactive $\mathrm{Cl}$ and $\mathrm{Cl}$ ions and thus higher etch rates.

Additionally, the observation of $\mathrm{BN}$ emission suggested that less B was available to recombine with reactive Cl. This explanation may also be applied to the peak GaN etch rates observed at $40 \% \mathrm{~N} 2$ in the ICP $\mathrm{BCl} 3 / \mathrm{N} 2 / \mathrm{Ar}$ plasmas. However, OES of the BCl3/N2/Ar ICP discharge did not reveal higher concentrations of reactive $\mathrm{Cl}$ nor a $\mathrm{BN}$ peak emission. In Figure 14, OES spectra are shown for (a) $100 \% \mathrm{BCl} 3$ (b) $75 \% \mathrm{BCl} 3-$ $25 \% \mathrm{~N} 2$, (c) $\mathrm{BCl} 3-75 \% \mathrm{~N} 2$ and (d) $100 \%$ N2 ICP plasmas. As $\mathrm{N} 2$ was added to the $\mathrm{BCl} 3$ plasma, the $\mathrm{BCl} 3$ emission (2710 $\mathrm{A}$ ) and $\mathrm{Cl}$ emission (5443 and $5560 \AA$ ) decreased while the BN emission (3856 $\AA$ ) was not obvious. $\mathrm{BCl}_{3} / \mathrm{Cl}_{2}$ plasmas have shown encouraging results in the etching of $\mathrm{GaN}$ films. The addition of $\mathrm{BCl}_{3}$ to a $\mathrm{Cl}_{2}$ plasma can improve sputter desorption due to higher mass ions and reduce surface oxidation by gettering $\mathrm{H}_{2} \mathrm{O}$ from the chamber. In Figure 15, GaN etch rates are shown as a function of $\% \mathrm{Cl}_{2}$ in a $\mathrm{BCl}_{3}$ / $\mathrm{Cl}_{2} / \mathrm{Ar}$ ICP plasma. As the $\% \mathrm{Cl}_{2}$ increased, $\mathrm{GaN}$ etch rates increased up to $80 \%$ due to higher concentrations of reactive $\mathrm{Cl}$. OES showed the $\mathrm{Cl}$ emission intensity increased and the $\mathrm{BCl}$ emission intensity decreased as the $\% \mathrm{Cl}_{2}$ increased.

Slower $\mathrm{GaN}$ etch rates in a pure $\mathrm{Cl}_{2}$ plasma were attributed to less efficient sputter desorption of etch products in the absence of $\mathrm{BCl}_{3}$. The fastest $\mathrm{GaN}$ etch rates were observed at $10 \% \mathrm{BCl}_{3}$ where the ion current density and $\mathrm{Cl}$ radical density were the greatest as measured by OES and a Langmuir probe. In general,
GaN:AlN and GaN:InN etch selectivities are $<10: 1$ as a function of plasma chemistry for $\mathrm{Cl}_{2}$ - or $\mathrm{BCl}_{3}$-based plasmas. GaN:AlN and GaN:InN etch selectivities were higher for $\mathrm{Cl}_{2}$-based ICP plasmas as compared to $\mathrm{BCl}_{3}$ based ICP plasma due to higher concentration of reactive $\mathrm{Cl}$ produced in the $\mathrm{Cl}_{2}$-based plasmas thus resulting in faster $\mathrm{GaN}$ etch rates. Alternatively, InN and $\mathrm{AlN}$ etch rates showed much less dependence on plasma chemistry and were fairly comparable in $\mathrm{Cl}_{2^{-}}$and $\mathrm{BCl}_{3^{-}}$ based plasmas. An example of etch selectivity dependence on plasma chemistry is shown in Figure 16. GaN, $\mathrm{AlN}$ and $\mathrm{InN}$ etch rates and etch selectivities are plotted as a function of $\% \mathrm{SF}_{6}$ for an $\mathrm{ICP} \mathrm{Cl}_{2} / \mathrm{SF}_{6} / \mathrm{Ar}$ plasma. $\mathrm{GaN}$ and $\mathrm{InN}$ etch rates decreased as $\mathrm{SF}_{6}$ was added to the plasma due to the consumption of $\mathrm{Cl}$ by $\mathrm{S}$ and therefore lower concentrations of reactive $\mathrm{Cl}$. The $\mathrm{AlN}$ etch rates increased with the addition of $\mathrm{SF}_{6}$ and reached a maximum at $20 \% \mathrm{SF}_{6}$. As $\mathrm{SF}_{6}$ was added to the $\mathrm{Cl}_{2}$ plasma, slower AlN etch rates were expected due to the formation of low volatility $\mathrm{AlF}_{3}$ etch products. However, due to the high ion flux in the ICP, the sputter desorption of the $\mathrm{AlF}_{3}$ may occur prior to passivation of the surface. Therefore, the GaN:AlN selectivity decreased rapidly from $\sim 6: 1$ to $<1: 1$ with the addition of $\mathrm{SF}_{6}$. The GaN:InN selectivity reached a maximum of $4: 1$ at $20 \%$ $\mathrm{SF}_{6}$.

The simple $\mathrm{Cl}_{2} / \mathrm{Ar}$ chemistry works very well for most device fabrication processes, providing controllable etch rates. Even at biases $<90 \mathrm{~V}$, the $\mathrm{GaN}$ etch rate is still typically $\sim 1000 \AA \cdot \mathrm{min}^{-1}$.

\section{$3.2 \mathrm{I}_{2}$ and $\mathrm{Br}_{2}$ Based.}

Other halogen-containing plasmas including $\mathrm{ICl} / \mathrm{Ar}$, $\mathrm{IBr} / \mathrm{Ar}, \mathrm{BBr}_{3} / \mathrm{Ar}$ and $\mathrm{BI}_{3} / \mathrm{Ar}$ have been used to etch $\mathrm{GaN}$ with promising results [5] [6] [8]. Vartuli and coworkers reported $\mathrm{GaN}$, InN, AlN, InN, InAlN and InGaN etch rates and selectivities in ECR $\mathrm{ICl} / \mathrm{Ar}$ and $\mathrm{IBr} / \mathrm{Ar}$ plasmas [5]. In general, etch rates increased for all films as a function of dc bias due to improved III-N bond breaking and sputter desorption of etch products from the surface. GaN etch rates $>1.3 \mu \mathrm{m} / \mathrm{min}$ were obtained in the $\mathrm{ICl} / \mathrm{Ar}$ plasma at a rf power of $250 \mathrm{~W}$ (bias of $-200 \mathrm{~V}$ ) while $\mathrm{GaN}$ etch rates were typically $<4000 \AA /$ min in IBr/Ar. Cho et.al. reported GaN etch rates typically $<2000 \AA /$ min in ICP-generated $\mathrm{BI}_{3} / \mathrm{Ar}$ and $\mathrm{BBR}_{3} / \mathrm{Ar}$ plasmas [5]. ICl/Ar and $\mathrm{IBr} / \mathrm{Ar} \mathrm{ECR}$ plasmas yielded GaN:InN, GaN:AlN, GaN:InGaN and GaN:InAlN selectivities <6:1, however, etch selectivities >100:1 were obtained for InN:GaN and InN:AlN in $\mathrm{BI}_{3}$ /ar plasmas. Fast etch rates obtained for $\mathrm{InN}$ were attributed to the high volatility of the $\mathrm{InI}_{3}$ etch products 
as compared to the $\mathrm{GaI}_{3}$ and $\mathrm{AlI}_{3}$ etch products which can form passivation layers on the surface. Maximum selectivities of $\sim 100: 1$ for InN:AlN and $\sim 7.5$ for InN:GaN were reported in the $\mathrm{BBr}_{3} / \mathrm{Ar}$ plasma. $\operatorname{InI}_{\mathrm{x}}$ products have higher volatility than corresponding $\mathrm{InGl}_{\mathrm{x}}$ species, making iodine an attractive enchant for InGaN alloys. The inter-halogen compounds are weakly bonded, and therefore should easily break apart under plasma excitation to form reactive iodine, bromine and chlorine.

Figure 17 shows etch rates for the binary nitrides and selectivities for InN over both GaN and AlN as a function of the boron halide percentage by flow in the gas load. The dc chuck self-bias decreases as the $\mathrm{BI}_{3}$ content increases, suggesting that the ion density in the plasma is increasing. The $\mathrm{InN}$ etch rate is proportional to the $\mathrm{BI}_{3}$ content, indicating the presence of a strong chemical component in its etching. In comparison, AlN and GaN show very low rates until $\sim 50 \% \mathrm{BI}_{3}(\sim 500 \AA$ $\mathrm{min}^{-1}$ for AlN and $\sim 1700 \AA / \mathrm{min}^{-1}$ for GaN). An increase in the $\mathrm{BI}_{3}$ content in the discharges actually produces a falloff in the etch rate for both AIN and GaN. We expect there are several possible mechanisms by which to explain these data. First, the decrease in chuck self-bias and hence ion energy under these conditions may more than compensate for the higher active iodine neutral flux. Second, the formation of the less volatile $\mathrm{GaI}_{\mathrm{x}}$ and $\mathrm{AlI}_{\mathrm{x}}$ etch products may create a selvege layer which suppresses the etch rate. This mechanism occurs in the $\mathrm{Cl}_{2}$ reactive ion etching of InP. In this system, etching does not occur unless elevated sample temperatures or higher dc biases are used to facilitate removal of the $\mathrm{InCl}_{3}$ etch product. In InN etch selectivity to both materials initially increases but also goes through a minimum. Note, however, that selectivities of $>100$ can be achieved for both InN/AlN and InN/GaN.

Data for $\mathrm{BBr}_{3} / \mathrm{Ar}$ discharges are also shown in Figure 17 for fixed source power $(750 \mathrm{~W})$ and rf chuck power $(350 \mathrm{~W})$. Higher rf powers were required to initiate etching with $\mathrm{BBr}_{3}$ compared to $\mathrm{BI}_{3}$ and the dc selfbias increased with the $\mathrm{BBr}_{3}$ content. The etch rate of $\mathrm{InN}$ is again a strong function of the boron halide content, while GaN shows significant rates $\left(\sim 1800 \AA / \mathrm{min}^{-1}\right)$ only for pure $\mathrm{BBr}_{3}$ discharges, AlN shows very low etch rates over the whole range of conditions investigated. Maximum selectivities of $\sim 100: 1$ for InN/AIN and 7.5:1 for InN/GaN are obtained.

Based on the results in Figure 17, we chose fixed plasma compositions, and varied the ion energy and flux through control of the source and chuck powers. Figure 18 shows that source power had a significant effect only on the InN etch rate for both $4 \mathrm{BI}_{3} / 6 \mathrm{Ar}$ and $4 \mathrm{BBr}_{3} / 6 \mathrm{Ar}$ discharges at fixed $\mathrm{rf}$ power $(150 \mathrm{~W})$. The etch rate of InN continues to increase with source power, which controls the ion flux and dissociation of the discharge, whereas the GaN and AlN rates are low for both plasma chemistries. The InN etch rates are approximately a factor of 2 faster in $\mathrm{BI}_{3} / \mathrm{Ar}$ than in $\mathrm{BBr}_{3} / \mathrm{Ar}$ even for lower rf chuck powers. This is expected from taking into consideration the relative stabilities of the respective In etch products (the $\mathrm{InI}_{3}$ melting point is $210^{\circ} \mathrm{C}$; $\mathrm{InBr}_{3}$ sublimes at $\left.<600^{\circ} \mathrm{C}\right)$. The resultant selectivities are shown at the bottom of Figure 18; once again a value of $\sim 100: 1$ for $\mathrm{InN}$ over $\mathrm{GaN}$ is achieved with $\mathrm{BI}_{3}$, whereas $\mathrm{BBr}_{3}$ produced somewhat lower values.

The dependence of the etch rate and InN/AlN and InN/GaN selectivities on rf chuck power for both plasma chemistries at fixed source power $(750 \mathrm{~W})$ is shown in Figure 19. While the GaN and AlN etch rates (top left) increase only at the highest chuck powers investigated for $4 \mathrm{BI}_{3} / 6 \mathrm{Ar}$ discharges, the InN etch rate increases rapidly to $250 \mathrm{~W}$. This is consistent with a strong ion-assisted component for the latter under these conditions. The subsequent decrease in the etch rate at higher power produces corresponding maxima $(\geq 100)$ in etch selectivity for chuck powers in the range of 150$250 \mathrm{~W}$. This type of behavior is quite common to high density plasma etching of III-V materials, where the etching is predominantly ion-assisted desorption of somewhat volatile products, with insignificant rates under ion-free conditions. In this scenario, at very high ion energies, the active etching species (iodine neutral in this case) can be removed by sputtering before they have a chance to complete the reaction with substrate atoms. Similar data for $\mathrm{BBr}_{3} / \mathrm{Ar}$ mixtures are also shown in Figure 19. For this chemistry the $\mathrm{InN}$ etch rate saturates and we did not observe any reduction in etch rate, although this might be expected to occur if higher powers could be applied (over power supply is limited to $450 \mathrm{~W}$ ). GaN does show an etch rate maximum at $\sim 350$ $\mathrm{W}$, producing a minimum in the resultant $\mathrm{InN} / \mathrm{GaN}$ selectivity. The etch selectivity of InN over the other two nitrides for $\mathrm{BI}_{3} / \mathrm{Ar}$ is again much higher than for $\mathrm{BBr}_{3} / \mathrm{Ar}$.

The effect of plasma composition on etch rates and selectivities if GaN, $\mathrm{AlN}$ and $\mathrm{InN}$ in $\mathrm{ICl} / \mathrm{Ar}$ and $\mathrm{IBr} / \mathrm{Ar}$ discharges at $750 \mathrm{~W}$ source power, $250 \mathrm{~W}$ rf chuck power and 5 mTorr is shown in Figure 20. The etch rates of InN and AlN are relatively independent of the plasma composition for both chemistries over a broad composition range, indicating the etch mechanism is dominated by physical sputtering. The dc bias voltage increased with increasing interhalogen concentrations. 
The decrease in ion flux also implies an increase in the concentrations of neutral species such as $\mathrm{Cl}, \mathrm{Br}$ and $\mathrm{I}$. The etch rate of $\mathrm{GaN}$ steadily increased with increasing $\mathrm{ICl}$ concentration. By contrast the etch rate of $\mathrm{GaN}$ saturated beyond $66.7 \% \mathrm{IBr}$. These results indicate that etching of $\mathrm{GaN}$ in both chemistries can be attributed more to chemical etching by increased concentrations of reactive neutrals than to ion-assisted sputtering. The effect of plasma composition showed an overall trend of decrease in selectivities for InN over both $\mathrm{AlN}$ and GaN as the concentration of $\mathrm{ICl}$ and $\mathrm{IBr}$ increased.

\section{3 $\mathrm{CH}_{4} / \mathrm{H}_{2} / \mathrm{Ar}$.}

Pearton and co-workers were the first to etch group-III nitride films in an ECR-generated $\mathrm{CH}_{4} / \mathrm{H}_{2} / \mathrm{Ar}$ plasma [5]. Etch rates for GaN, InN and AIN were $<400 \AA / m i n$ at $\sim-250 \mathrm{~V}$ dc bias. Vartuli et.al. reported ICP GaN, InN and AlN etch rates approaching $2500 \AA / m i n$ in $\mathrm{CH}_{4} /$ $\mathrm{H}_{2} \mathrm{Ar}$ and $\mathrm{CH}_{4} / \mathrm{H}_{2} / \mathrm{N}_{2}$ plasmas [5]. Etch rates increased with increasing dc bias or ion flux and were higher in $\mathrm{CH}_{4} / \mathrm{H}_{2} / \mathrm{Ar}$ plasmas. Anisotropy and surface morphology were good over a wide range of conditions. As compared to $\mathrm{Cl}$-based plasmas, etch rates were consistently slower which may make the $\mathrm{CH}_{4} / \mathrm{H}_{2}$-based processes applicable for devices where etch depths are relatively shallow and etch control is extremely important.

Vartuli and co-workers compared etch selectivities in $\mathrm{CH}_{4} / \mathrm{H}_{2} / \mathrm{Ar}$ and $\mathrm{Cl}_{2} / \mathrm{Ar}$ plasmas in both RIE- and ECR-generated plasmas [5]. For $\mathrm{CH}_{4} / \mathrm{H}_{2} / \mathrm{Ar}$ plasmas, InN:GaN and $\mathrm{InGaN}: \mathrm{GaN}$ etch selectivities ranged from $1: 1$ to $6: 1$ whereas etch selectivities of $1: 1$ or favoring $\mathrm{GaN}$ over the In-containing films was reported for $\mathrm{Cl}_{2} /$ Ar plasmas.

\section{Etch Profile And Etched Surface Morphology}

Sidewall morphology is especially critical in the formation of laser mesas for ridge waveguide emitters or for buried planar devices. The vertical striations observed in the GaN sidewall in Figure 21(a) were due to striations in the photoresist mask which were transferred into the GaN feature during the etch. The sidewall morphology and in particular the vertical striations were improved in an $\mathrm{ICP} \mathrm{Cl}_{2} / \mathrm{BCl}_{3}$ plasma at $-150 \mathrm{~V}$ dc bias. The etch conditions were at 2 mTorr chamber pressure, $500 \mathrm{~W}$ ICP power, $32 \mathrm{sccm} \mathrm{Cl}_{2}, 8 \mathrm{sccm} \mathrm{BCl}_{3}, 5 \mathrm{sccm}$ Ar, $25^{\circ} \mathrm{C}$ temperature, and a dc bias of $-150 \pm 10 \mathrm{~V}$. Ren et.al. have demonstrated improved $\mathrm{GaN}$ sidewall morphology etched in an ECR using a $\mathrm{SiO}_{2}$ mask. Vertical striations in the $\mathrm{SiO}_{2}$ mask were reduced by optimizing the lithography process used to pattern the $\mathrm{SiO}_{2}$. The
$\mathrm{SiO}_{2}$ was then patterned in a $\mathrm{SF}_{6} / \mathrm{Ar}$ plasma in which a low temperature dielectric overcoat was used to protect the resist sidewall during the etch.

In several studies atomic force microscopy (AFM) has been used to quantify the etched surface morphology as root-mean-square (rms) roughness. Rough etch morphology often indicates a nonstoichiometric surface due to preferential removal of either the group-III or group-V species.

A summary of etch rate results for the nitrides with different chemistries and different techniques is shown in Table II.

\section{Plasma-Induced Damage}

Plasma-induced damage often degrades the electrical and optical properties of compound semiconductor devices. Since GaN is more chemically inert than GaAs and has higher bonding energies, more aggressive etch conditions (higher ion energies and plasma flux) may be used with potentially less damage to the material. Limited data have been reported for plasma-induced damage of the group-III nitrides [5] [11]. Pearton and co-workers reported increased plasma-induced damage as a function of ion flux and ion energy for InN, InGaN and InAlN in an ECR [5]. The authors also reported: (a) more damage in InN films as compared to InGaN; (b) more damage in lower doped materials and (c) more damage under high ion energy conditions due to formation of deep acceptor states which reduce the carrier mobility and increased resistivity. Postetch annealing processes removed the damage in the $\mathrm{InGaN}$ while the InN damage was not entirely removed.

Ren and co-workers measured electrical characteristics for InAlN and GaN FET structures to study plasmainduced damage for ECR $\mathrm{BCl}_{3}, \mathrm{BCl}_{3} / \mathrm{N}_{2}$ and $\mathrm{CH}_{4} / \mathrm{H}_{2}$ plasmas [10]. They reported: (a) doping passivation in the channel layer in the presence of hydrogen; (b) high ion bombardment energies can create deep acceptor states that compensate the material and (c) preferential loss of $\mathrm{N}$ can produce rectifying gate characteristics. Ping and co-workers studied Schottky diodes for Ar and $\mathrm{SiCl}_{4} \mathrm{RIE}$ plasmas [6]. More damage was observed in pure Ar plasmas and under high dc-bias conditions. Plasma-induced damage of $\mathrm{GaN}$ was also evaluated in ICP and ECR Ar plasma using photoluminescence (PL) measurements as a function of cathode rf power and source power [12]. The peak PL intensity decreased with increasing ion energy independent of etch technique. As a function of source power or plasma density the results were less consistent. The PL intensity showed virtually no change at low ICP source power and then decreased as the plasma density increased. In the ECR plasma, the PL intensity increased by $\sim 115 \%$ at 
low ECR source power and improved at higher ECR source powers but at a lower rate. The effect of postetch annealing in Ar varied depending on initial film conditions, however, annealing at temperatures above $440^{\circ} \mathrm{C}$ resulted in a reduction in the PL intensity.

Surface stoichiometry can also be used to evaluate plasma-induced damage. Nonstoichiometric surfaces can be created by preferential loss of one of the lattice constituents. This may be attributed to higher volatility of the respective etch products, leading to enrichment of the less volatile species, or preferential sputtering of the lighter element. Auger electron spectroscopy (AES) can be used to measure surface stoichiometry. Figure 22 shows characteristic Auger spectra for (a) as-grown GaN samples and samples exposed to an ECR plasma $\mathrm{t}$ $850 \mathrm{~W}$ applied microwave power and cathode rf powers of (b) 65 and (c) $275 \mathrm{~W}$. For the as-grown sample, the Auger spectrum showed a $\mathrm{Ga}: \mathrm{N}$ ratio of 1.5 with normal amounts of adventitious carbon and native oxide on the GaN surface. Following plasma exposure, the Ga:N ratio increased as the cathode rf power increased with some residual atomic $\mathrm{Cl}$ from the plasma. Under high ion energy conditions, preferential removal of the lighter $\mathrm{N}$ atoms as observed resulting in Ga-rich surfaces.

\section{$5.1 \mathrm{n}$-GaN.}

The etching requirements for electronic devices are more demanding than those for photonic devices, at least from the electrical quality viewpoint. One of the most sensitive tests of near-surface electrical properties is the quality of rectifying contacts deposited on the etched surface. There has been relatively little work in this area to date. Ren et.al. [10]. found that rectifying contacts on electron cyclotron resonance plasma etched GaN and InAlN surfaces were very leaky, though some improvement could be obtained by postetch annealing at $400^{\circ} \mathrm{C}$. Ping et.al. [6]. found that reactively ion etched n-GaN surfaces had poor Schottky contact properties, but that plasma chemistries with a chemical component (e.g. $\mathrm{Cl}_{2}$-based mixtures) produced less degradation than purely physical etching.

The layer structure and contact metals are shown schematically in Figure 23. The GaN was grown by rf plasma-assisted molecular beam epitaxy on $c$-plane $\mathrm{Al}_{2} \mathrm{O}_{3}$ substrates. The Ti/Au ohmic contracts were patterned by lift-off and annealed at $750^{\circ} \mathrm{C}$, producing contact resistances in the $10^{-5} \Omega \mathrm{cm}^{-2}$ range. Samples were exposed to either pure $\mathrm{N}_{2}$ or $\mathrm{H}_{2}$ discharges in a Plasma Therm 790 ICP system at a fixed pressure of 5 mTorr. The gases were injected into the ICP source at a flow rate of 15 standard cubic centimeters per minute $(\mathrm{sccm})$. The experimentally varied parameters were source power (300-1000 W) and rf chuck power (40-250 W), which control ion flux and ion energy, respectively. In some cases the samples were either annealed in $\mathrm{N}_{2}$ for $30 \mathrm{~s}$ at $300-850^{\circ} \mathrm{C}$, or photoelectrochemically etched in $0.2 \mathrm{M} \mathrm{KOH}$ solutions at $25^{\circ} \mathrm{C}$ after plasma exposure. The Pt/Au Schottky metallization was then deposited through a stencil mass by e-beam evaporation. Currentvoltage characteristics were recorded on a HP4145A parameter analyzer, and we defined the reverse breakdown voltage $\left(\mathrm{V}_{\mathrm{B}}\right)$ as the voltage at which the leakage current was $10^{-3} \mathrm{~A}$. We found in all cases that plasma exposure caused significant increases in forward and reverse current, with ideality factors increasing from typical values of $1.4-1.7$ on control samples to $>2$. For this reason we were unable to extract meaningful values of either ideality factor or barrier height. Figure 24 shows a series of $\mathrm{I}-\mathrm{V}$ characteristics from the $\mathrm{GaN}$ diodes fabricated on samples exposed to either $\mathrm{H}_{2}$ or $\mathrm{N}_{2}$ discharges at different source powers. It is clear that $\mathrm{N}_{2}$ plasma exposure creates more degradation of the diode characteristics than does $\mathrm{H}_{2}$ exposure. This implicates the ion mass $\left({ }^{28} \mathrm{~N}_{2}{ }^{+},{ }^{2} \mathrm{H}_{2}{ }^{+}\right.$for the main positive ion species) as being more important in influencing the electrical properties of the GaN surface than a chemical effect, since $\mathrm{H}_{2}$ would be likely to preferentially remove nitrogen from the $\mathrm{GaN}$ as $\mathrm{NH}_{3}$.

The variations of $V_{B}$ of the diodes with the source power during plasma exposure are shown in Figure 25. For any exposure to the $\mathrm{N}_{2}$ discharges $\mathrm{V}_{\mathrm{B}}$ is severely reduced. By contrast there is less degradation with the $\mathrm{H}_{2}$ plasma to the lower average ion energy at those conditions, as shown at the bottom of Figure 25. The average ion energy is approximately equal to the sum of $\mathrm{dc}$ self-bias and plasma potential, with the later being in the range -22 to $-28 \mathrm{~V}$ as determined by Langmuir probe measurements. Ion induced damage in $\mathrm{GaN}$ displays $n$ type conductivity, and in addition the heavy $\mathrm{N}_{2}{ }^{+}$ions are also more effective in preferential sputtering of the $\mathrm{N}$ relative to $\mathrm{Ga}$, compared to the $\mathrm{H}_{2}{ }^{+}$ions of similar energy.

Similar conclusions can be drawn from the data on the effect of increasing rf chuck power. There were once again very severe decreases in breakdown voltage and increase in leakage current. The $\mathrm{V}_{\mathrm{B}}$ values fall by more than a factor of two even for very low self-biases, and emphasize how sensitive the GaN surface is to degradation by energetic ion bombardment. The degradation saturates beyond $\sim 100 \mathrm{~W}$ chuck power, corresponding to ion energies of $\sim 175 \mathrm{eV}$. We assume that once the immediate surface becomes sufficiently damaged, the contact properties basically cannot be made any worse and the issue is then whether the damage depth increases with the different plasma parame- 
ters. Since ion energy appears to be a critical factor in creating the near-surface damage, we would expect damage depth to increase with ion energy in a nonetching process. In the case of simultaneous etching and damage creation (e.g. in $\mathrm{Cl}_{2} / \mathrm{Ar}$ etch processing), higher etch rates would lead to lower amounts of residual damage because the disordered region would be partially removed.

The damage depth was established by photoelectrochemically wet etching different amounts of the plasmaexposed GaN surfaces, and then depositing the $\mathrm{Pt} / \mathrm{Au}$ metal. Figure 26 (top) show the effect on the I-V characteristics of this removal of different depth of GaN. There is a gradual restoration of the reverse breakdown voltage, as shown at the bottom of the figure. Note that the forward part of the characteristics worsens for removal of $260 \AA$ of $\mathrm{GaN}$, and shows signs of high series resistance. This would be consistent with the presence of a highly resistive region underneath the conducting near-surface layer, created by point defect diffusion from the surface. A similar model applies to iondamaged InP, i.e. a nonstoichiometric near-surface region (deficient in $\mathrm{P}$ in that case), followed by a transition to a stoichiometric but point defect-compensated region, and finally to unperturbed InP.

The fact that plasma exposure severely degraded the surface was clear from the atomic force microscopy (AFM) data. Exposure to the $500 \mathrm{~W}$ source power, 150 W rf chuck power (dc self-bias - $221 \mathrm{~V}$ ), 5 mTorr $\mathrm{N}_{2}$ discharge increased the root-mean-square (rms) surface roughness form 0.8 to $4.2 \mathrm{~nm}$. Subsequent photoelectrochemical etching restored the initial morphology. However, we observed the onset of increasingly rough surfaces for deeper etch depths [4], reducing a relatively inaccurate measure of how much of the surface had to be removed in order to restore the diode breakdown voltage to its original value. We were able to estimate this depth as $\sim 600 \pm 150 \AA$ for the $\mathrm{N}_{2}$ plasma conditions mentioned above. Another method for trying to restore the electrical properties of the plasma-exposed surface is annealing. I-V data from annealed samples are shown in Figure 27. At the top are characteristics from samples, which were plasma exposed $\left(\mathrm{N}_{2}, 500 \mathrm{~W}\right.$ source power, $150 \mathrm{~W}$ rf chuck power, 5 mTorr), then annealed and the contact deposited. These samples show that increasing annealing temperature up to $750^{\circ} \mathrm{C}$ brings a substantial improvement in $\mathrm{V}_{\mathrm{B}}$ (Figure 27, bottom). However for annealing at $850^{\circ} \mathrm{C}$ the diode began to degrade and this is consistent with the temperature at which $\mathrm{N}_{2}$ begins to be lost from the surface. In the case where the samples were exposed to the $\mathrm{N}_{2}$ plasma, and then the $\mathrm{Pt} / \mathrm{Au}$ contact was deposited prior to annealing, the I-V characteristics show continued worsening upon annealing (Figure 27, center). In this case, the $\mathrm{Pt} / \mathrm{Au}$ contact is stable to $700^{\circ} \mathrm{C}$ on unetched samples. The poorer stability in etched samples could be related to the surface damage enhancing interfacial reaction between the $\mathrm{Pt}$ and $\mathrm{GaN}$.

The main findings of this study can be summarized as follows:

There is a severe degradation in the electrical quality of GaN surfaces after ICP $\mathrm{H}_{2}$ or $\mathrm{N}_{2}$ discharge exposure. Under all conditions there is a strong reduction of $V_{B}$ in diode structures to the point at which the Schottky contacts show almost ohmic-like behavior. These observations are consistent with the creation of a conducting $n$ type surface layer resulting from energetic ion bombardment. Heavier ions $\left(\mathrm{N}_{2}^{+}\right)$create more damage than lighter ions $\left(\mathrm{H}_{2}^{+}\right)$in this situation, where damage is accumulating without any concurrent etching of the surface.

The depth of the damage is approximately $600 \AA$, as judged by the return of the diode characteristics to their control values.

Annealing at $750^{\circ} \mathrm{C}$ is also effective in helping remove the effects of plasma exposure. Higher temperatures lead to degradation in GaN diode properties for uncapped anneals.

\section{2 p-GaN.}

The layer structure consisted of $1 \mu \mathrm{m}$ of undoped $\mathrm{GaN}$ $\left(\mathrm{n} \sim 5 \times 10^{16} \mathrm{~cm}^{-3}\right)$ grown on a c-plane $\mathrm{Al}_{2} \mathrm{O}_{3}$ substrate, followed by $0.3 \mu \mathrm{m}$ of $\mathrm{Mg}$ doped $\left(\mathrm{p} \sim 10^{17} \mathrm{~cm}^{-3}\right) \mathrm{GaN}$. The samples were grown by rf plasma-assisted Molecular Beam Epitaxy. Ohmic contacts were formed with $\mathrm{Ni} / \mathrm{Au}$ deposited by e-beam evaporation, followed by lift-off and annealing at $750^{-\circ} \mathrm{C}$. The GaN surface was then exposed for $1 \mathrm{~min}$ to ICP $\mathrm{H}_{2}$ or Ar plasmas in a Plasma-Therm 790 System. The $2 \mathrm{MHz}$ ICP source power was varied from 300-1400 W, while the 13.56 $\mathrm{MHz}$ rf chuck power was varied from $20-250 \mathrm{~W}$. The former parameter controls ion flux incident on the sample, while the latter controls the average ion energy. Prior to deposition of $250 \mu \mathrm{m}$ diameter Ti/Pt/Au contacts through a stencil mask, the plasma exposed surfaces were either annealed under $\mathrm{N}_{2}$ in a rapid thermal annealing system, or immersed in boiling $\mathrm{NaOH}$ solutions to remove part of the surface. As reported previously it is possible to etch damaged $\mathrm{GaN}$ in a self-limiting fashion in hot alkali or acid solutions. The current-voltage (I-V) characteristics of the diodes were recorded on a HP 4145A parameter analyzer. The unetched control diodes have reverse breakdown voltages of $\sim 2.5-4 \mathrm{~V}$ depending on the wafer - these values were uniform $( \pm 12 \%)$ across a particular water. 
Figure 28 shows the I-V characteristics from samples exposed to either $\mathrm{H}_{2}$ (top) or Ar (bottom) ICP discharges (150 W rf chuck, 2 mTorr) as a function of source power. In both cases there is an increase in both the reverse breakdown voltage and the forward turn-on voltage, with these parameters increasing monotonically with the source power during plasma exposure.

Figure 29 shows this increase in breakdown voltage as a function of source power, and also the variation of the chuck dc self-bias. As the source power increases, the ion density also increases and the higher plasma conductivity suppresses the developed dc bias. Note that the breakdown voltage of the diodes continues to increase even as this bias (and hence ion energy, which is the sum of this bias and the plasma potential) decreases. These results show that ion flux lays an important role in the change of diode electrical properties. The other key result is that Ar leads to consistently more of an increase in breakdown voltage, indicating that ion mass is important rather than any chemical effect related to removal of $\mathrm{N}_{2}$ or $\mathrm{NH}_{3}$ in the $\mathrm{H}_{2}$ discharges.

The increase in breakdown voltage on the $\mathrm{p}-\mathrm{GaN}$ is due to a decrease in hole concentration in the near-surface region through the creation of shallow donor states. The key question is whether there is actually conversion to an n-type surface under any of the plasma condition. Figure 30 shows the forward turn-on characteristics of the $\mathrm{p}-\mathrm{GaN}$ diodes exposed to different source power $\mathrm{Ar}$ discharge at low source power $(300 \mathrm{~W})$, the turn-on remains close to that of the unexposed control sample. However there is a clear increase in the turn-on voltage at higher source powers, and in fact at $\geq 750 \mathrm{~W}$ the characteristics are those of an $n-p$ junction. Under these conditions the concentration of plasma-induced shallow donors exceeds the hole concentration and there is surface conversion. In other words the metal-p GaN diode has become a metal-n GaN-p GaN junction. We always find that plasma exposed $\mathrm{GaN}$ surfaces are $\mathrm{N}_{2}$-deficient relative to their unexposed state, and therefore the obvious conclusion is nitrogen vacancies create shallow donor levels. This is consistent with thermal annealing experiments in which $\mathrm{N}_{2}$ loss from the surface produced increased n-type conduction.

An important question is the depth of the plasmainduced damage. We found we were able to etch p-GaN very slowly in boiling $\mathrm{NaOH}$ solutions, at rates that depended on the solution molarity (Figure 31) even without any plasma exposure of the material. This enabled us to directly measure the damage depth in plasma exposed samples in two different ways. The first method involved measuring the etch rate as a function of depth from the surface. Defective $\mathrm{GaN}$ resulting from plasma, thermal or implant damage can be wet chemically etched at rates much faster than undamaged material because the acid or base solutions are able to attack the broken or strained bonds present. Figure 32 shows the $\mathrm{GaN}$ etch rate as a function of depth in samples exposed to a $750 \mathrm{~W}$ source power, $150 \mathrm{~W}$ rf chuck power Ar discharge. The etch rate is a strong function of the depth from the surface and saturates between $~ 425$ $550 \AA$. Within this depth range the etch rate is returned to the "bulk" value characteristic of undamaged p-GaN.

The other method of removing plasma-induced damage is annealing. In these experiments we exposed the samples to the same type of plasma (Ar, $750 \mathrm{~W}$ source power, $150 \mathrm{~W}$ rf chuck power) and then annealed under $\mathrm{N}_{2}$ at different temperatures. Figure 34 (top) shows the I-V characteristics of these different samples, while Figure 34 (bottom) shows the resulting breakdown voltages as a function of annealing temperature. On this wafer, Plasma exposure caused an increase in breakdown voltage from $\sim 2.5$ to $\sim 18 \mathrm{~V}$. Subsequent annealing at $400^{\circ} \mathrm{C}$ initially decreased the breakdown voltage, but higher temperature produced a large increase. At temperatures above $700^{\circ} \mathrm{C}$, the diodes characteristics returned toward their initial values and were back to the control values by $900^{\circ} \mathrm{C}$. This behavior is similar to that observed in implant-isolated compound semiconductors where ion damage compensates the initial doping in the material, producing higher sheet resistance. In many instances the damage site density is larger than that needed to trap all of the free carriers, and trapped electrons or holes may move by hopping conduction. Annealing at higher temperatures removes some of the damage sites, but there are still enough to trap all the conduction electrons/holes. Under these conditions the hopping conduction is reduced and the sample sheet resistance actually increases. At still higher annealing temperatures, the trap density falls below the conduction electron or hole concentration and the latter are returned to their respective bands. Under these conditions the sample sheet resistance returns to its pre-implanted value. The difference in the plasma exposed samples is that the incident ion energy is a few hundred eV compared to a few hundred $\mathrm{keV}$ in implant-isolated material. In the former case the main electrically active defects produced are nitrogen vacancies near the surface, whereas in the latter case there will be vacancy and interstitial complexes produced in far greater numbers to far greater depths. In our previous work on plasma damage in $\mathrm{n}-\mathrm{GaN}$ we found that annealing at $\sim 750^{\circ} \mathrm{C}$ almost returned the electrical properties to their initial values. If the same defects are present in both n- and p-type material after plasma exposure, this difference in annealing temperature may be a result of a Fermi level 
dependence to the annealing mechanism. The main conclusions of this study may be summarized as follow:

The effect of either $\mathrm{H}_{2}$ or Ar plasma exposure on pGaN surfaces is to decrease the net acceptor concentration through creation of shallow donor levels, most likely $\mathrm{N}_{\mathrm{V}}$. At high ion fluxes or ion energies there can be type conversion of the initially p-type surface. The change in electrical properties is more pronounced with Ar than with $\mathrm{H}_{2}$ plasmas under the same conditions.

Two different techniques for measuring the damage depth find it to be in the range 400-500 $\AA$ under our conditions. After removing this amount of $\mathrm{GaN}$, both the breakdown voltage and wet chemical etch rates are returned to their initial values.

Post-etch annealing in $\mathrm{N}_{2}$ at $900^{\circ} \mathrm{C}$ restores the initial breakdown voltage on plasma exposed p-GaN. Annealing at higher temperatures degraded the electrical properties, again most likely due to $\mathrm{N}_{2}$ loss from the surface.

\subsection{Schottky Diodes.}

Contrary to initial expectations, the surface of $\mathrm{GaN}$ is relatively sensitive to energetic ion bombardment or thermal degradation encountered during device processing. In particular it can preferentially lose $\mathrm{N}_{2}$, leaving a strong n-type conducting regions. While dry etching has been used extensively for patterning of photonic devices (light-emitting and laser diodes) and opto-electronic devices (UV detectors), there has been little work performed on understanding the electrical effects of ioninduced point defects or non-stoichiometric surfaces resulting from the plasma exposure. Several groups have reported increases in sheet-resistance of $\mathrm{GaN}$ exposed to high density plasmas, along with decreases in reverse breakdown voltage $\left(\mathrm{V}_{\mathrm{B}}\right)$ and reductions in Schottky barrier height $\left(\phi_{\mathrm{B}}\right)$ in diodes formed on n-type $\mathrm{GaN}$. In this latter case, low-bias forward currents were increased up to two orders of magnitude after exposure of the diode to pure Ar discharges. Conversely, while the rectifying contact properties were degraded by plasma exposure, the specific resistance of n-type ohmic contacts was improved. Similarly, in p-type GaN, the effect of $\mathrm{Ar}$ or $\mathrm{H}_{2}$ high density plasma exposure was to decrease the net acceptor concentration to depths of $\sim 500 \AA$. At high ion fluxes or energies, there was typeconversion of the initially $\mathrm{p}-\mathrm{GaN}$ surface.

Dry etching is needed for a range of $\mathrm{GaN}$ electronic devices, including mesa diodes rectifiers, thyristors and heterojunction bipolar transistors for high temperature, high power operation. These applications include control of power flow in utility grids, radar and electronic motor drives. It is critical to understand the depth and thermal stability of dry etch damage in both n- and p- type $\mathrm{GaN}$ and its effect on the current-voltage (I-V) characteristics of simple diode structures.

In this section we report on a comparison of the effects of $\mathrm{Cl}_{2} / \mathrm{Ar}$ and Ar Inductively Coupled Plasma (ICP) exposure on the electrical properties of $\mathrm{n}$ - and $\mathrm{p}$ $\mathrm{GaN}$ Schottky diodes. In some cases it was found that $\mathrm{Cl}_{2} / \mathrm{Ar}$ discharges could produce even more damage than pure Ar, due to the slightly higher ion energies involved. The damage saturates after a short exposure to either $\mathrm{Cl}_{2} / \mathrm{Art}$ or $\mathrm{Ar}$ discharges and is significant even for low ion energies. Annealing between $700-800^{\circ} \mathrm{C}$ restored $\geq 70 \%$ of the reverse breakdown voltage on $n$ $\mathrm{GaN}$, while the damage depth was again established to be $\sim 500 \AA$ in $\mathrm{p}-\mathrm{GaN}$.

The $\mathrm{GaN}$ layers were grown by rf plasma-assisted Molecular Beam Epitaxy on c-plane $\mathrm{Al}_{2} \mathrm{O}_{3}$ substrates. The Ti/Al (for n-type) and Ni/Au (for p-type) ohmic contacts were patterned by lift-off and annealed at $750^{\circ} \mathrm{C}$. The samples were exposed to either $10 \mathrm{Cl}_{2} / 5 \mathrm{Ar}$ or $15 \mathrm{Ar}$ (where the numbers denote the gas flow rate in standard cubic centimeters per minute) ICP discharges in a Plasma-Therm ICP reactor at a fixed pressure of 3 mTorr. We investigated a range of rf chucks powers $(25-250 \mathrm{~W})$ and etch times (4-100 secs), with a fixed source power of $500 \mathrm{~W}$. In some cases, the samples were either annealed in $\mathrm{N}_{2}$ for 30 secs at $500-800^{\circ} \mathrm{C}$ or wet etching in $0.1 \mathrm{M} \mathrm{NaOH}$ solutions at $\sim 100^{\circ} \mathrm{C}$ after plasma exposure. The Schottky metallization ( $\mathrm{Pt} / \mathrm{Au}$ in both cases) was then deposited through a stencil mask ( $\phi$ $=70$ or $90 \mu \mathrm{m}$ ) by e-beam evaporation. Current-voltage characteristics were recorded on an HP 4145A parameter analyzer, and we defined the reverse breakdown voltage as that at which the leakage current was $10^{-3} \mathrm{~A}$. The forward on-voltage $V_{F}$ was defined as the voltage at which the forward current was $100 \mathrm{~A} \cdot \mathrm{cm}^{-2}$. In all cases the ideality factors increased from 1.3-1.6 on control samples to $>2$ after plasma exposure and thus we were unable to extract meaningful values of either barrier height or ideality factor.

Figure 35 shows a series of I-V characteristics from n-type GaN diodes fabricated on samples exposed to either $\mathrm{Cl}_{2} / \mathrm{Ar}$ (top) or $\mathrm{Ar}$ (bottom) discharges at different rf chuck powers. There is a significant reduction in $V_{B}$ under all conditions, with Ar producing less damage at low chuck powers. This is probably related to two factors - the slightly higher chuck bias with $\mathrm{Cl}_{2} / \mathrm{Ar}$ due to the lower positive ion density in the plasma $(\mathrm{Cl}$ is more electronegative than Ar) and the heavier mass of the $\mathrm{Cl}_{2}{ }^{+}$ions compared to $\mathrm{Ar}^{+}$. This is consistent with our past data on the relative effects of $\mathrm{N}_{2}$ and $\mathrm{H}_{2}$ plasma exposure, in which ion mass was found to be more 
important in influencing the electrical properties of the $\mathrm{GaN}$ surface than any chemical effects.

The variations of $V_{B}$ and $V_{F}$ with the rf chuck power during plasma exposure are shown in Figure 36 (top). At powers $\leq 100 \mathrm{~W}$, the $\mathrm{Cl}_{2} / \mathrm{Ar}$ creates more degradation of $\mathrm{V}_{\mathrm{B}}$, as discussed above, while at higher powers the damage saturates. The average ion energy is the sum of dc self-bias (shown at the bottom of the figure) and plasma potential (which is about 22-25 eV under these conditions). Thus for ion energies $<\sim 150 \mathrm{eV}$, Ar produces less damage than $\mathrm{Cl}_{2} / \mathrm{Ar}$, even though the etch rate with the latter is much higher. This is also reflected in the variation of ${ }_{F}$ with $\mathrm{rf}$ chuck power.

Figure 37 shows a series of I-V characteristics from $\mathrm{n}$-type $\mathrm{GaN}$ diodes fabricated on samples exposed to the two different plasmas for different times at fixed rf chuck power $(150 \mathrm{~W})$ and source power $(500 \mathrm{~W})$. It is clear that the damage accumulates rapidly, with the I-V characteristics becoming linear at longer times. It should be remembered that this is damage accumulating ahead of the etch front. To examine the thermal stability of the etch damage, n-type samples were exposed to $\mathrm{Ar}$ or $\mathrm{Cl}_{2} / \mathrm{Ar}$ discharges at a fixed source power $(500 \mathrm{~W})$ and rf chuck power $150 \mathrm{~W} \mathrm{rf}$ ), and then annealed at different temperatures prior to deposition of the rectifying contact. The annealing produces a significant recovery of the electrical properties for samples exposed to either type of plasma. The $\mathrm{V}_{\mathrm{B}}$ values are shown in Figure 38, as a function of post-plasma exposure annealing temperature. Annealing temperatures between $700-800^{\circ} \mathrm{C}$ restore $>70 \%$ of the original $\mathrm{V}_{\mathrm{B}}$ value, but clearly annealing alone cannot remove all of the dry etch induced damage. Annealing temperatures above $800^{\circ} \mathrm{C}$ were found to lead to preferential loss of $\mathrm{N}_{2}$ from the surface, with a concurrent degradation in $\mathrm{V}_{\mathrm{B}}$.

Figure 40 shows two methods for determining the depth of the damaged region in $\mathrm{p}-\mathrm{GaN}$ diodes. At top is a plot of the variation of $\mathrm{V}_{\mathrm{F}}$ and $\mathrm{V}_{\mathrm{B}}$ with the depth of material removed by $\mathrm{NaOH}$ etching. The values of both parameters are returned to their control values by depths of 500-600 $\AA$. What is clear from this data is that the immediate surface is not where the p-doping concentration is most affected, since the maximum values peak at depths of 300-400 $⿱$. This suggests that $\mathrm{N}_{\mathrm{V}}$ or other compensating defects created at the surface diffuse rapidly into this region even near room temperature. This is consistent with results in other semiconductors, where damage depths are typically found to be many times deeper than the projected range of incident ions. The bottom part of Figure 40 shows the wet etch depth in plasma damaged $\mathrm{p}-\mathrm{GaN}$ as a function of etching time. The etch depth saturates at depths of 500-600 $\mathrm{A}$, consis- tent with the electrical data. It has previously been shown that the wet etch depth on thermally- or ion-damaged GaN was self-limiting. This is most likely a result of the fact that defective or broken bonds in the material are readily attached by the acid or base, whereas in undamaged $\mathrm{GaN}$ the etch rate is negligible.

The main finding of our study may be summarized as follows:

(1) Large changes in $\mathrm{V}_{\mathrm{B}}$ and $\mathrm{V}_{\mathrm{F}}$ of $\mathrm{n}$ - and $\mathrm{p}-\mathrm{GaN}$ Schottky diodes were observed after exposure to both $\mathrm{Cl}_{2} / \mathrm{Ar}$ and $\mathrm{Ar}$ ICP discharges. In some cases the electrical properties are more degraded with $\mathrm{Cl}_{2} / \mathrm{Ar}$ even though this plasma chemistry has a much higher etch rate.

The damage accumulates in the near-surface even for very short exposure times (4 secs). The damage depth was established to be 500-600 $\AA$ from both the changes in electrical properties and the depth dependence of wet etch rate.

Annealing in the range $700-800^{\circ} \mathrm{C}$ partially restores $\mathrm{V}_{\mathrm{B}}$ in $\mathrm{n}-\mathrm{GaN}$ diodes, but full recover can only be achieved with an additional wet etch step for removal of the damaged material. The combination of annealing and a wet etch clean-up step looks very promising for GaN device fabrication.

\section{1 p-n Junctions.}

Layer structures were grown by Metal Organic Chemical Vapor Deposition on c-plane $\mathrm{Al}_{2} \mathrm{O}_{3}$ substrates at $1040^{\circ} \mathrm{C}$. The structure consisted of a low temperature $\left(530^{\circ} \mathrm{C}\right) \mathrm{GaN}$ buffer, $1.2 \mu \mathrm{m}$ of $\mathrm{n}\left(2 \times 10^{17} \mathrm{~cm}^{-3}, \mathrm{Si}-\right.$ doped) GaN, $0.5 \mu \mathrm{m}$ of nominally undoped $\left(\mathrm{n} \sim 10^{16} \mathrm{~cm}^{-}\right.$ ${ }^{3}$ ) $\mathrm{GaN}$ and $1.0 \mu \mathrm{m}$ of $\mathrm{p}\left(\mathrm{N}_{\mathrm{A}} \sim 5 \times 10^{19} \mathrm{~cm}^{-3}, \mathrm{Mg}\right.$-doped $)$ $\mathrm{GaN}$. The p-ohmic metal (Ni/Au) was deposited by ebeam evaporation and lift-off, then alloyed at $750^{\circ} \mathrm{C}$. A mesa was then formed by $\mathrm{BCl}_{3} / \mathrm{Cl}_{2} / \mathrm{Ar}(8 / 32 / 5$-sccm) ICP etching to a depth of $1.6 \mu \mathrm{m}$ under different plasma conditions in order to examine the effect of ion energy and ion flux, respectively. The ICP reactor was a loadlocked Plasma-Therm SLR 770, which used a $2 \mathrm{MHz}$, 3 -turn coil ICP source. All samples were mounted using a thermally conductive paste on an anodized $\mathrm{Al}$ carrier that was clamped to the cathode and cooled with $\mathrm{He}$ gas. The ion energy or dc-bias or dc-bias was defined by superimposing a rf-bias (13.56 MHz) on the sample. The n-type ohmic metallization (Ti/Al) was then deposited. Reverse I-V measurements were made on $300 \mu \mathrm{m}$ diameter diodes with a HP 4145B semiconductor parameter analyzer. In this study the reverse leakage current was measured at a bias of $-30 \mathrm{~V}$. Etch rates were calculated from bulk GaN samples patterned with AZ4330 photoresist. The depth of etched features was measured with an Alpha-step stylus profilometer after 
the photoresist was removed. Etch profile and surface morphology were analyzed with scanning electron microscopy and atomic force microscopy, respectively.

Figure 41 shows the effect of dc chuck bias on the reverse junction leakage current, along with the corresponding GaN etch rates. There is little effect on the current below chuck biases of $-250 \mathrm{~V}$. This corresponds to an ion energy of approximately $-275 \mathrm{eV}$, since this energy is the sum of chuck bias and plasma potential (about $-25 \mathrm{eV}$ in this tool under these conditions). The reverse current decreases slightly as the dc self-bias is increased from -25 to $-50 \mathrm{~V}$. This may result from the sharp increase in etch rate which leads to faster removal of near-surface damage. The reverse current increases rapidly above $-275 \mathrm{~V}$ ion energy, which is a clear indication of severe damage accumulating on the sidewall. The damage probably takes the form of point defects such as nitrogen vacancies, which increase the n-type conductivity of the surface. The total reverse current density, $\mathrm{J}_{\mathrm{R}}$ is the sum of three components namely diffusion, generation and surface leakage according to

$$
J_{R}=\left(\frac{e D_{h}}{l_{h} N_{D}}+\frac{e D_{e}}{l_{e} N_{A}}\right) n_{i}^{2}+\frac{e W n_{i}}{\tau_{g}}+J_{S L}
$$

where e is the electronic charge, $\mathrm{D}_{\mathrm{e}}$, are the diffusion coefficients of electrons or holes, $1_{e}, h$ are the lengths of the $n$ and $p$ regions outside the depletion region in a $p-n$ junction, $\mathrm{N}_{\mathrm{D}}, \mathrm{A}$ are the donor/acceptor concentrations on wither side of the junction, $\mathrm{n}_{\mathrm{I}}$ is the intrinsic carrier concentration, $\mathrm{W}$ the depletion with $\tau_{\mathrm{g}}$ the thermal generation lifetime of carriers and $\mathrm{J}_{\mathrm{SL}}$ is the surface current component which is bias-dependent. The latter component is most affected by the dry etch process, and dominates the reverse leakage in diodes etched in high ion energies.

GaN sidewall profiles and etch morphologies have been evaluated from previous results as a function of dcbias. The etch becomes more anisotropic as the dc-bias increased from -50 to $-150 \mathrm{~V}$ dc-bias due to the perpendicular nature of the ion bombardment energies. However, at $-300 \mathrm{~V}$ dc-bias a tiered etch profile with vertical striations in the sidewall was observed due to erosion of the mask-edge under high ion bombardment energies. The physical degradation (both profile and morphology) of the etched sidewall at $-300 \mathrm{~V}$ could help explain higher reverse leakage currents above $-250 \mathrm{~V}$ dc-bias. Under high bias conditions, more energetic ions scattering from the surface could strike the sidewalls with significant momentum thus increasing the likelihood of increased damage and higher reverse leakage currents. Under low bias conditions, the sidewall profile is less anisotropic implying increased lateral etching of the $\mathrm{GaN}$ (undercutting of the mask). Under these conditions the etch process becomes dominated by the chemical component of the etch mechanism, which may account for the slightly higher reverse leakage observed at $-25 \mathrm{~V}$ dc-bias. Figure 42 shows the effect of ICP source power on the junction reverse leakage current. The plasma flux is proportional to source power. In this experiment the ion energy was held constant at $-100 \mathrm{~V}$ dc-bias. There is minimal effect on leakage current for source powers $\leq 500 \mathrm{~W}$, with severe degradation of the junction characteristics at higher powers even thought the $\mathrm{GaN}$ etch rate continues to increase. This is an important result because it shows that the conditions that produce the highest etch rate are not necessarily those that lead to the least damage. Increased sidewall damage under high plasma flux conditions may be due to increased ion scattering as well as more interactions of reactive neutrals with the sidewall of the mesa. SEM micrographs from bulk GaN samples also show a degradation of sidewall profile under high ICP source power conditions. At an ICP source power of $1000 \mathrm{~W}$, the sidewall has a tiered profile with vertical striations possibly due to erosion of the mask edge. However, sidewall profiles at 250 and $500 \mathrm{~W}$ looked reasonably anisotropic and smooth. Reverse leakage currents were relatively insensitive to chemistry effects in a $\mathrm{Cl}_{2} / \mathrm{BCl}_{3} / \mathrm{Ar}$ ICP discharge. The reverse leakage current ranged between $\sim 10$ and $40 \mathrm{nA}$ as the $\% \mathrm{Cl}_{2}$ changed from 0 to 100 . This is not too surprising given that $\mathrm{BCl}_{3}$ ions will be the heaviest ions in the discharge under all these conditions, and we expect ion damage to be dominated at this flue. The reverse leakage currents were measured from a different $\mathrm{GaN}$ wafer as compared to other samples used in this study. The surface morphology for the as-grown wafer was significantly higher for this sample and may account for higher reverse leakage currents measured under the standard conditions. Notice the $\mathrm{GaN}$ etch rate increased as $\mathrm{Cl}_{2}$ was added to the $\mathrm{BCl}_{3} / \mathrm{Ar}$ plasma up to $80 \%$. In $\mathrm{Cl}_{2} / \mathrm{Ar}$ plasma the $\mathrm{GaN}$ etch rate decreased due to lower concentrations of reactive $\mathrm{Cl}$ neutrals. Etch profiles were relatively anisotropic and smooth except for the $\mathrm{Cl}_{2} / \mathrm{Ar}$ plasma where the etch was slightly rough.

Two samples were annealed in this study to determine if the defects caused by plasma-induced-damage to the p-n junction could be removed and low reverse leakage currents recovered. The first sample was initially exposed to the following ICP conditions: $32 \mathrm{sccm}$ $\mathrm{Cl}_{2}, 8 \mathrm{sccm} \mathrm{BCl}_{3}, 5 \mathrm{sccm}$ Ar, $500 \mathrm{~W}$ ICP power, $-300 \mathrm{~V}$ dc-bias and 2 mTorr pressure. The reverse leakage remained essentially constant up to $600^{\circ} \mathrm{C}$ where the reverse leakage increased by more than an order of magnitude (see Figure 43). (Note all reverse leakage data 
were taken at $-30 \mathrm{~V}$ except for the $600^{\circ} \mathrm{C}$ data, which was taken at lower voltages due to breakdown at $-30 \mathrm{~V}$ ). A similar trend was observed for the second sample. Although there was much more scatter in the data, which was exposed to the same ICP conditions with the exceptions of $750 \mathrm{~W}$ ICP source power and $-100 \mathrm{~V}$ dcbias. The inability to remove damage from these samples may be due to anneal temperatures which were not high enough. Improved breakdown voltages for dry etched n- and p-GaN Schottky diodes occur after annealing in the range of 400 to $700^{\circ} \mathrm{C}$, however anneal temperatures $>800^{\circ} \mathrm{C}$ were needed to produce nearcomplete recovery in breakdown voltage.

In summary there are high-density plasma etching conditions for $\mathrm{GaN}$ where there is minimal degradation in the reverse leakage current of $\mathrm{p}-\mathrm{i}-\mathrm{n}$ mesa diodes. Both ion energy and ion flux are important in determining the magnitude of this current, and a high etch rate is not necessarily the best choice for minimizing dry etch damage.

\section{Device Processing}

\subsection{Microdisk Lasers.}

A novel laser structure is the microdisk geometry, which does not require facet formation. These lasers should in principle have low thresholds because of their small active volume. While microcylinder geometries are possible, superior performance is expected when the active disk region sits only on a thin support post or pedestal. To fabricate this latter geometry, it is necessary to have a selective wet etch for the material under the active layer. A microcylinder is initially formed by anisotropic dry etching. We have employed ECR or ICP $\mathrm{Cl}_{2} / \mathrm{Ar}$ discharges to produce the initial vertical etch. The undercut is then produced by use of $\mathrm{KOH}$ solutions at $\sim 80^{\circ} \mathrm{C}$ to selectively etch the AlN buffer layer on which the InGaN/GaN quantum well is grown. SEM micrographs of two different lasers are shown in Figure 44. In both cases we used an upper cladding layer of $\mathrm{AlGaN}$, which was etched somewhat slower than the pure AlN bottom cladding layer.

\subsection{Ridge Waveguide Lasers.}

The achievement of continuous wave GaN-InGaN laser diodes has tremendous technological significance. For commercially acceptable laser lifetimes (typically $\geq$ $10,000 \mathrm{~h}$ ), there is immediate application in the compact disk data storage market. The recording and reading of data on these disks are currently performed with nearinfrared $(\sim 780 \mathrm{~nm})$ laser diodes. The switch to the much shorter wavelength $(\sim 400 \mathrm{~nm}) \mathrm{GaN}$-based laser diodes will allow higher recording densities [by $\sim(780 /$ $400)^{2}$ or almost a factor of 4]. There is also a large potential market in projection displays, where laser diodes with the three primary colors (red, green and clue) would replace the existing liquid crystal modulation system. The laser-based system would have advantages in terms of greater design simplicity, lower cost and broader color coverage. The key development is the need to develop reliable green InGaN laser diodes. The high output power of GaN-based lasers and fast off/on times should also have advantages for improved printer technology, with higher resolution than existing systems based on infrared lasers. In underwater military systems, GaN lasers may have application for covert communications because of a transmission passband in water between 450 and $550 \mathrm{~nm}$.

While a number of groups have now reported roomtemperature lasers in the InGaN/GaN/AlGaN heterostructure system under pulsed and cw operation [3] [4], the field has been completely dominated by Nakamura et.al. [4]. The growth is performed by MOCVD, generally at atmospheric pressure. Initial structures were grown on c-plane (0001) sapphire, with a low temperature $\left(550^{\circ} \mathrm{C}\right) \mathrm{GaN}$ buffer, a thick $\mathrm{n}^{+} \mathrm{GaN}$ lower contact region, an $\mathrm{n}^{+} \mathrm{InGaN}$ strain-relief layer, and $\mathrm{n}^{+} \mathrm{AlGaN}$ cladding layer, a light-guiding region of $\mathrm{GaN}$, then a multiquantum well region consisting of Si-doped $\mathrm{In}_{0.15} \mathrm{Ga}_{0.85} \mathrm{~N}$ wells separated by Si-doped $\mathrm{In}_{0.02} \mathrm{Ga}_{0.98} \mathrm{~N}$ barriers. The $\mathrm{p}$ side of the device consisted of sequential layers of $\mathrm{p}-\mathrm{AlGaN}, \mathrm{p}^{+} \mathrm{GaN}$ lightguiding, $\mathrm{p}-\mathrm{Al}_{0.09} \mathrm{Ga}_{0.92} \mathrm{~N}$ cladding and $\mathrm{p}^{+} \mathrm{GaN}$ contact. A ridge geometry was fabricated by dry etching in most cases (material removed down to the p$\mathrm{Al}_{0.08} \mathrm{Ga}_{0.92} \mathrm{~N}$ layer), followed by dry etching, cleaving or polishing to form a mirror facet. These facets are coated (with $\mathrm{TiO}_{2} / \mathrm{SiO}_{2}$ in the Nichia case) to reduce laser threshold, while Ni/Au (p type) and Ti/Al (n type) were employed for ohmic metallization.

For this type of structure, threshold current densities are typically $\geq 4 \mathrm{kA} \mathrm{cm}^{-2}$ with an operating voltages of $\geq 5 \mathrm{~V}$ at the threshold current. The emission mechanism is still the subject of intense study, but may be related to localization of excitons at compositional fluctuations (leading to potential minima in the band structure) in the InGaN wells.. These devices display relatively short lifetimes under $\mathrm{cw}$ operation, typically tens to hundreds of hours. The failure mechanism is most commonly short-circuiting of the p-n junction, a result of p-contact metallization punch through. It is not that surprising that in this high defect density material that the metal can migrate down threading dislocations or voids under high drive-current conditions. The threshold carrier density of the laser diodes on sapphire are typically 
$\sim 10^{20} \mathrm{~cm}^{-3}$, well above the theoretical values $\left(\sim 10^{19} \mathrm{~cm}^{-}\right.$ $3)$.

A major breakthrough in laser diode lifetime occurred with two changes to the growth. The first was replacement of the $\mathrm{AlGaN}$ cladding layers with AlGaN/ $\mathrm{GaN}$ strained-layer superlattices, combined with modulation doping. These changes had the effect of reducing formation of cracks that often occurred in the AlGaN, and also to reduce the diode operating voltage [4]. The second was the use of epitaxial lateral overgrowth (ELOG) [3] [4]. In this technique $\mathrm{GaN}$ is selectively grown on an $\mathrm{SiO}_{2}$ masked $\mathrm{GaN} / \mathrm{Al}_{2} \mathrm{O}_{3}$ structure. After $\sim 10 \mu \mathrm{m}$ of $\mathrm{GaN}$ is deposited over the $\mathrm{SiO}_{2}$ stripes, it coalesces to produce a flat surface. For a sufficiently wide stripe width, the dislocation density becomes negligible, compared to $\geq 10^{9} \mathrm{~cm}^{-2}$ in the window regions. The laser itself is fabricated slightly off-center from the mask regions, due to gaps that occur there due to imperfect coalescence of the GaN. These devices have lower threshold current density $\left(\leq 4 \mathrm{kA} \mathrm{cm}^{-2}\right)$ and operating voltage (4-6 V) and much longer (10,000 h) room-temperature lifetimes. The reduction in threading dislocation density dramatically changes the lifetime, since the $\mathrm{p}$ metal no longer has a direct path for shorting out the junction during operation. The carrier density at threshold is also reduced to $\sim 3 \times 10^{19} \mathrm{~cm}^{-3}$, not far above the expected values. Output power $>400 \mathrm{~mW}$, and lifetime $>160 \mathrm{~h}$ at $30 \mathrm{~mW}$ constant output power has been reported.

Subsequent work from Nichia has focused on growth of the laser diodes on quasi-GaN substrates. The thick $(100-200 \mu \mathrm{m}) \mathrm{GaN}$ is grown on ELOG structures by either MOCVD or hydride VPE. The sapphire substrate is then removed by polishing, to leave a freestanding $\mathrm{GaN}$ substrate. The mirror facet can then be formed by cleaving. The GaN substrate has better thermal conductivity than sapphire.

One of the most important features of the etching of the ridge waveguide is the smoothness of the sidewall. Figure 45 shows SEM micrographs of features etched into pure $\mathrm{GaN}$, using a $\mathrm{SiN}_{\mathrm{x}}$ mask and an $\mathrm{ICP} \mathrm{Cl}_{2} / \mathrm{Ar}$ discharge at moderate powers $(500 \mathrm{~W}$ source power, 150 $\mathrm{W}$ rf chuck power). While the sidewalls are reasonably vertical, one can see striations, which result from roughness on the photoresist mask used to pattern the $\operatorname{SiN}_{\mathrm{x}}$. Another problem than can occur is illustrated in the SEM micrograph at the top of Figure 46. In this a very high ion energy was employed during the etching, leading to roughening of the feature sidewall. This problem is absent when ion energies below approximately 200 $\mathrm{eV}$ are employed, as shown in the micrograph at the bottom of Figure 46.
When careful attention is paid to the lithography, the etching of the $\mathrm{SiN}_{\mathrm{x}}$ mask and also the etching of the nitride laser structure, then results like those shown in the SEM micrographs of Figure 47 are obtained. The active region of the laser is visible as the horizontal lines along the middle of the sidewall.

\subsection{Heterojunction Bipolar Transistors.}

Wide bandgap semiconductor heterojunction bipolar transistors (HBTs) are attractive candidates for applications in high frequency switching, communications and radar. While field effect transistors can be used for these same applications, HBTs have better linearity, higher current densities and excellent threshold voltage uniformity. The GaN/AlGaN system is particularly attractive because of its outstanding transport properties and the experience base that has developed as a result of the success of light-emitting diodes, laser diodes and UV detectors fabricated from AlGaInN materials. GaN/SiC HBTs have been reported with excellent high temperature $\left(535^{\circ} \mathrm{C}\right)$ performance [13]. Recently two reports have appeared on operation of GaN/AlGaN HBTs [14] [15]. In one case the extrinsic base resistance was reduced through a selective regrowth of $\mathrm{GaN}(\mathrm{Mg})$, and devices with $3 \times 20 \mu \mathrm{m}^{2}$ emitters showed dc current gain of $\sim 3$ at $25^{\circ} \mathrm{C}$ [14]. In work from our group, GaN/ AlGaN HBTs have been fabricated with a non-selfaligned, low damage dry etch process based on that developed for the GaAs/AlGaAs, GaAs/InGaP and InGaAs/AlInAs systems. The performance of GaN/ AlGaN devices fabricated by that method also showed low gains at room temperature, typically $\leq 3$. When operated at higher temperatures the gain improved, reaching $\sim 10$ at $300^{\circ} \mathrm{C}$ as more acceptors in the base region became ionized and the base resistance decreased.

In this section we review the fabrication process for GaN/AlGaN HBTs, examine the temperature dependence of the p-ohmic contacts and report measurements of typical background impurity concentrations, determined by Secondary Ion Mass Spectrometry (SIMS).

Structures grown by two different methods were examined. In the first, rf plasma-assisted Molecular Beam Epitaxy (MSE) at a rate of $\sim 0.5 \mu \mathrm{m}-\mathrm{hr}^{-1}$ was used to grow the HBT structure on top of a $2 \mu \mathrm{m}$ thick undoped GaN buffer that was grown on c-plane (0001) sapphire. An $8000 \AA$ thick GaN subcollector $\left(\mathrm{Si} \sim 10^{18}\right.$ $\mathrm{cm}^{-3}$ ) was followed by a $5000 \AA$ thick $\mathrm{GaN}$ collector $(\mathrm{Si}$ $\sim 10^{17} \mathrm{~cm}^{-3}$ ), a $1500 \AA$ thick GaN base (Mg acceptor concentration $\sim 10^{18} \mathrm{~cm}^{-3}$ ), a $1000 \AA$ thick $\mathrm{Al}_{0.15} \mathrm{Ga}_{0.85} \mathrm{~N}$ emitter $\left(\mathrm{Si} \sim 5 \times 10^{17} \mathrm{~cm}^{-3}\right)$, and a $500 \AA$ grade to a $2000 \AA$ thick GaN contact layer $\left(\mathrm{Si} \sim 8 \times 10^{18} \mathrm{~cm}^{-3}\right.$ ). 
The second structure was grown by Metal Organic Chemical Vapor Deposition (MOCVD) on c-plane sapphire, using trimethylgallium, trimethylaluminum and ammonia as the precursors and high purity $\mathrm{H}_{2}$ as the carrier gas. The basic layer structure is shown in Figure 48.

The process flow for device fabrication is shown schematically in Figure 49. First the emitter metal $(\mathrm{Ta} /$ $\mathrm{Al} / \mathrm{Pt} / \mathrm{Au})$ is patterned by lift-off and used as an etch mask for the fabrication of the emitter mesa. The dry etching was performed in a Plasma-Therm 770 Inductively Coupled Plasma (ICP) system using $\mathrm{Cl}_{2} / \mathrm{Ar}$ discharges. The process pressure was $5 \mathrm{mTorr}$ and the source was excited with $300 \mathrm{~W}$ of $2 \mathrm{MHz}$ power. This power controlled the ion flux and neutral density, while the incident ion energy was controlled by application of $40 \mathrm{~W}$ of $13.56 \mathrm{MHz}$ power to the sample chuck. Base metallization of $\mathrm{Ni} / \mathrm{Pt} / \mathrm{Au}$ was patterned by lift-off, and then the mesa formed by dry etching. The etch rate of $\mathrm{GaN}$ under our conditions was $\sim 1100 \AA-\mathrm{min}^{-1}$, and was terminated at the subcollector where Ti/Al/Pt/Au metallization was deposited. The contacts were alloyed at $700-800^{\circ} \mathrm{C}$. It has been firmly established that high specific contact resistivities are a limiting factor in $\mathrm{GaN}$ based device performance, and in particular the p-ohmic contact. We examined the alloying temperature dependence of the current-voltage (I-V) characteristics for several different p-metal schemes. The as-deposited contacts are rectifying. Annealing at progressively higher temperatures produced a significant improvement. But even for $800^{\circ} \mathrm{C}$ anneals the contacts were not purely ohmic when measured at room temperature. This is consistent with past data, showing that p-metallization on $\mathrm{GaN}$ is often better described as a leaky Schottky contact. As the measurement temperature is increased, the hole concentration in the $\mathrm{p}-\mathrm{GaN}$ increases through higher ionization efficiency of the $\mathrm{Mg}$ acceptors. For example the hole concentration would increase from $\sim 10 \%$ of the acceptor density at $25^{\circ} \mathrm{C}$ to $\sim 60 \%$ at $300^{\circ} \mathrm{C}$, based on Fermi-Dirac statistics. The p-contact becomes truly ohmic at $\geq 300^{\circ} \mathrm{C}$. From transmission line measurements, we found $\rho_{\mathrm{c}} \sim 2 \times 10^{-2} \Omega \mathrm{cm}^{-2}$ at this temperature. This indicates that the GaN/AlGaN HBT will perform better at elevated temperatures, where the base contact resistivity is lower. The contact barrier is of order $0.5 \mathrm{eV}$, whereas the $\mathrm{Mg}$ acceptor has an ionization level of $0.18 \mathrm{eV}$.

The device performance of both the MBE and MOCVD grown devices was similar, namely a common-emitter current gain of $\leq 3$ at $25^{\circ} \mathrm{C}$, increasing to $\sim 10$ at $300^{\circ} \mathrm{C}$. In both devices the performance was still limited by the base resistance, and methods to increase the base doping and lower the extrinsic resistance in this region will be critical for future efforts in this area. The common base current gain, $\propto$, was in the range 0.75 $\left(25^{\circ} \mathrm{C}\right)$ to $0.9\left(300^{\circ} \mathrm{C}\right)$, indicating that the base transport factor is close to unity and that $\mathrm{I}_{\mathrm{B}}$ is dominated by reinjection to the emitter.

Another important aspect of the realization of GaN/ AlGaN HBTs is confinement of the Mg doping to the base. If the p-type spills over into the relatively lightly doped emitter, then the junction is displaced and the advantage of the heterostructure is lost.

In summary, GaN/AlGaN HBTs have been fabricated both on MBE and MOCVD grown material, and they display similar performance, i.e. a common-emitter current gain of $\sim 10$ when operated at $\sim 300^{\circ} \mathrm{C}$. However junction leakage is also higher at elevated temperatures, which is a major drawback in most applications. The fabrication process developed previously for other compound semiconductor systems works well for the GaN/ AlGaN system, with the main difference being higher annealing temperatures required for the ohmic contacts. The device performance is still limited by the base doping for both MBE and MOCVD structures.

\subsection{Field Effect Transistors.}

There has been much recent attention on development of $\mathrm{AlGaN} / \mathrm{GaN}$ heterostructure field effect transistors (HFETs) for high frequency and high power application. Both enhancement and depletion mode devices have been demonstrated, with gate lengths down to $0.2 \mu \mathrm{m}$. Excellent dc performance has been reported up to $360^{\circ} \mathrm{C}$, and the best devices have a maximum frequency of oscillation $\mathrm{f}_{\max }$ of $77 \mathrm{GHz}$ at room temperature. Even better speed performance could be expected from InAlN channel structures, both because of the superior transport properties and the ability to use highly doped $\mathrm{In}_{\mathrm{x}} \mathrm{Al}_{1-\mathrm{x}} \mathrm{N}(\mathrm{x}=0 \rightarrow 1)$ graded contact layers which should produce low specific contact layers which should produce specific contact resistivities. We have previously demonstrated that nonalloyed $\mathrm{Ti} / \mathrm{Pt} / \mathrm{Au}$ metal on degenerately doped $\mathrm{InN}\left(\mathrm{n}=5 \times 10^{20} \mathrm{~cm}^{-3}\right)$ has $\rho_{\mathrm{c}}$ $\sim 1.8 \times 10^{17} \Omega \mathrm{cm}^{2}$. While metalorganic chemical vapor deposition (MOCVD) has generally been employed for growth of nitride-based photonic devices and for most of the prototype electronic devices, the ability of the molecular beam techniques to control layer thickness and incorporate higher In concentration in the ternary alloys is well suited to growth of HFET structures.

The exceptional chemical stability of the nitrides has meant that dry etching must be employed for patterning. To date most of the work in this area has concentrated on achievement of higher etch rates with minimal mask erosion, in particular because a key application is formation of dry etched layer facets. In that case etch rate, 
etch anisotropy and sidewall smoothness are the most important parameters, and little attention has been paid to the effect of dry etching on the stoichiometry and electrical properties of the nitride surface.

In these experiments, we used an InAlN and GaN FET structure as a test vehicle for measuring the effect of electron cyclotron resonance (ECR) $\mathrm{BCl}_{3}$-based dry etching on the surface properties of InAlN and GaN. Preferential loss of $\mathrm{N}$ leads to roughened morphologies and creation of a thin $\mathrm{n}^{+}$surface layer which degrades the rectifying properties of subsequently deposited metal contacts.

The InAlN samples were grown by MOMBE on 2" diameter GaAs substrates using a WAVEMAT ECR $\mathrm{N}_{2}$ plasma and metalorganic group III precursors (Trimethylamine alane, triethylindium). A low temperature $\left(\sim 400^{\circ} \mathrm{C}\right) \mathrm{AlN}$ nucleation layer was followed by a $500 \AA$ thick AlN buffer layer grown at $700^{\circ} \mathrm{C}$. The $\operatorname{In}_{0.3} \mathrm{Al}_{0.7} \mathrm{~N}$ channel layer $\left(\sim 5 \times 10^{17} \mathrm{~cm}^{-2}\right)$ was $500 \AA$ thick, and then an ohmic contact layer was produced by grading to pure InN over a distance of $\sim 500 \AA$.

The GaN layer structure was grown on double side polished $\mathrm{c}-\mathrm{Al}_{2} \mathrm{O}_{3}$ substrates prepared initially by $\mathrm{HCl}$ / $\mathrm{HNO}_{3} / \mathrm{H}_{2} \mathrm{O}$ cleaning and an in-situ $\mathrm{H}_{2}$ bake at $1070^{\circ} \mathrm{C}$. A GaN buffer $<300 \AA$ thick was grown at $500^{\circ} \mathrm{C}$ and crystallized by ramping the temperature to $1040^{\circ} \mathrm{C}$, where trimethylgallium and ammonia were again used to grow $\sim 1.5 \mu \mathrm{m}$ of undoped GaN ( $<3 \times 10^{16} \mathrm{~cm}^{-3}$ ), a $2000 \AA$ channel $\left(\mathrm{n}=2 \times 10^{17} \mathrm{~cm}^{-3}\right)$ and a $1000 \AA$ contact layer $\left(\mathrm{n}=1 \times 10^{18} \mathrm{~cm}^{-3}\right)$.

FET surfaces were fabricated by depositing TiPtAu source/drain ohmic contacts, which were protected by photoresists. The gate mesa was formed by dry etching down to the InAlN or n-GaN channel using an ECR $\mathrm{BCl}_{3}$ or $\mathrm{BCl}_{3} / \mathrm{N}_{2}$ plasma chemistry. During this process, we noticed that the total conductivity between the ohmic contacts did not decrease under some conditions. $\mathrm{CH}_{4} / \mathrm{H}_{2}$ etch chemistry was also studied. To simulate the effects of this process, we exposed the FET substrates to $\mathrm{D}_{2}$ plasma, we saw strong reductions in sample conductivity. The incorporation of $\mathrm{D}_{2}$ into the InAlN was measured by secondary ion mass spectrometry. Changes to the surface stoichiometry were measured by Auger electron spectroscopy (AES). All plasma processes were carried out in a Plasma Therm SLR 770 System with an Astex 7700 low profile ECR source operating at $500 \mathrm{~W}$. The samples were clamped to an rf-powered, He backside cooled chuck, which was left at floating potential (about $-30 \mathrm{~V}$ ) relative to the body of the plasma.
Upon dry etch removal of the InAIN capping layer, a $\mathrm{Pt} / \mathrm{Ti} / \mathrm{Pt} / \mathrm{Au}$ gate contact was deposited on the exposed InAlN to complete the FET processing. if pure $\mathrm{BCl}_{3}$ was employed as the plasma chemistry, we observed ohmic and not rectifying behavior for the gate contact. If $\mathrm{BCl}_{3} / \mathrm{N}_{2}$ was used, there was some improvement in the gate characteristics. A subsequent attempt at a wetetch clean-up using either $\mathrm{H}_{2} \mathrm{O}_{2} / \mathrm{HCl}$ or $\mathrm{H}_{2} \mathrm{O}_{2} / / \mathrm{HCl}$ produced a reverse breakdown in excess of $2 \mathrm{~V}$ (Figure 50). These results suggest that the InAlN surface becomes nonstoichiometric during the dry etch step, and that addition of $\mathrm{N}_{2}$ retards some of this effect.

Figure 51 shows the $\mathrm{I}_{\mathrm{DS}}$ values obtained as a function of dry etch time in ECR discharges of either $\mathrm{BCl}_{3}$ or $\mathrm{BCl}_{3} / \mathrm{N}_{2}$. In the former case the current does not decrease as material is etched away, suggesting that a conducting surface layer is continually being created. By contrast $\mathrm{BCl}_{3} / \mathrm{N}_{2}$ plasma chemistry does reduce the drain-source current as expected, even though the breakdown characteristics of gate metal deposited on this surface are much poorer than would be expected.

Figure 52 shows the gate current-voltage characteristics when the gate metal is deposited on the as-etched GaN surface. The Schottky contact is extremely leaky, with poor breakdown voltage. We believe this is caused by the presence of a highly conducting $\mathrm{N}$ deficient surface, similar to the situation encountered on dry etching InP where preferential loss of $\mathrm{P}$ produces a metal-rich surface which precludes achievement of rectifying contacts. Auger electron spectroscopy analysis of the etched GaN surface showed an increasing Ga-to-N ratio (from 1.7 to 2.0 in terms of raw counts) upon etching. However, a $5 \mathrm{~min}$. anneal at $400^{\circ} \mathrm{C}$ under $\mathrm{N}_{2}$ was sufficient to produce excellent rectifying contacts, with a gate breakdown of $\sim 25 \mathrm{~V}$ (Figure 53). We believe the presence of the conducting surface layer after etching is a strong contributing factor $t$ the excellent $\rho_{c}$ values reported by Lin et. al. [3] for contacts on a reactively ion etched $\mathrm{n}-\mathrm{GaN}$.

The drain I-V characteristics of the $1 \times 50 \mu \mathrm{m}^{2}$ MESFET are shown in Figure 54. The drain-source breakdown was $-20 \mathrm{~V}$, with a threshold voltage of $-0.3 \mathrm{~V}$. The device displays good pinch-off and no slope to the I-V curves due to gate leakage, indicating that the anneal treatment is sufficient to restore the surface breakdown characteristics. We believe these devices are well suited for high power applications since $\mathrm{GaN}$ is a robust material and the contract metallizations employed are also very stable.

III-nitrides FET structures are sensitive to several effects during dry etching of the gate mesa. Firstly, if hydrogen is present in the plasma there can be passiva- 
tion of the doping in the channel layer. Secondly, the ion bombardment from the plasma can create deep acceptor states that compensate the material. Thirdly, even when these problems are avoided through use of $\mathrm{H}$ free plasma chemistries and low ion energies and fluxes, preferential loss of $\mathrm{N}$ can produce poor rectifying gate characteristics for metal deposited on the etched surface. Ping et.al. observed that pure Ar etching produced more damage in Schottky diodes than $\mathrm{SiCl}_{4}$ RIE. The diodes characteristics were strongly dependent on plasma selfbias, while annealing at $680^{\circ} \mathrm{C}$ removed much of the damage.

\subsection{UV Detectors.}

Gallium nitride $(\mathrm{GaN})$ and its alloys of aluminum gallium nitride $(\mathrm{AlGaN})$ are the most promising semiconductors for development of ultraviolet (UV) photodetectors for applications such as combustion monitoring, space-based UV spectroscopy and missile plume detection. With a direct bandgap energy of approximately $3.39 \mathrm{eV}(366 \mathrm{~nm}), \mathrm{GaN}$ is an ideal material for the fabrication of photodetectors capable of rejecting near infrared and visible regions of the solar spectrum while retaining near unity quantum efficiency in the UV. The use of AlGaN materials in photodetector fabrication enables bandgap engineering of the peak responsivity to shorter wavelengths in the deep UV. $\mathrm{GaN}$ is also an extremely robust semiconductor suitable for high temperature $\left(>200^{\circ} \mathrm{C}\right)$ applications.

Nitride-based UV photodetectors which have been reported include $\mathrm{p}$-n photodiode devices with $0.05 \mathrm{~mm}^{2}$ junction area and $0.07 \mathrm{~A} / \mathrm{W}$ peak responsivity [3], with $0.04 \mathrm{~mm}^{2}$ junction area devices, with $0.25 \mathrm{~mm}^{2}$ junction area $0.1 \mathrm{~A} / \mathrm{W}$ peak responsivity and $0.59 \mathrm{~mm}^{2}$ junction area and $0.195 \mathrm{~A} / \mathrm{W}$ peak responsivity. Photodetector also reported include semi-transparent Schottky junction devices and metal-semiconductor-metal devices.

The $\mathrm{GaN}$ and $\mathrm{AlGaN}$ ultraviolet (UV) photodiodes were grown on (0001) basal-plane sapphire substrates by molecular beam epitaxy (MBE) using an RF atomic nitrogen plasma source. $\mu \mathrm{m}$ wide The $\mathrm{p}-\mathrm{i}-\mathrm{n}$ detector epitaxial layers consisted of a $5 \times 10^{18} \mathrm{~cm}^{-3} \mathrm{n}$-GaN layer followed by a $5000 \AA$ intrinsic region with unintentional n-type doping in the $10^{15} \mathrm{~cm}^{-3}$ decade. The topmost epitaxial layer consisted of $1000-2000 \AA 1 \times 10^{18} \mathrm{~cm}^{-3} \mathrm{p}$ $\mathrm{GaN}$. Mesas reaching the $\mathrm{n}-\mathrm{GaN}$ cathode contact layer were formed by inductively coupled plasma (ICP) plasma etching with chlorine-based chemistry. Ohmic contacts to the n-type and p-type GaN were made by Tibased and Ni-based metallizations, respectively. All of the GaN p-i-n UV detectors were fabricated with an optical detection area of $0.5 \mathrm{~mm}^{2}$ and a p-i-n junction area of $0.59 \mathrm{~mm}^{2}$, which is considerably larger (> 12.5 times) than other $\mathrm{GaN}$ p-n detectors reported with noise measurements.

In addition to fabricating p-i-n type detectors, shorter UV wavelength MSM photodetectors, operating in a quasi-photoconductive mode, were fabricated from $1.5 \mu \mathrm{m}$ thick silicon doped $\left(\sim 1 \times 10^{17} \mathrm{~cm}^{-3}\right) \mathrm{n}$-AlGaN with a bandgap energy of approximately $320 \mathrm{~nm}$. The MSMs were fabricated by first depositing a Pt-group metallization $1 \mu \mathrm{m}$ wide with a $5 \mu \mathrm{m}$ pitch to form the Schottky contacts. next a dielectric was deposited to act as an insulator between the $\mathrm{AlGaN}$ semiconductor and the bond pads. The dielectric process was not optimized to function as an anti-reflection coating. Reported here are results for AlGaN MSMs with active areas of 0.25 $\mathrm{mm}^{2}$.

Shunt resistance and spectral responsivity data were collected using on-wafer probing. The shunt resistance was determined by the linear trace of the current-voltage (IV) characteristic from $-10 \mathrm{mV}$ to $+10 \mathrm{mV}$. The spectral responsivities of the UV photodiodes were measured in photovoltaic mode (zero bias) for p-i-n devices and a photoconductive mode (biased) for MSM devices using a $75 \mathrm{~W}$ xenon arc lamp chopped at $700 \mathrm{~Hz}$ and filtered by a $1 / 8$ meter monochromator set to a $5 \mathrm{~nm}$ bandpass. The power of the monochromatic light was measured with a calibrated, NIST traceable, silicon photodiode and then focused onto the GaN wafers resting on a micropositioner stage.

The GaN p-i-n UV photodetector responsivity measurements reported were obtained with the devices operating in the unbiased, photovoltaic mode. Shown in Figure 55 is a $25^{\circ} \mathrm{C}$ spectral responsivity curve for a baseline UV photodetector with 0.194 A/W peak responsivity and 4 orders of magnitude visible rejection which has been previously reported. The maximum theoretical peak responsivity at the $360 \mathrm{~nm}$ bandgap is 0.28 $\mathrm{A} / \mathrm{W}$ with no reflection and $0.23 \mathrm{~A} / \mathrm{W}$ including reflection at the $\mathrm{GaN}$ surface. Also included on the plot is a trace for a GaN p-i-n UV photodetector with an improved p-type epitaxial process, which yields a greater visible rejection and more constant deep UV responsivity. The improved GaN p-i-n device was fabricated with a $1000 \AA$ p-type cathode layer. The shunt resistances for these improved $0.59 \mathrm{~mm}^{2}$ devices ranged from $200 \mathrm{M} \Omega$ to $50 \mathrm{G} \Omega$ depending on the process. The device exhibits a low dark current and excellent forward-biased diode IV characteristics with a built-in potential of approximately $3.1 \mathrm{~V}$.

The AlGaN MSM exhibited a substantial photoconductive gain $(>700 \mathrm{X})$ at $6 \mathrm{~V}$ bias, which yielded a responsivity of $7 \mathrm{~A} / \mathrm{W}$ at $250 \mathrm{~nm}$. The AlGaN device band-edge response does not decay as rapidly as that 
seen in devices fabricated from $\mathrm{GaN}$ material. The MSM devices, fabricated from AlGaN, which exhibited a luminescent peak at $320 \mathrm{~nm}$, exhibited slightly more than 3 orders of magnitude $(1278 \mathrm{X})$ rejection of 360 $\mathrm{nm}$ light over $320 \mathrm{~nm}$ light. The rejection ratio for 250 $\mathrm{nm}$ light over $360 \mathrm{~nm}$ light was more than 5.5 orders of magnitude $(5263 \mathrm{X})$. The increased gain at shorter wavelengths is believed to be the result of greater electron-hole generation near the high electric field regions at the surface of the device. As expected, the MSM devices exhibited excellent shunt resistance (> $100 \mathrm{G} \Omega$ ) and dark current characteristics at low bias as shown in Figure 55. GaN p-i-n UV photodetectors with an optically active surface area of $0.5 \mathrm{~mm}^{2}$ and a junction area of $0.59 \mathrm{~mm}^{2}$ have been fabricated on 3-inch diameter GaN p-i-n epitaxial wafers and characterized. Wafer maps of photodetector peak responsivity (maximum of $0.194 \mathrm{~A} / \mathrm{W}$ at $359 \mathrm{~nm}$ ) indicated that more than $60 \%$ $( \pm 1 \sigma)$ of all the GaN UV photodetectors performed within a $\pm 12 \%$ deviation from the average peak responsivity. Further, the vast majority of GaN UV photodetectors were characterized with shunt resistances that were within one decade of each other.

High temperature testing of the GaN p-i-n photodetectors up to $300^{\circ} \mathrm{C}$ indicated no significant increase in visible spectral responsivity or short-term degradation. The room temperature spectral responsivity of the $\mathrm{GaN}$ photodetectors was fully recovered after $300^{\circ} \mathrm{C}$ testing. The $300^{\circ} \mathrm{C} \mathrm{GaN}$ photodetector $1 / f$ noise power densities were measured to be $6.6 \times 10^{-19}$ and $2.1 \times 10^{-21} \mathrm{~A}^{2} / \mathrm{Hz}$ at $100 \mathrm{~Hz}$ and $1 \mathrm{kHz}$, respectively. The room temperature, $100 \mathrm{~Hz}$ and $1 \mathrm{kHz}$ noise power density of the GaN p-i-n photodetectors was extrapolated to be on the order of $10^{-30} \mathrm{~A}^{2} / \mathrm{Hz}\left(\sim 10^{-15} \mathrm{~A} / \mathrm{Hz}^{1 / 2}\right.$ noise current density).

The AlGaN MSM photodetectors, which were fabricated from $\mathrm{AlGaN}$ with a near bandgap luminescent peak of $320 \mathrm{~nm}$, exhibited substantial photoconductive gain resulting in $7 \mathrm{~A} / \mathrm{W}$ responsivity at $250 \mathrm{~nm}$ and 1.7 A/W responsivity at $320 \mathrm{~nm}$. The AlGaN MSMs were characterized with 5263 and 1278 responsivity rejection ratios for $250 \mathrm{~nm}$ and $320 \mathrm{~nm}$ light, respectively, versus $360 \mathrm{~nm}$ light.

\section{ACKNOWLEDGMENTS}

The work at UF is partially supported by a DARPA/ EPRI grant, No. MDA972-98-1-0006 (D. Radack and
B. Damsky) monitored by ONR (J.C. Zolper) and a NSF grant DMR97-32865 (L.D. Hess). Sandia is a multiprogram laboratory operated by Sandia Corporation, a Lockheed-Martin Company, for the US Department of Energy under contract No. DEAC04-94-AC-85000.

\section{REFERENCES}

[1] Stephen J. Pearton, GaN and Related Materials , (Gordon and Breach Science Publishers, Amsterdam, 1997), .

[2] J.I. Pankove, T.D. Moustaka, Gallium Nitride I , (Academic Press, San Diego, 1997), .

[3] H. Morkoc, Wide Band Gap Nitrides and Devices (Springer, Berlin, 1998)

[4] Shuji Nakamura, Gerhard Fasol, The Blue Laser Diode - GaN based Light Emitters and Lasers , (Springer-Verlag, Heidelberg, 1997), .

[5] S.J. Pearton and R.J. Shul,'Dry Etching" in Gallium Nitride I, edited by J.I. Pankove and T.D. Moustakas (Academic, San Diego, 1998)

[6] I. Adesida, "Etching of GaN and Related Compounds," in Properties, Processing and Applications of GaN and Related Semiconductors, ed. J. Edgar, S. Strite, I. Akasaki, H. Amano and C. Wetzel, EMIS Data Review No. 23 (INSPEC, IEE, London 1999)

[7] R. J. Shul, G. B. McClellan, S. J. Pearton, C. R. Abernathy, C. Constantine, C. Barratt, Electron. Lett. 32, 1408 (1996).

[8] R.J. Shul, "ICP Etching of III-Nitrides," in GaN and Related Materials II, edited by S.J. Pearton (Gordon and Breach, New York 1998)

[9] H. P. Gillis, D. A. Choutov, K. P. Martin, L. Song, Appl. Phys. Lett. 68, 2255 (1996).

[10] F. Ren, S. J. Pearton, R. J. Shul, J. Han, J. Electron. Mater. 27, 175 (1998).

[11] C. R. Eddy, Jr, B. Molnar, J. Electron. Mater. 28, 314 (1999).

[12] R.J. Shul, R.D. Briggs, J. Han, S.J. Pearton, J.W. Lee, C.B. Vartuli, K.P. Killeen, M.J. Ludowise, Mater. Res. Soc. Symp. Proc. 468, 355 (1997).

[13] J. I. Pankove, M. Leksono, S. S. Chang, C. Walker, B. Van Zeghbroeck, MRS Internet J. Nitride Semicond. Res. 1, 39 (1996).

[14] L. S. McCarthy, P. Kozodoy, S. P. DenBaars, M. Rodwell, U. K. Mishra, IEEE Electron Dev. Lett. EDL-20, 277 (1999).

[15] Fan Ren, Cammy R. Abernathy, J. M. Van Hove, P. P. Chow, R. Hickman, J. J. Klaassen, R. F. Kopf, Hyun Cho, K. B. Jung, J. R. La Roche, R. G. Wilson, J. Han, R. J. Shul, A. G. Baca, S.J. Pearton, MRS Internet J. Nitride Semicond. Res. 3, 41 (1998). 


\section{FIGURES}

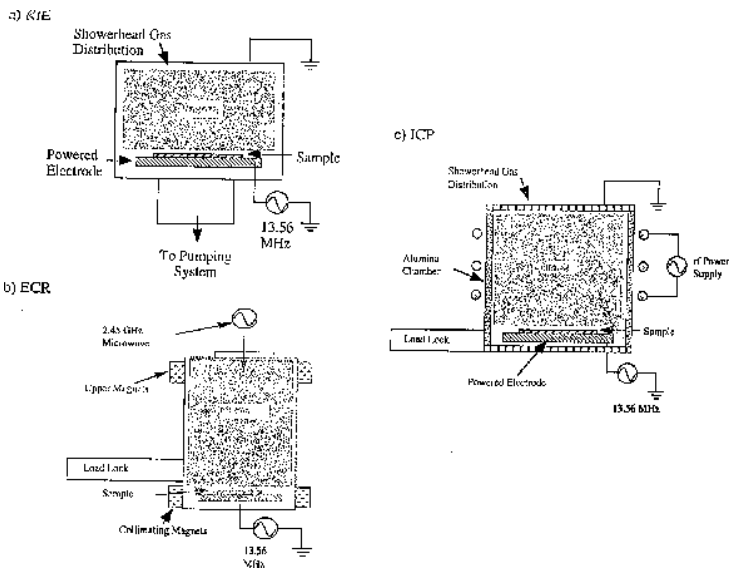

Figure 1. Schematic diagram of (a) RIE, (b) ECR and (c) ICP etch platforms.

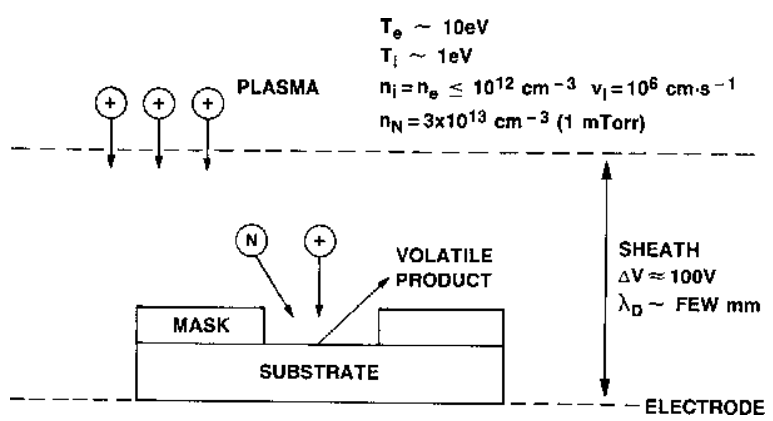

Figure 2. Schematic diagram of high density plasma etching process.

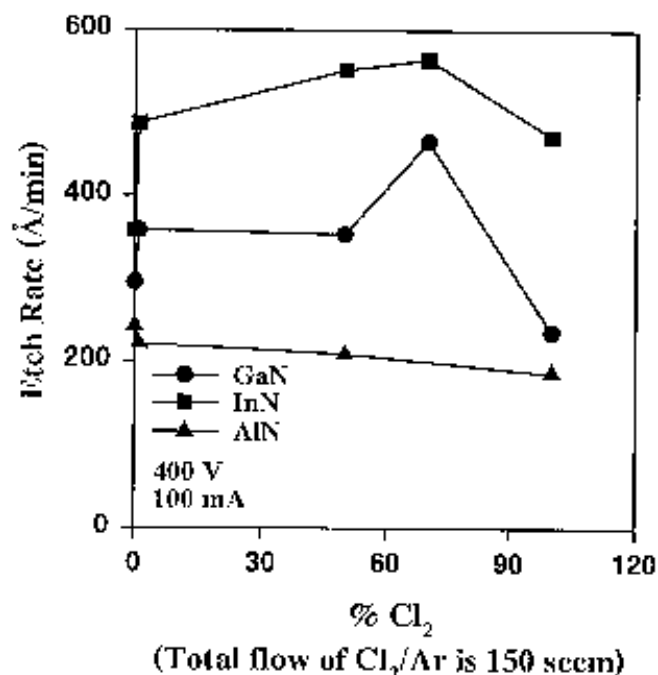

Figure 3. RIBE nitride removal rates as a function of $\mathrm{Cl}_{2}$ percentage in $\mathrm{Cl}_{2} / \mathrm{Ar}$ beams

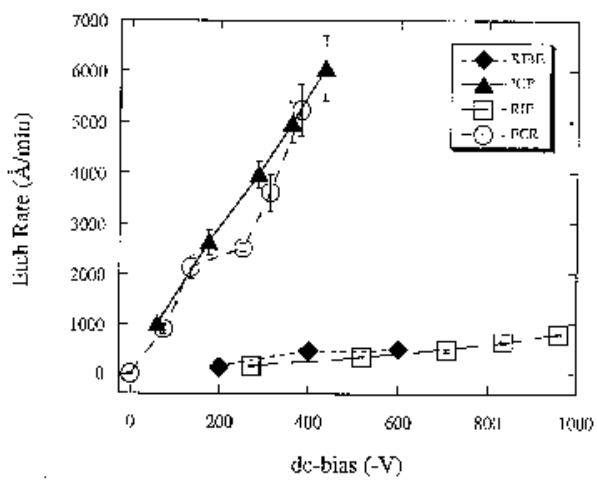

Figure 4. $\mathrm{GaN}$ etch rates in RIE, ECR, ICP and $\mathrm{RIBE} \mathrm{Cl}_{2}$-based plasmas as a function of dc bias.

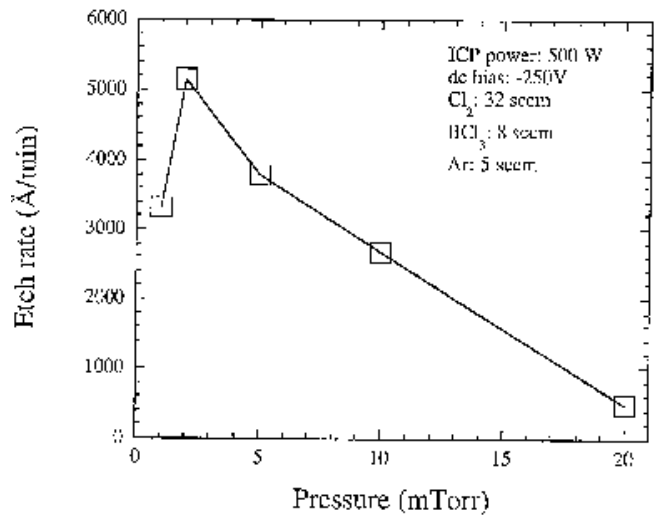

Figure 5. GaN etch rates as a function of pressure in an ICPgenerated $\mathrm{BCl}_{3} / \mathrm{Cl}_{2} / \mathrm{Ar}$ plasma at $32 \mathrm{sccm} \mathrm{Cl}_{2}, 8 \mathrm{sccm} \mathrm{BCl}_{5}, 5$ sccm Ar, $500 \mathrm{~W}$ IPC source power, dc-bias $-150 \mathrm{~V}$ and $10^{\circ} \mathrm{C}$ electrode temperature.

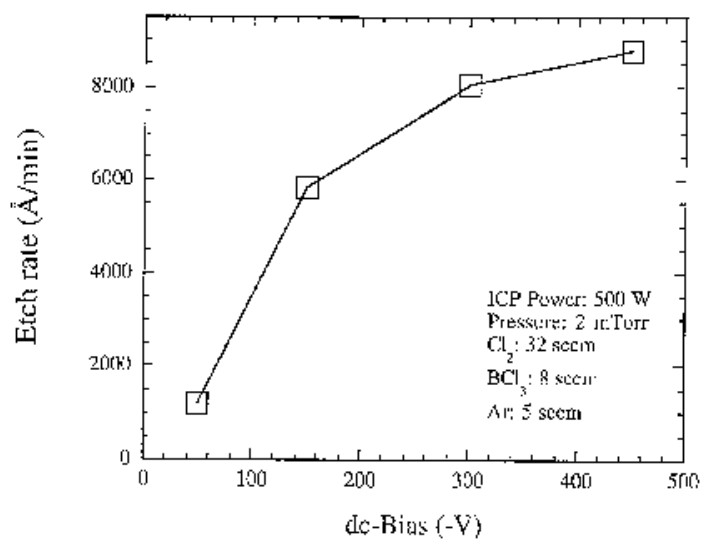

Figure 6. GaN etch rates as a function of dc bias in an ICPgenerated $\mathrm{BCl}_{3} / \mathrm{Cl}_{2} / \mathrm{Ar}$ plasma at $32 \mathrm{sccm} \mathrm{Cl}_{2}, 8 \mathrm{sccm} \mathrm{BCl}_{3}, 5$ sccm Ar, $500 \mathrm{~W}$ ICP source power, 2 mTorr pressure and $10^{\circ} \mathrm{C}$ electrode temperature. 


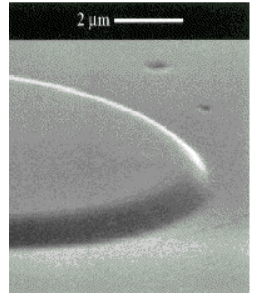

(a)

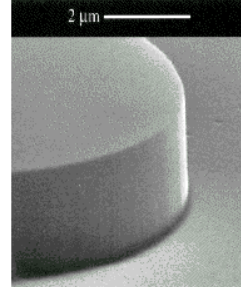

(b)

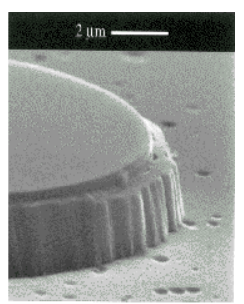

(c)
Figure 7. SEM micrographs for GaN etched at (a) -50 , (b) -150 and (c) $-300 \mathrm{~V} \mathrm{dc}$ bias. ICP etch conditions were $32 \mathrm{sccm} \mathrm{Cl} \mathrm{s}_{2}$, $8 \mathrm{sccm} \mathrm{BCl}_{3}, 5 \mathrm{sccm} \mathrm{Ar,} 500 \mathrm{~W}$ ICP source power, 2 mTorr pressure and $10^{\circ} \mathrm{C}$ electrode temperature.

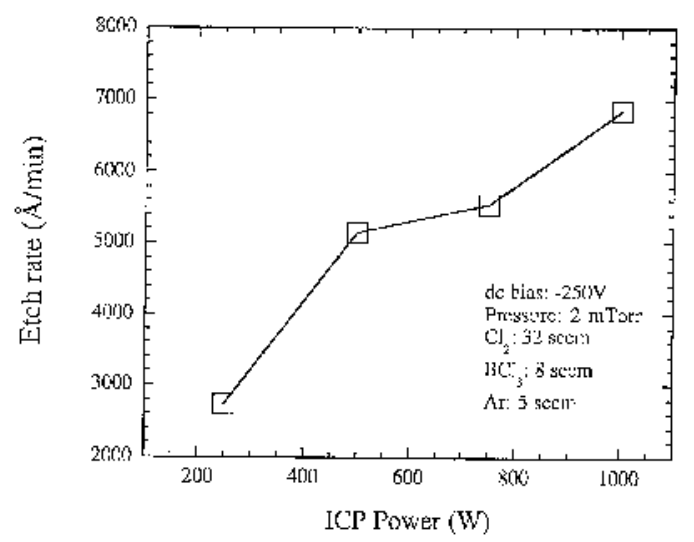

Figure 8. GaN etch rates as a function of ICP source power in an ICP-generated $\mathrm{BCl}_{3} / \mathrm{Cl}_{2} / \mathrm{Ar}$ plasma at $32 \mathrm{sccm} \mathrm{Cl} 2,8 \mathrm{sccm}$ $\mathrm{BCl}_{3}, 5 \mathrm{sccm} \mathrm{Ar},-250 \mathrm{~V} \mathrm{dc}$ bias, 2 mTorr pressure and $10^{\circ} \mathrm{C}$ electrode temperature. i)

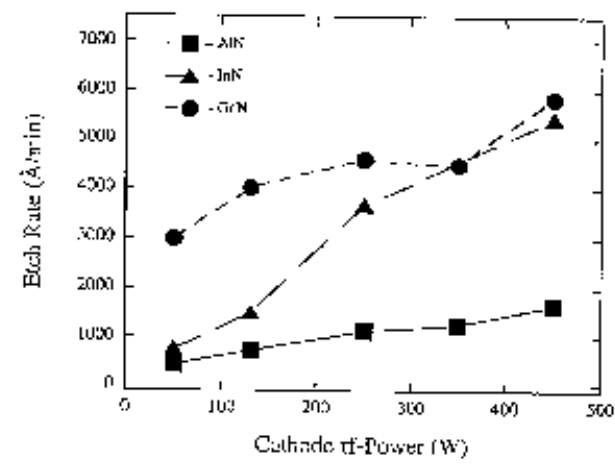

li)

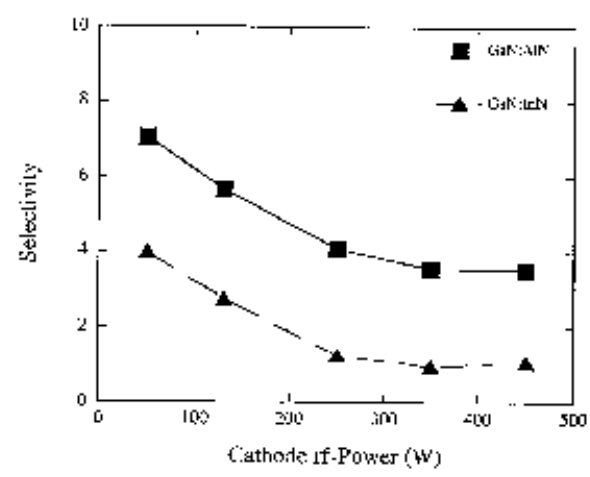

Figure 9. GaN, InN and AlN (a) etch rates and (b) GaN:AlN and $\mathrm{GaN}$ :InN etch selectivities as a function of dc bias in $\mathrm{Cl}_{2} /$ Ar ICP plasma. Plasma conditions were: $25 \mathrm{sccm} \mathrm{Cl}_{2}, 5 \mathrm{sccm}$ Ar, 2 mTorr chamber pressure, $500 \mathrm{~W}$ ICP-source power and $25^{\circ} \mathrm{C}$ cathode temperature.

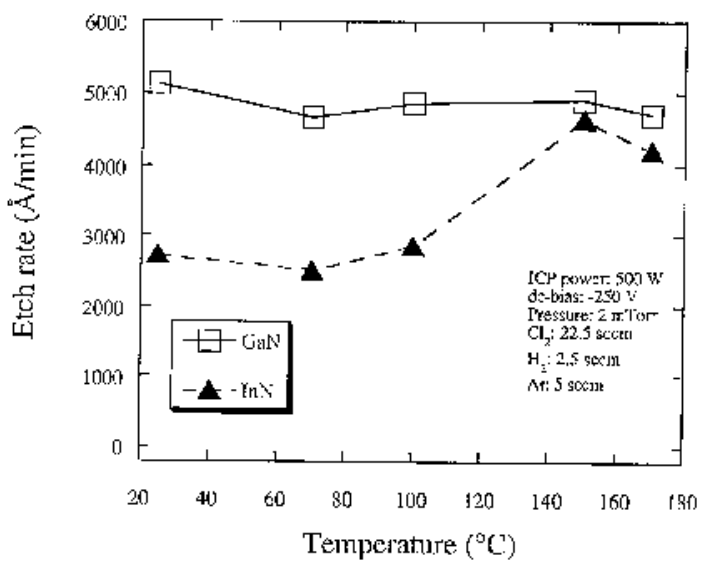

Figure 10. GaN and InN etch rates as a function of temperature for an ICP-generated $\mathrm{Cl}_{2} / \mathrm{H}_{2} / \mathrm{Ar}$ plasmas. ICP etch conditions were $22.5 \mathrm{sccm} \mathrm{Cl}_{2}, 2.5 \mathrm{sccm} \mathrm{H}_{2}, 5 \mathrm{sccm} \mathrm{Ar}, 500 \mathrm{~W}$ ICP source power, $-250 \mathrm{~V} \mathrm{dc}$ bias and $2 \mathrm{mTorr}$ pressure. 


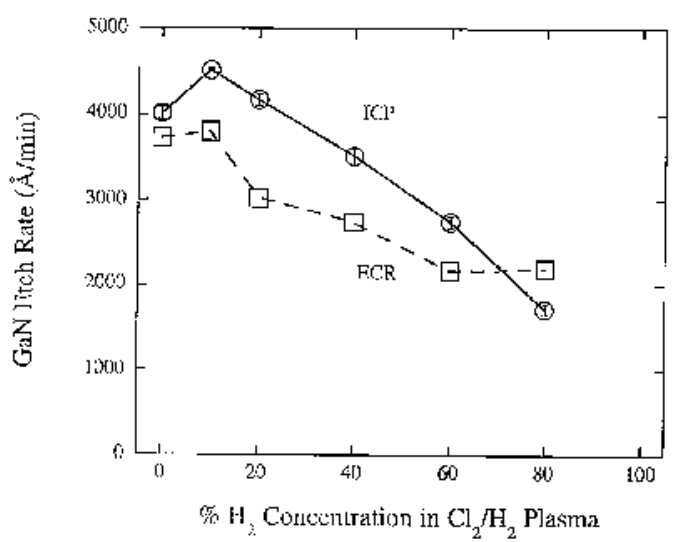

Figure 11. GaN etch rates in an ICP and ECR $\mathrm{Cl}_{2} \mathrm{H}_{2} / \mathrm{Ar}$ plasma as a function of $\% \mathrm{H}_{2}$.

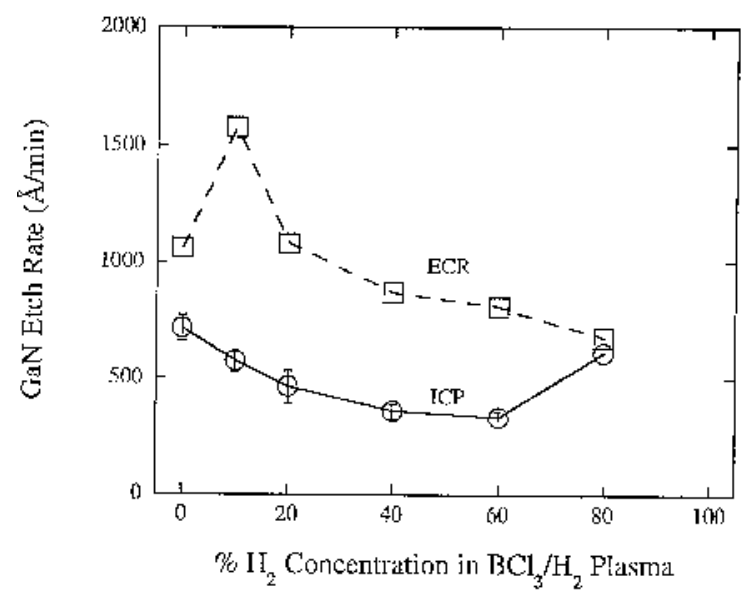

Figure 12. GaN etch rates in an ICP and ECR $\mathrm{BCl}_{3} / \mathrm{H}_{2} / \mathrm{Ar}$ plasma as a function of

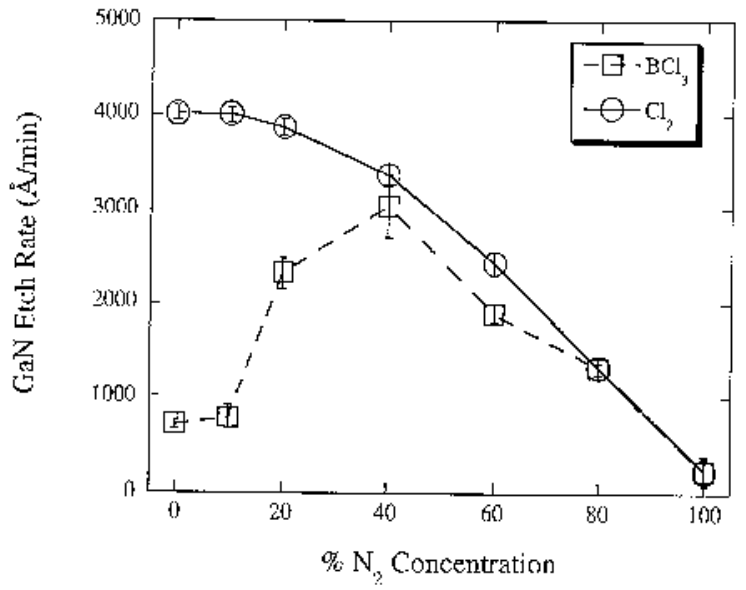

Figure 13. GaN etch rates as a function of $\% \mathrm{~N}_{2}$ for ICPgenerated $\mathrm{Cl}_{2}$ - and $\mathrm{BCl}_{3}$-based plasmas.
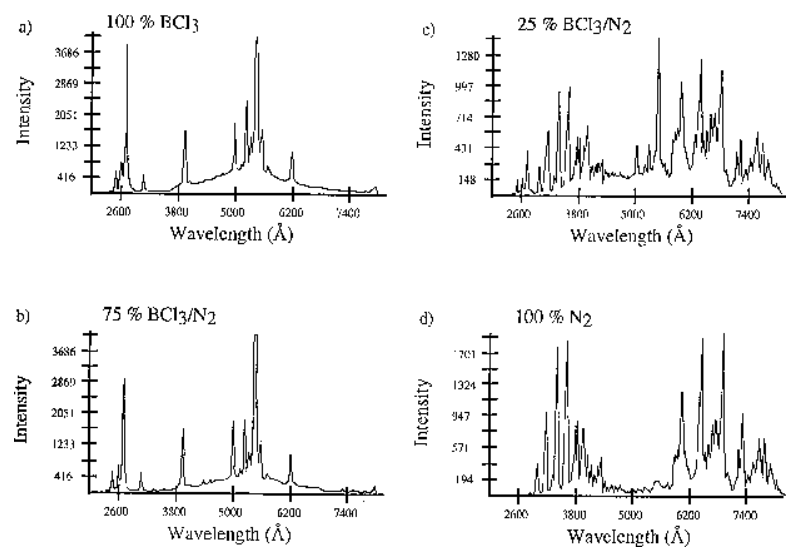

Figure 14. Optical emission spectra (OES) for an ICPgenerated $\mathrm{BCl}_{3} / \mathrm{N}_{2}$ plasma as a function of $\mathrm{BCl}_{3}$ percentage.

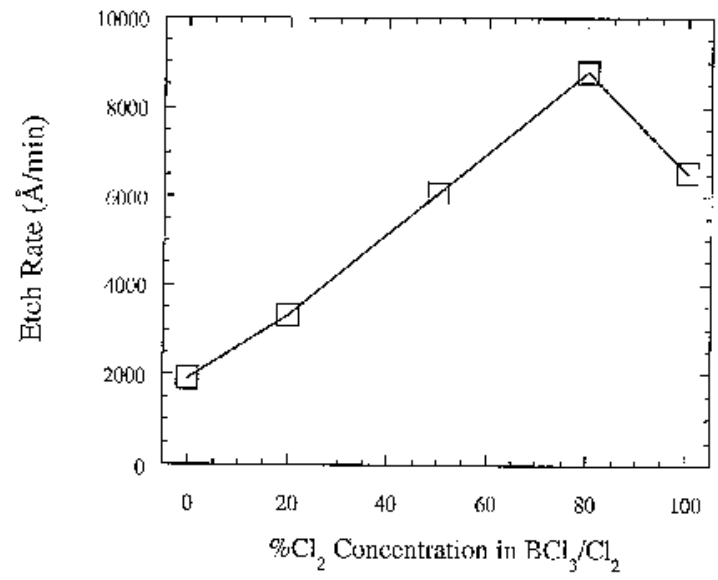

Figure 15. GaN etch rates in an ICP $\mathrm{BCl}_{3} / \mathrm{Cl}_{2}$ plasmas as a function of $\mathrm{Cl}_{2}$. 
a)

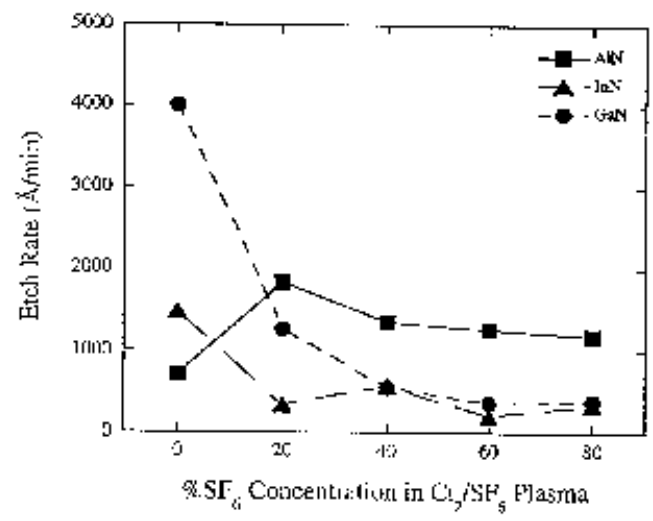

b)

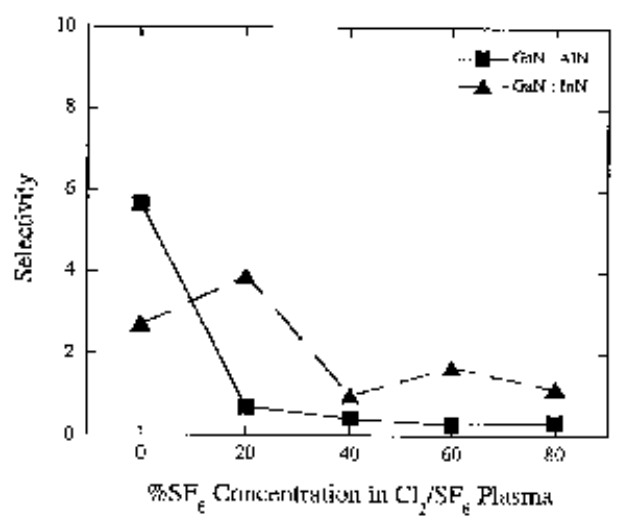

Figure 16. GaN, InN and AlN (a) etch rates and (b) GaN:AlN and $\mathrm{GaN}: \mathrm{InN}$ etch selectivities

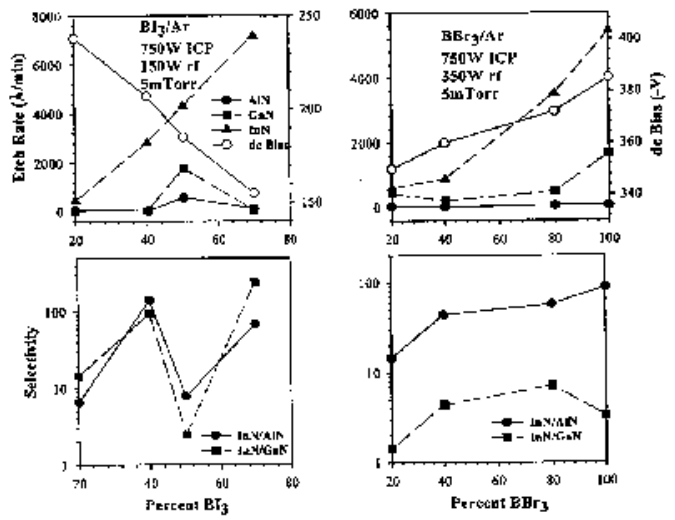

Figure 17. Nitride etch rates (top) and etch selectivities for InN/ AlN and InN/GaN (bottom in $\mathrm{BI}_{3} / \mathrm{Ar}$ or $\mathrm{BBr}_{3} / \mathrm{Ar}$ discharges (750 W source power, 5 mTorr) as a function of the boron halide content.
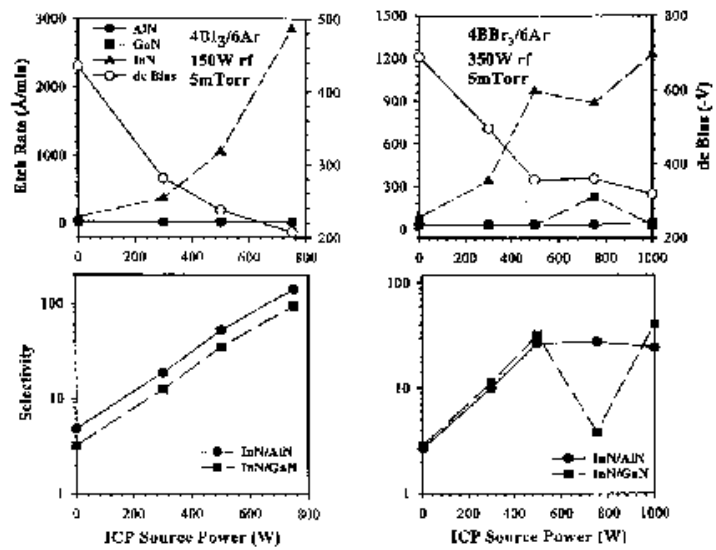

Figure 18. Nitride etch rates (top) and etch selectivities for InN/ AlN and InN/GaN (bottom) in $\mathrm{BI}_{3} / \mathrm{Ar}$ or $\mathrm{BBr} 3 / \mathrm{Ar}$ discharges as a function of source power.
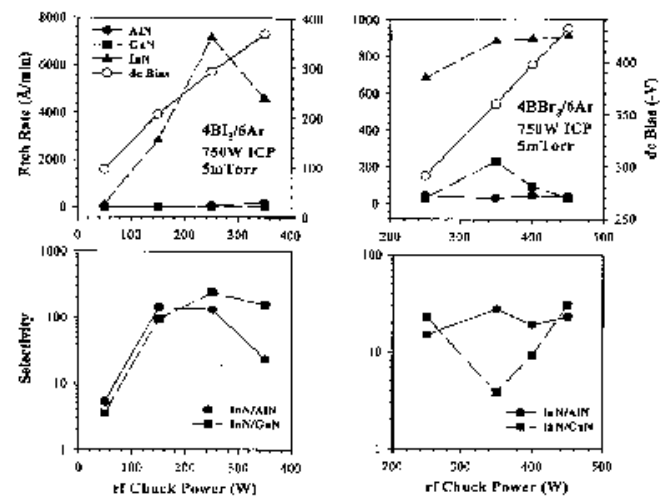

Figure 19. Nitride etch rates (top) and etch selectivities for InN/ $\mathrm{AlN}$ and $\mathrm{InN} / \mathrm{GaN}$ (bottom) in $\mathrm{BI}_{3} / \mathrm{Ar}$ or $\mathrm{BBr}_{3} / \mathrm{Ar}$ discharges as a function of $\mathrm{rf}$ chuck power.

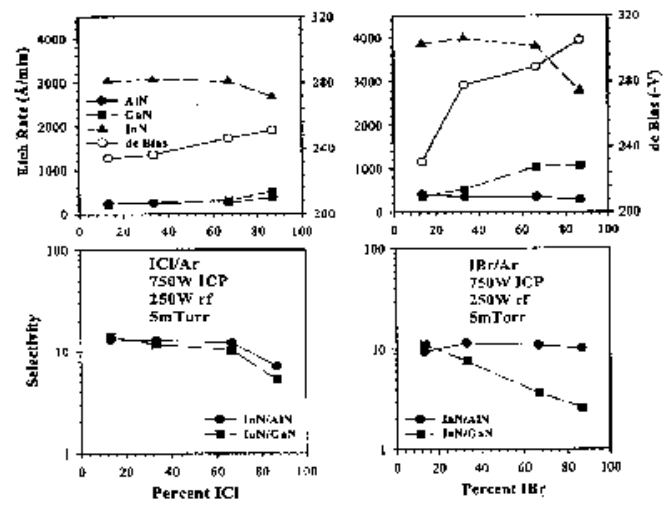

Figure 20. Nitride etch rates (top) and etch selectivities for InN/ AlN and InN/GaN (bottom) in ICl/Ar or IBr/Ar discharges (750 $\mathrm{W}$ source power, $250 \mathrm{~W}$ rf chuck power, $5 \mathrm{mTorr}$ ) as a function of interhalogen content. 


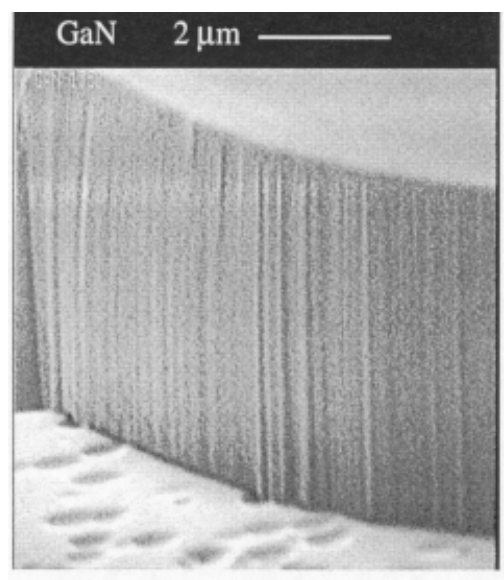

a)

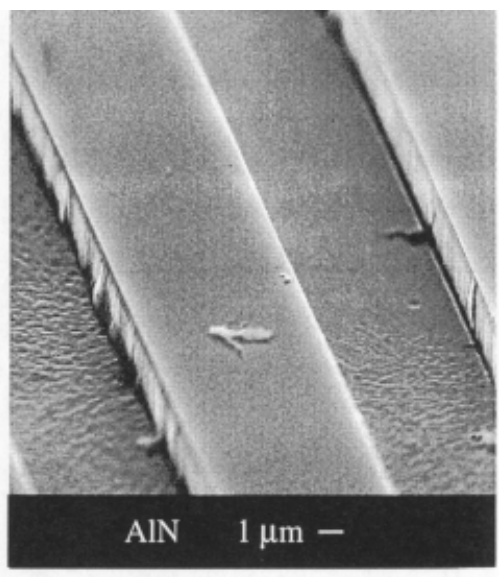

b)

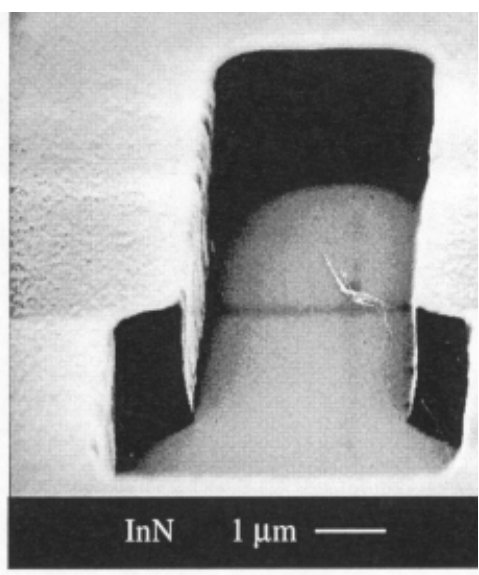

c)

Figure 21. SEM micrographs of (a) GaN, (b) $\mathrm{AlN}$ and (c) InN etched in $\mathrm{Cl}_{2}$-based ICP plasmas.

(a)

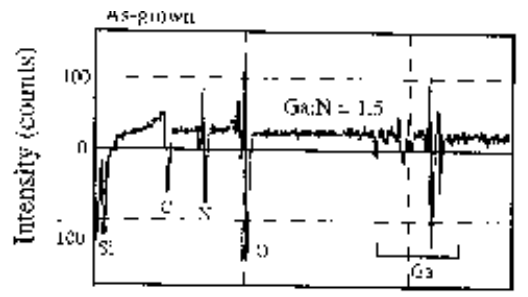

(b)

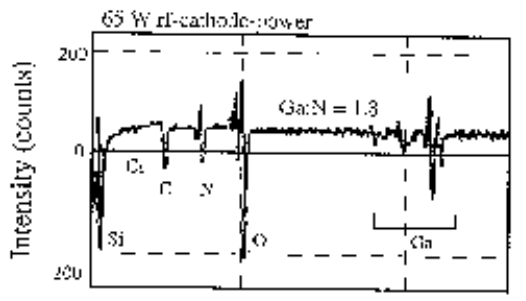

(c)

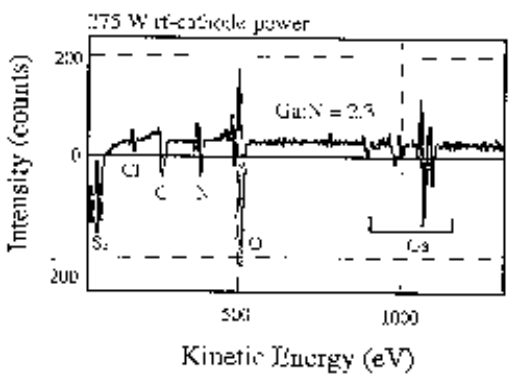

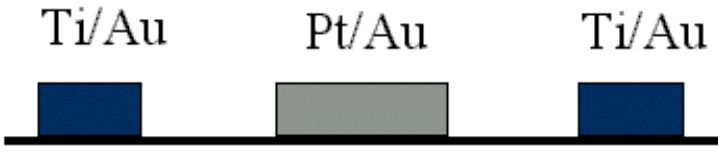

$3 \mu \mathrm{m}$ undoped $\left(\mathrm{n} \sim 10^{17} \mathrm{~cm}^{-3}\right) \mathrm{GaN}$

$0.5 \mu \mathrm{m} \mathrm{n}^{+}\left(10^{18} \mathrm{~cm}^{-3}\right) \mathrm{GaN}$

$\mathrm{Al}_{2} \mathrm{O}_{3}$ substrate

Figure 23. Schematic of GaN Schottky diode structure.

Figure 22. AES surface scans of GaN (a) before exposure to the plasma, (b) at $65 \mathrm{~W}(-120 \mathrm{~V}$ bias) and (c) $275 \mathrm{~W}$ rf-cathode power (-325 V bias), $1 \mathrm{mTorr}, 170^{\circ} \mathrm{C}$, and $850 \mathrm{~W}$ microwave power in an ECR-generated $\mathrm{Cl}_{2} / \mathrm{H}_{2}$ discharge. 

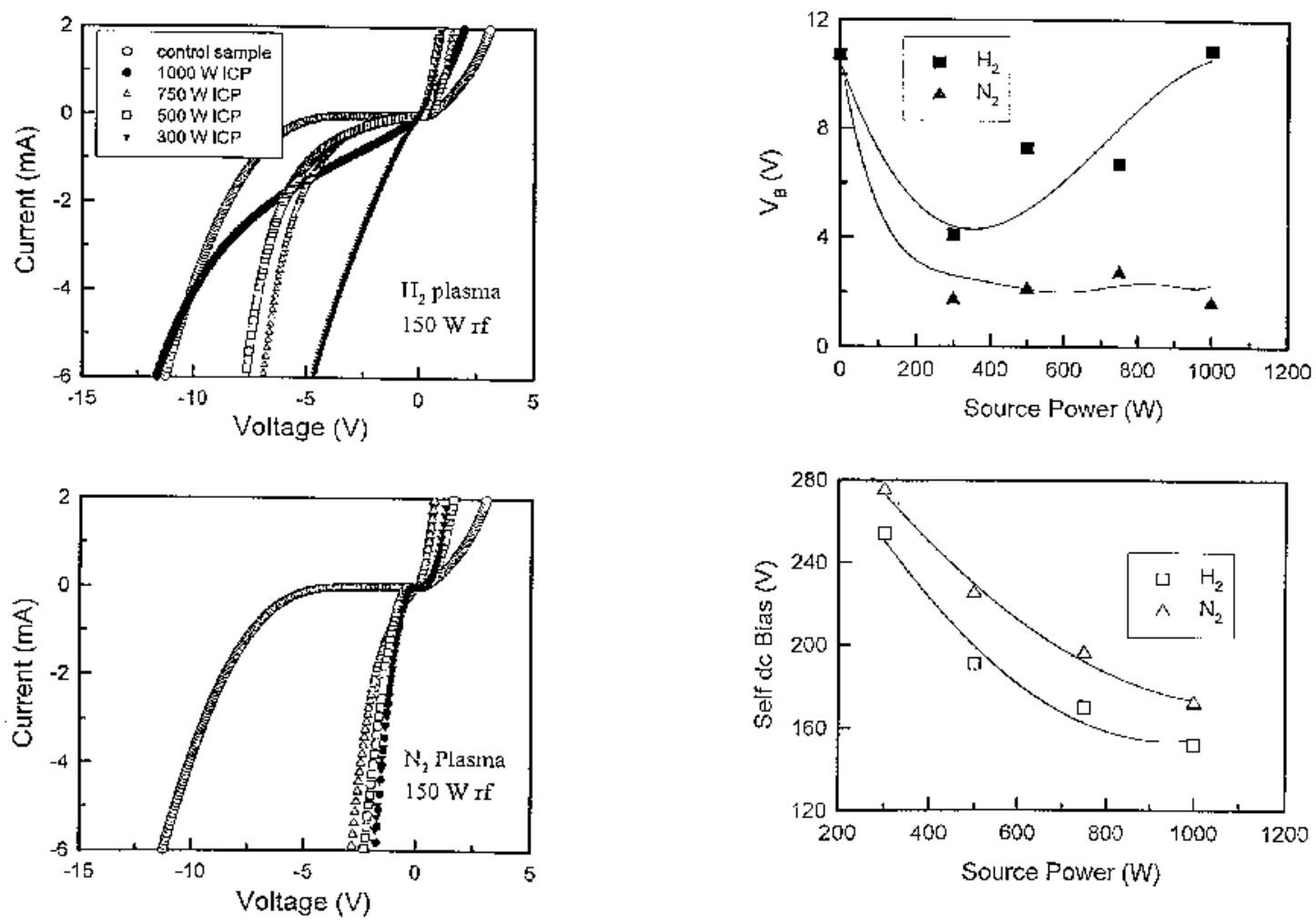

Figure 24. I-V characteristics from GaN diodes before and after $\mathrm{H}_{2}$ (top) or $\mathrm{N}_{2}$ (bottom) plasma exposure (150 W rf chuck power, 5 mTorr) at different ICP source powers.

Figure 25. Variation of $\mathrm{V}_{\mathrm{B}}$ in GaN diodes (top) and dc chuck self-bias (bottom) as a function of ICP source power in $\mathrm{H}_{2}$ or $\mathrm{N}_{2}$ plasmas (150 W rf chuck power, 5 mTorr). 

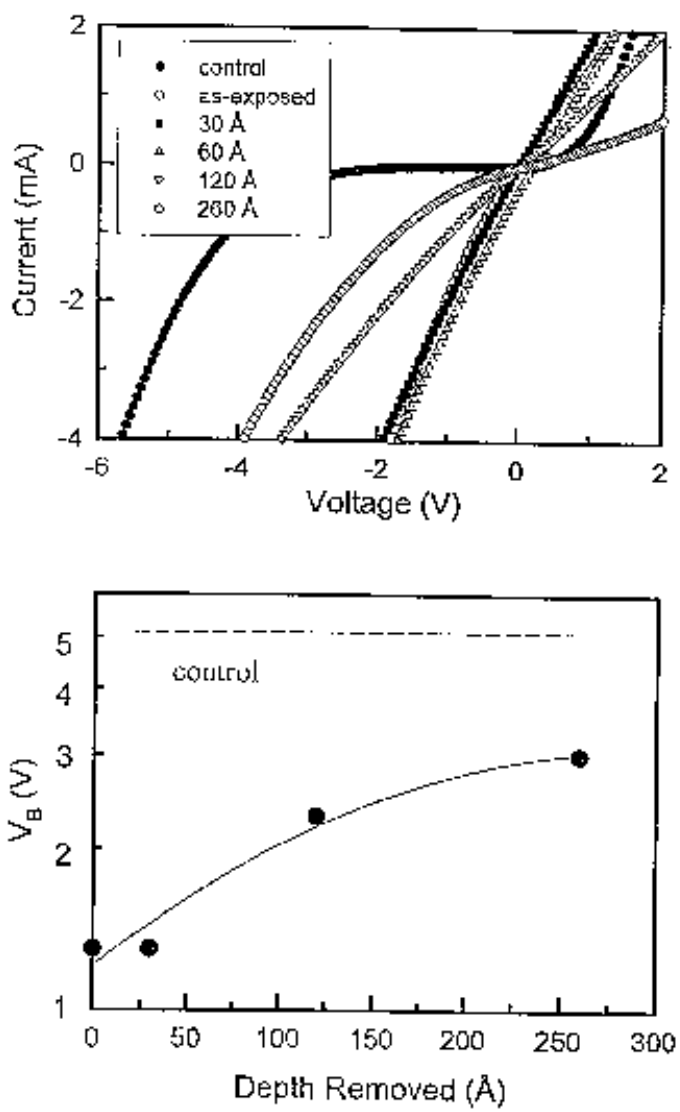

Figure 26. I-V characteristics from $\mathrm{N}_{2}$ plasma exposed $\mathrm{GaN}$ diodes before and after wet etch removal of different amounts of GaN prior to deposition of the Schottky contact (top) and variation of $\mathrm{V}_{\mathrm{B}}$ as a function of the amount of material removed (bottom).
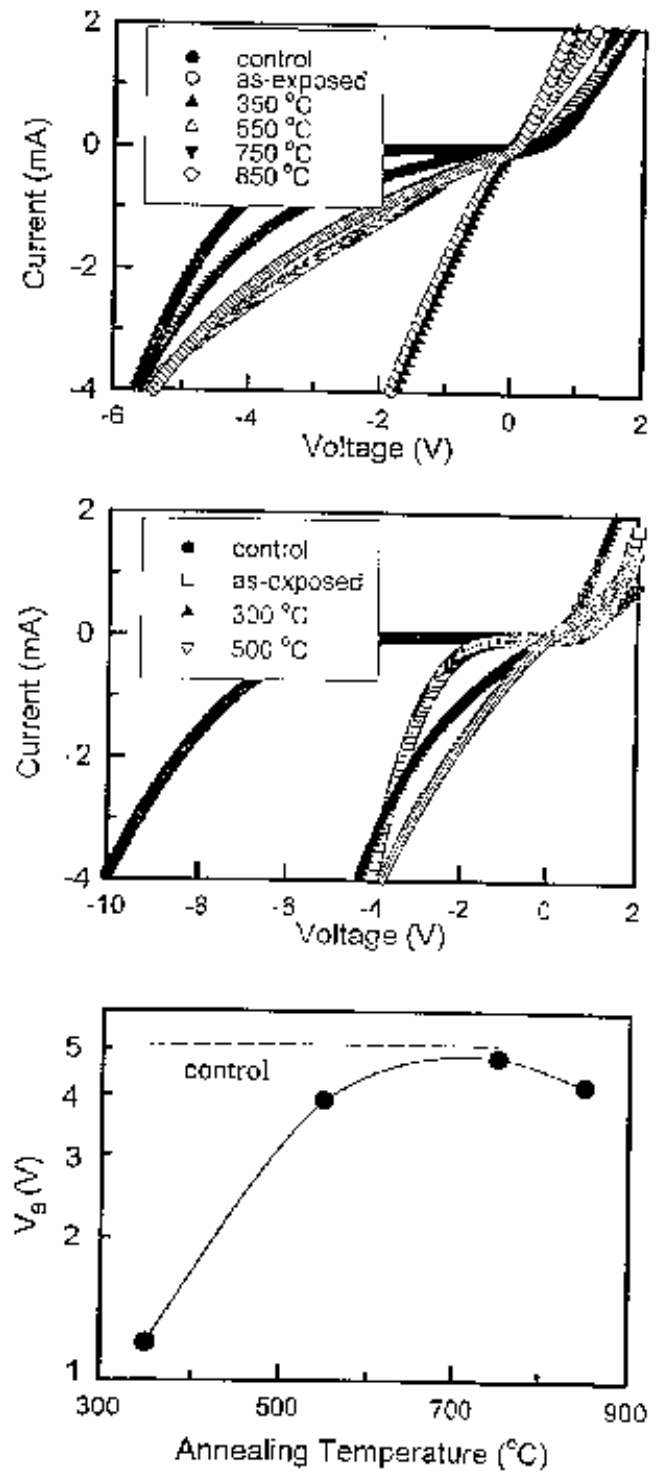

Figure 27. I-V characteristics from GaN diodes before and after $\mathrm{N}_{2}$ plasma exposure $(500 \mathrm{~W}$ source power, $150 \mathrm{~W}$ rf chuck power, 5 mTorr) and subsequent annealing either prior (top) or subsequent (center) to the deposition of the Schottky metallization. The variation of $\mathrm{V}_{\mathrm{B}}$ in the samples annealed prior to metal deposition is shown at the bottom of the figure. 

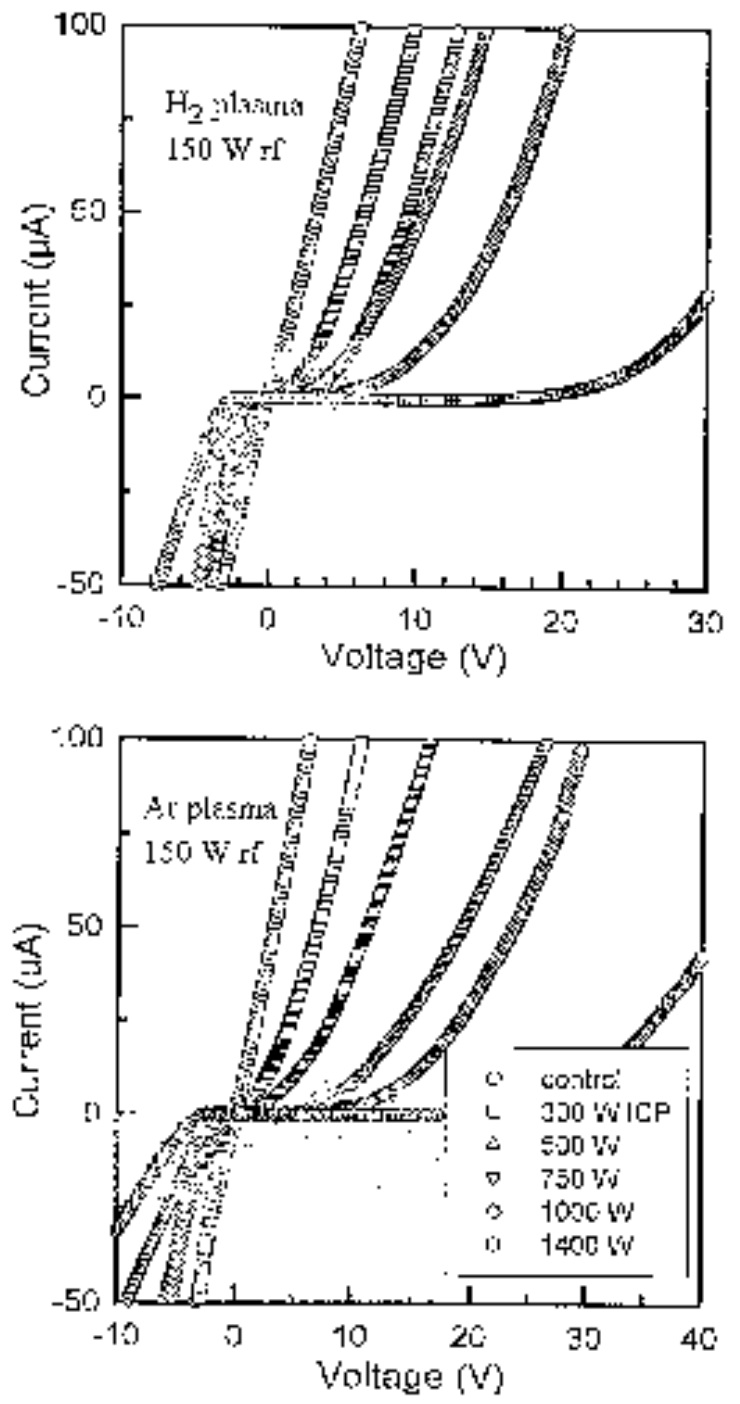

Figure 28. I-V characteristics from samples exposed to either $\mathrm{H}_{2}$ (top) or $\mathrm{Ar}$ (bottom) ICP discharges (150 W rf chuck power) as a function of ICP source power prior to deposition of the Ti/ $\mathrm{Pt} / \mathrm{Au}$ contact.

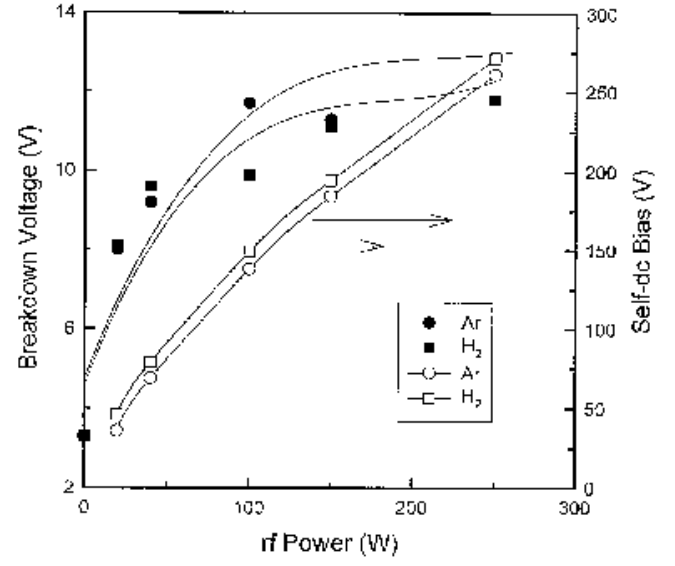

Figure 29. Variation of diode breakdown voltage in samples exposed to $\mathrm{H}_{2}$ or Ar ICP discharges ( $150 \mathrm{~W}$ rf chuck power) at different ICP source powers prior to deposition of the Ti/Pt/Au contact. The dc chuck self-bias during plasma exposure is also shown.

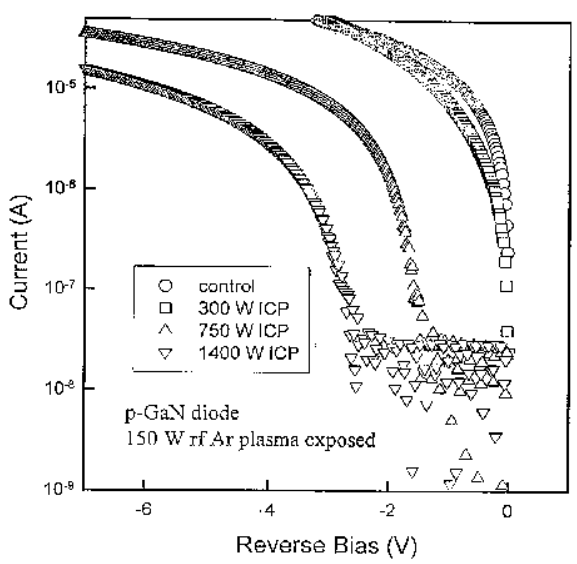

Figure 30. Forward turn-on characteristics of diodes exposed to ICP Ar discharges (150 W rf chuck power) at different ICP source powers prior to deposition of the Ti/Pt/Au contact. 


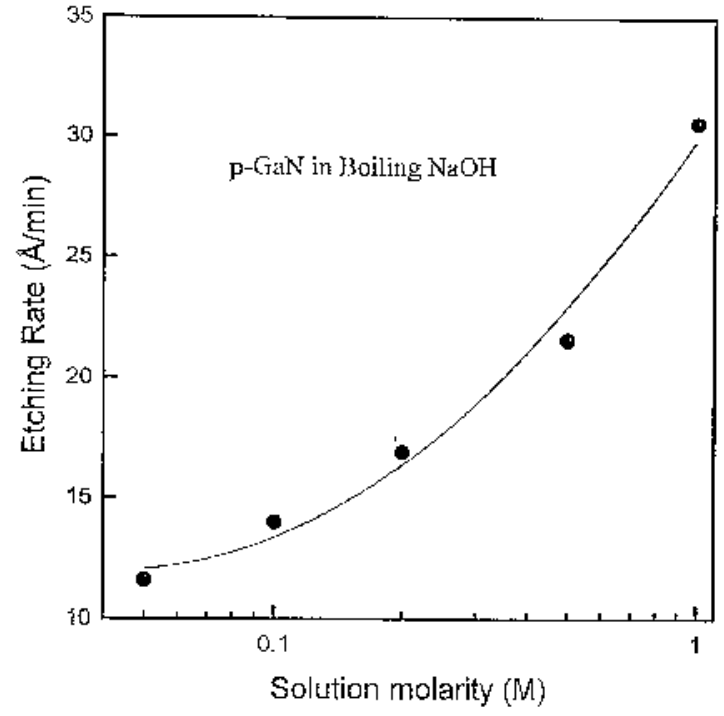

Figure 31. Wet etching rate of $\mathrm{p}-\mathrm{GaN}$ in boiling $\mathrm{NaOH}$ solutions as a function of solution molarity.

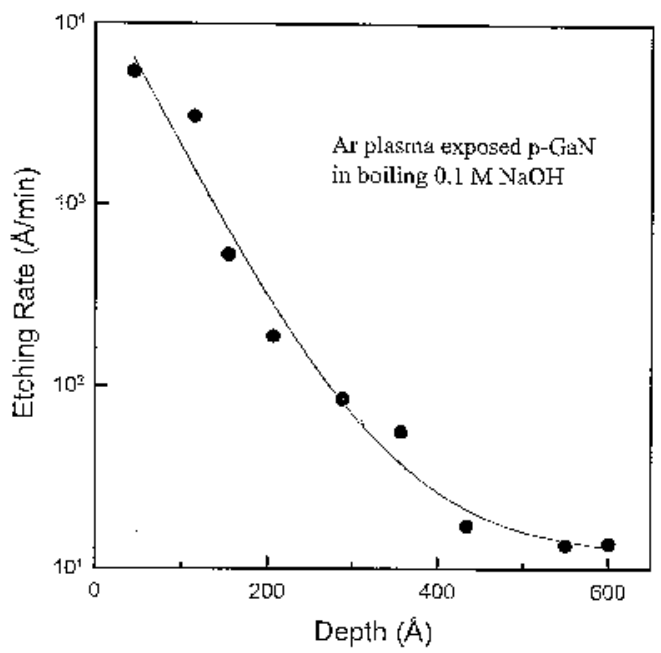

Figure 32. Wet etching rate of Ar plasma exposed (750 W source power, $150 \mathrm{~W}$ rf chuck power) $\mathrm{GaN}$ as a function of depth into the sample.
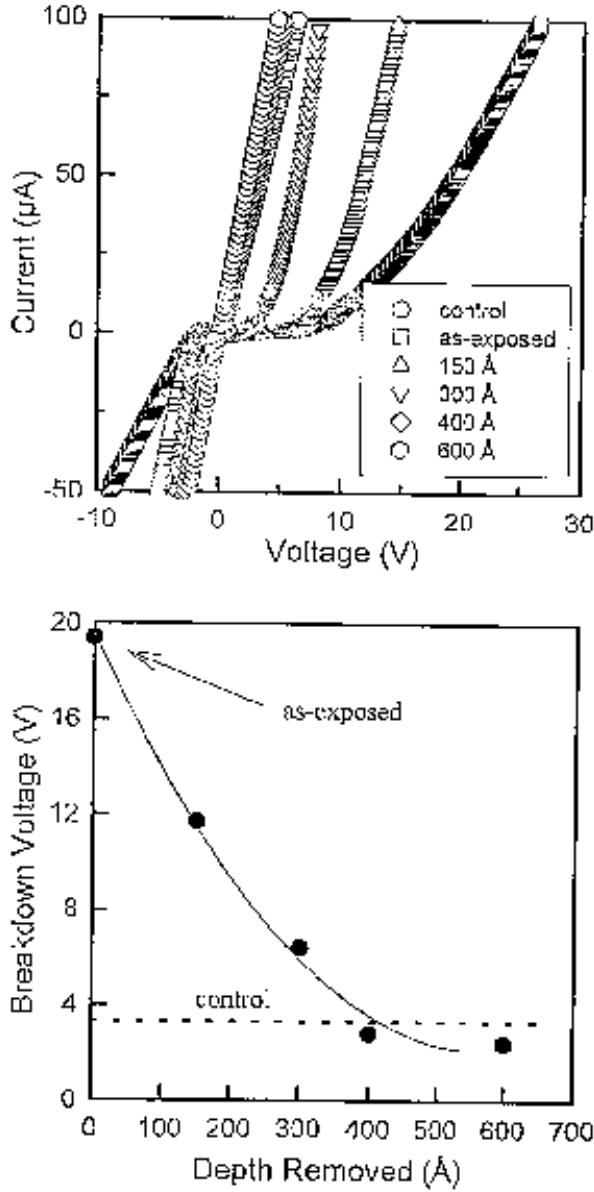

Figure 33. I-V characteristics from samples exposed to ICP Ar discharges (750 W source power, $150 \mathrm{~W}$ rf chuck power) and subsequently wet etched to different depths prior to deposition of the $\mathrm{Ti} / \mathrm{Pt} / \mathrm{Au}$ contact (top) and breakdown voltage as a function of depth removed (bottom). 

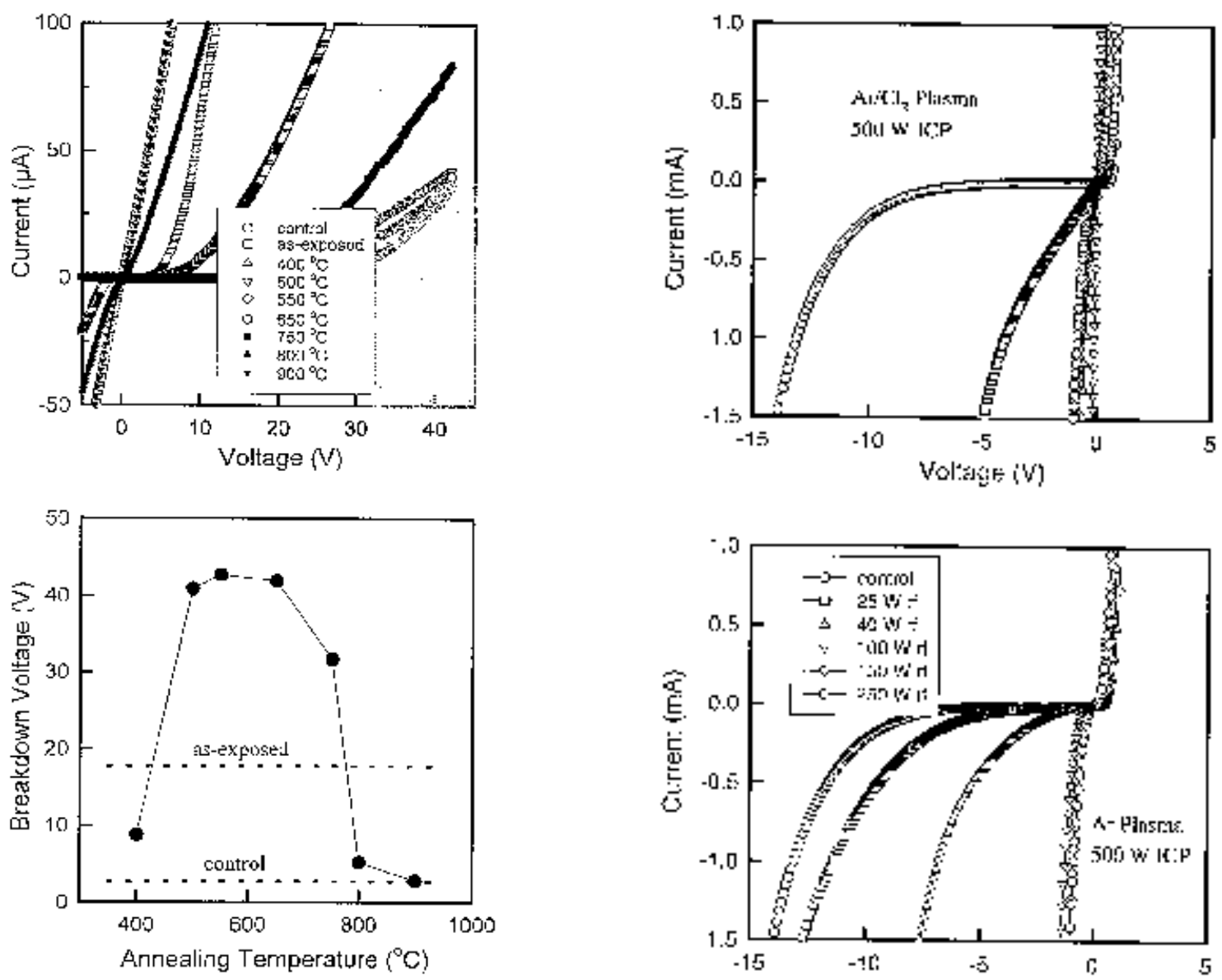

Figure 34. I-V characteristics from samples exposed to ICP Ar discharges (750 W source power, $150 \mathrm{~W}$ rf chuck power) and subsequently annealed at different temperatures prior to deposition of the $\mathrm{Ti} / \mathrm{Pt} / \mathrm{Au}$ contact (top) and breakdown voltage as a function of annealing temperature (bottom).

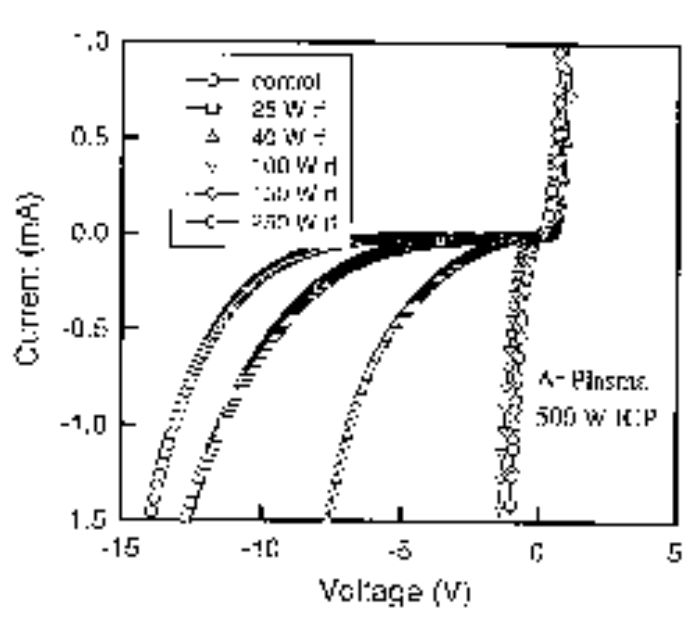

Figure 35. I-V characteristics from n-GaN samples exposed to ICP $\mathrm{Cl}_{2} / \mathrm{Ar}$ (top) or $\mathrm{Ar}$ (bottom) discharges (500 W source power) as a function of rf chuck power prior to deposition of the rectifying contact. 

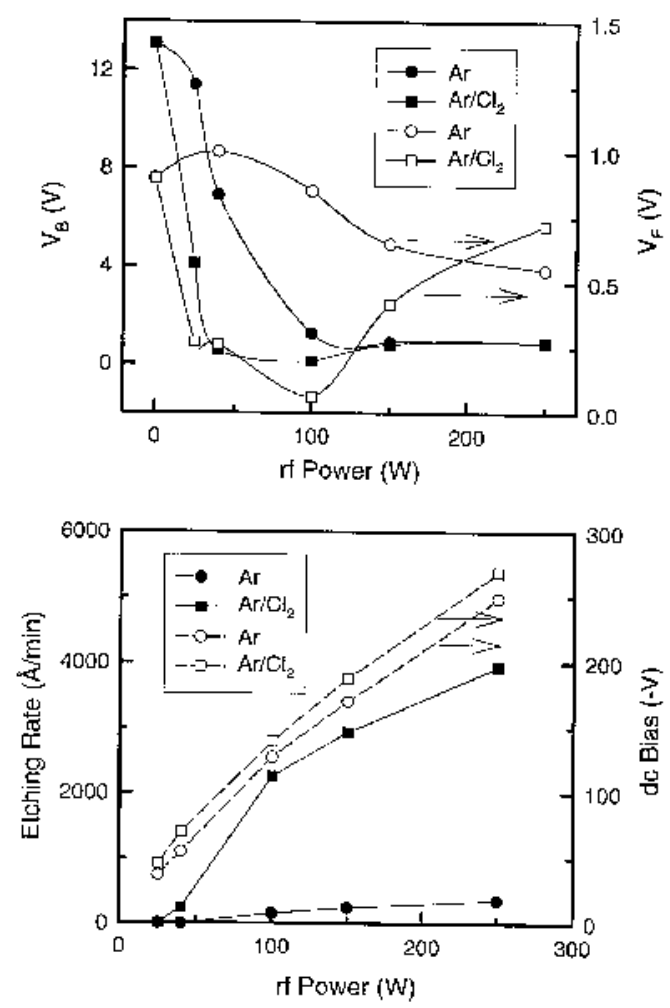

Figure 36. Variations of $\mathrm{V}_{\mathrm{B}}$ and $\mathrm{V}_{\mathrm{F}}$ (top) and of $\mathrm{n}-\mathrm{GaN}$ etching rate (bottom) as a function of rf chuck power for $\mathrm{n}-\mathrm{GaN}$ diodes exposed to $\mathrm{ICP} \mathrm{Cl}_{2} / \mathrm{Ar}$ discharges ( $500 \mathrm{~W}$ source power).
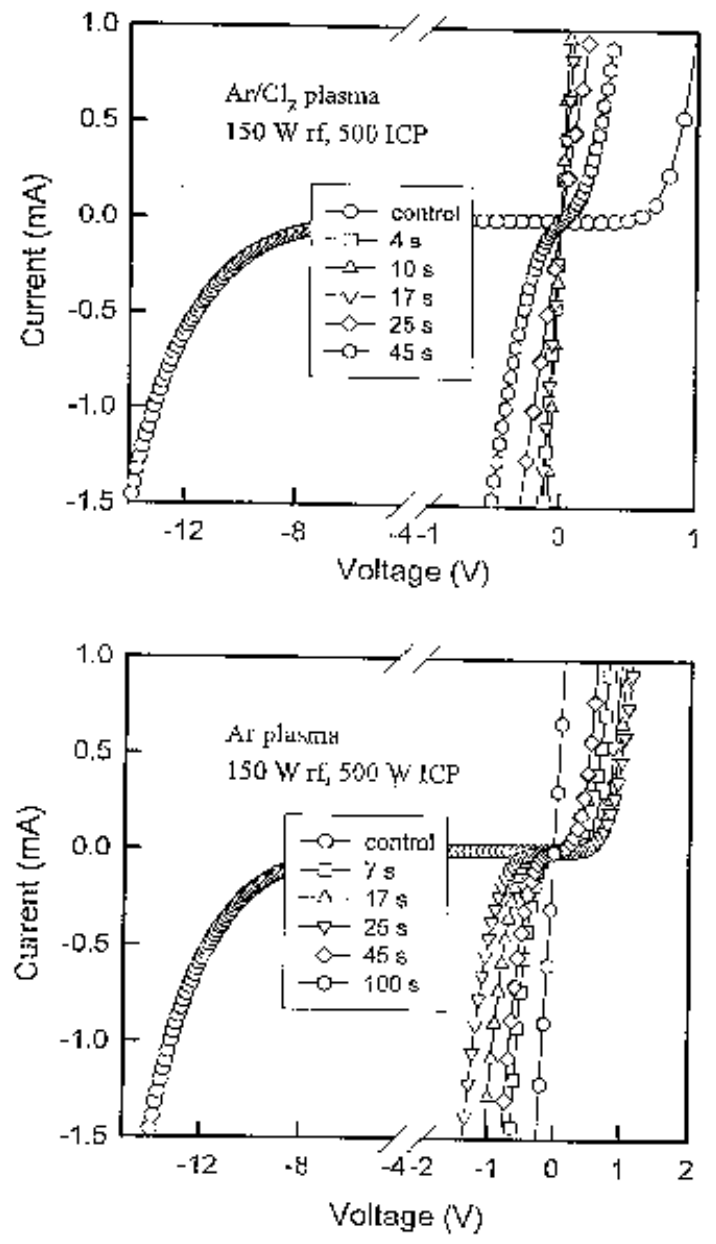

Figure 37. I-V characteristics from $\mathrm{n}-\mathrm{GaN}$ samples exposed to ICP $\mathrm{Cl}_{2} / \mathrm{Ar}$ (top) or Ar (bottom) discharges (150 W rf chuck power, $500 \mathrm{~W}$ source power) as a function of plasma exposure time prior to deposition of the rectifying contact. 


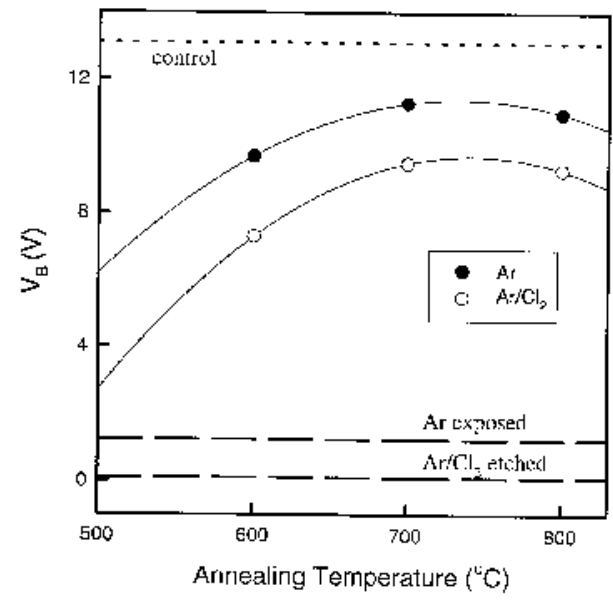

Figure 38. Variation of $\mathrm{V}_{\mathrm{B}}$ in $\mathrm{n}-\mathrm{GaN}$ diodes exposed to $\mathrm{ICP} \mathrm{Cl}_{2} /$ Ar or Ar discharges $(500 \mathrm{~W}$ source power, $100 \mathrm{~W}$ rf chuck power) with annealing temperature prior to deposition of the rectifying contact.
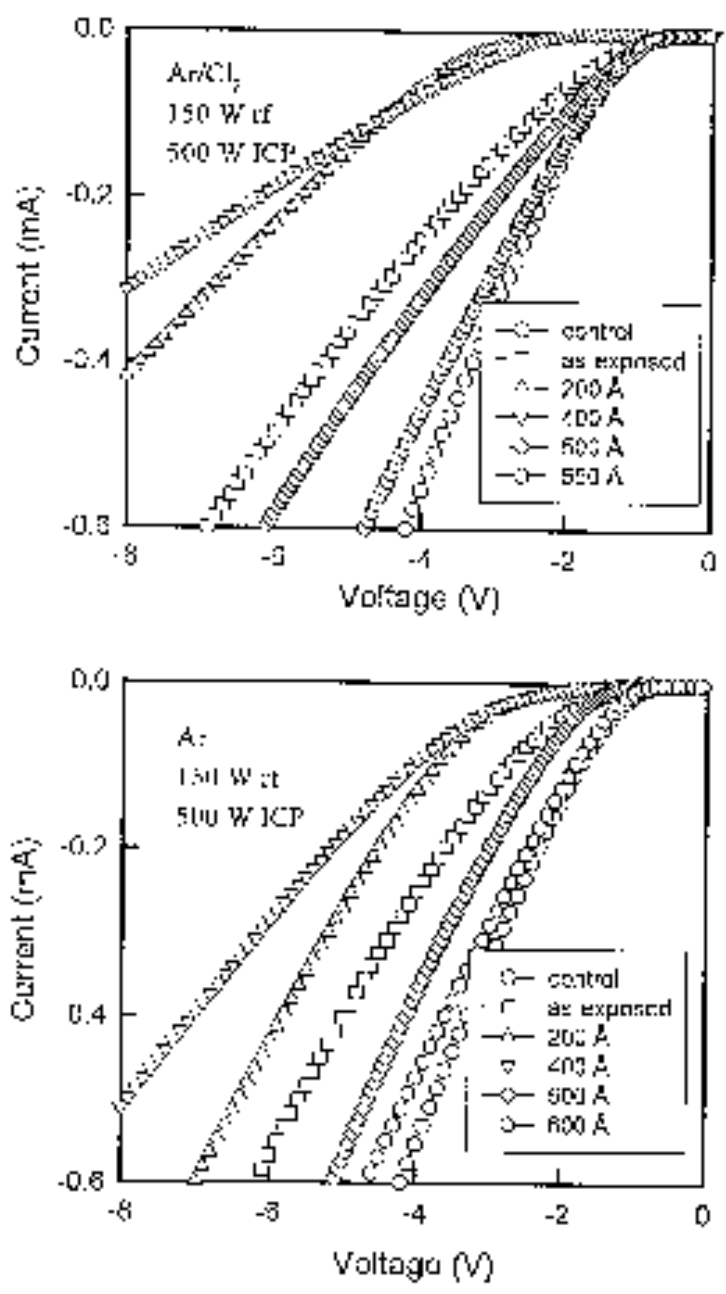

Figure 39. I-V characteristics from $\mathrm{p}-\mathrm{GaN}$ samples exposed to ICP $\mathrm{Cl}_{2} / \mathrm{Ar}$ (top) or Ar (bottom) discharges $(500 \mathrm{~W}$ source power, $150 \mathrm{~W}$ rf chuck power) and wet etched in boiling $\mathrm{NaOH}$ to different depths prior to deposition of the rectifying contact. 

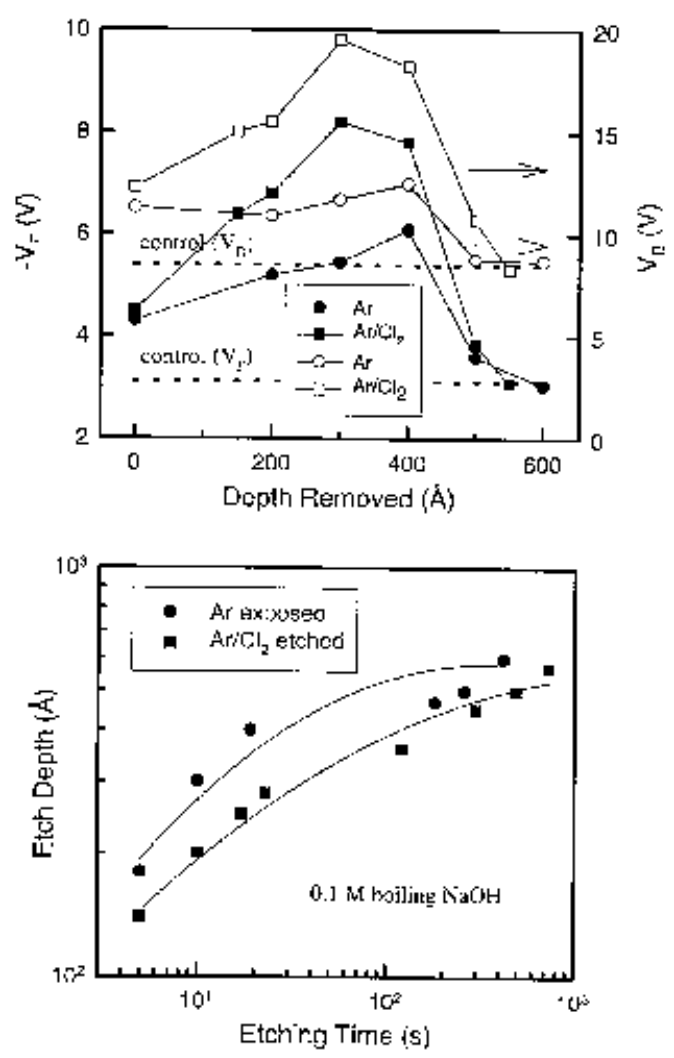

Figure 40. Variation of $\mathrm{V}_{\mathrm{B}}$ and $\mathrm{V}_{\mathrm{F}}$ (top) with depth of $\mathrm{p}-\mathrm{GaN}$ removed by wet etching prior to deposition of the rectifying contact, and wet etch depth versus etch time in boiling $\mathrm{NaOH}$ solutions for plasma damaged p-GaN (bottom).

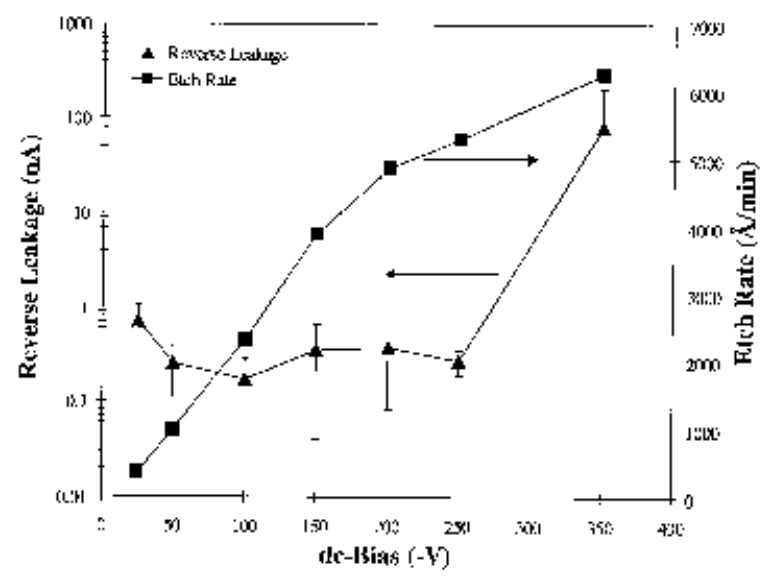

Figure 41. Reverse leakage current measured at $-30 \mathrm{~V}$ for $\mathrm{GaN}$ p-i-n junctions etched in ICP $32 \mathrm{Cl}_{2} / 8 \mathrm{BCl}_{3} / 5 \mathrm{Ar}$ discharges $(500$ $\mathrm{W}$ source power, 2 mTorr), as a function of dc chuck self-bias.

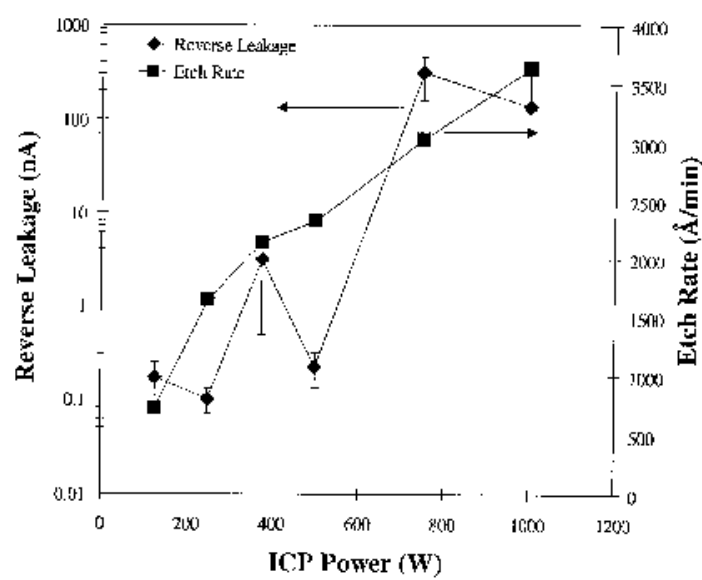

Figure 42. Reverse leakage current measured at $-30 \mathrm{~V}$ for $\mathrm{GaN}$ p-i-n junctions etched in ICP $32 \mathrm{Cl}_{2} / 8 \mathrm{BCl}_{3} / 5 \mathrm{Ar}$ discharges ($100 \mathrm{~V} \mathrm{dc}$ chuck self-bias, $2 \mathrm{mTorr}$ ), as a function of source power.

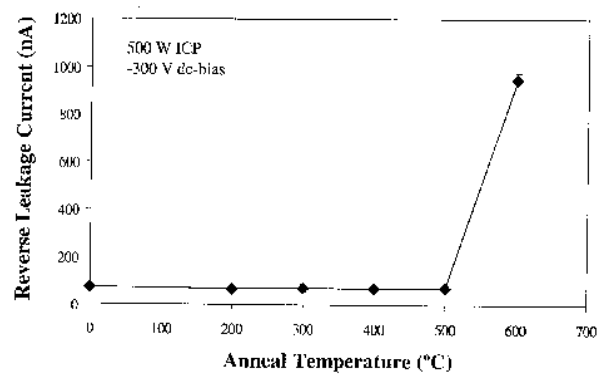

Figure 43. Reverse leakage current measured at $-30 \mathrm{~V}$ for $\mathrm{GaN}$ p-i-n junctions etched in ICP $32 \mathrm{Cl}_{2} / 8 \mathrm{BCl}_{3} / 5 \mathrm{Ar}$ discharges ($300 \mathrm{~V}$ dc chuck self-bias, $500 \mathrm{~W}$ ICP source power, 2 mTorr), as a function of anneal temperature. 

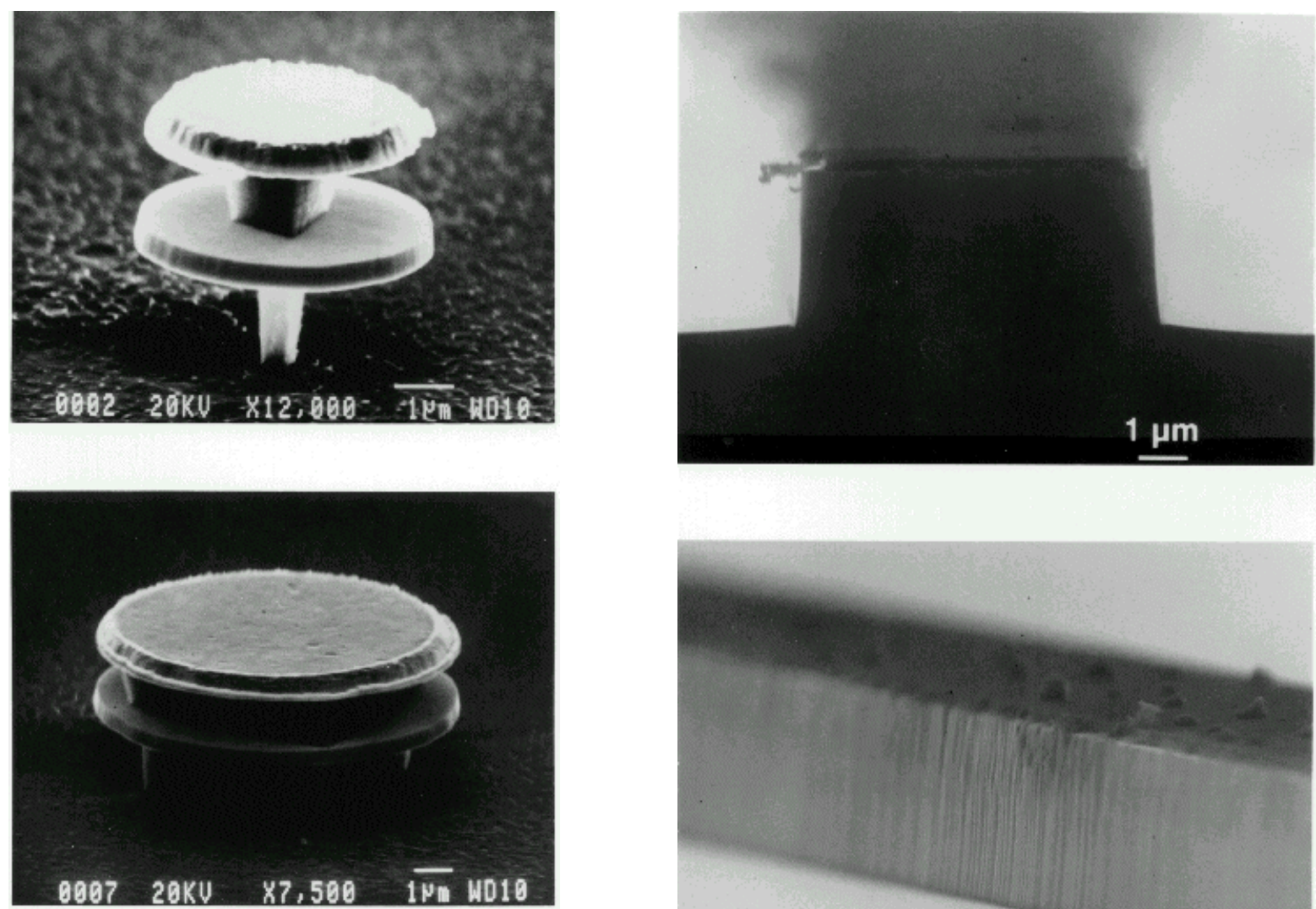

Figure 44. SEM micrographs of GaN/InGaN/AlN microdisk laser structures.

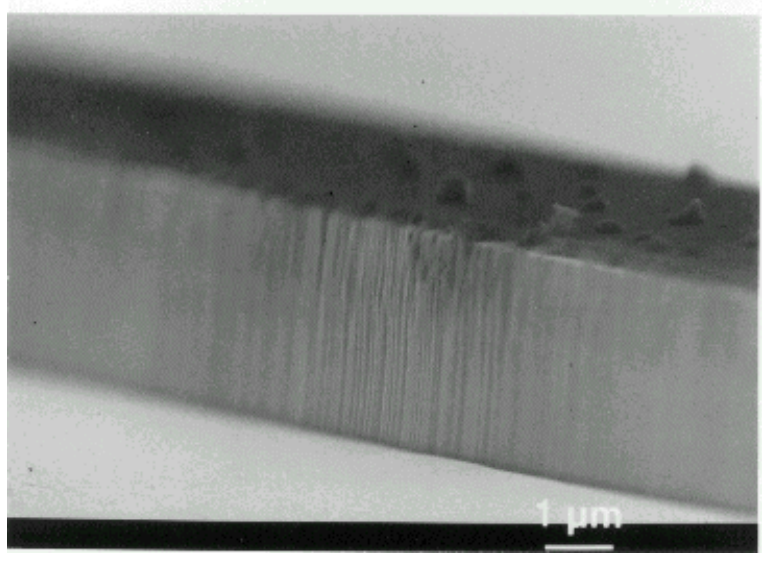

Figure 45. SEM micrograph of dry etched GaN feature. 

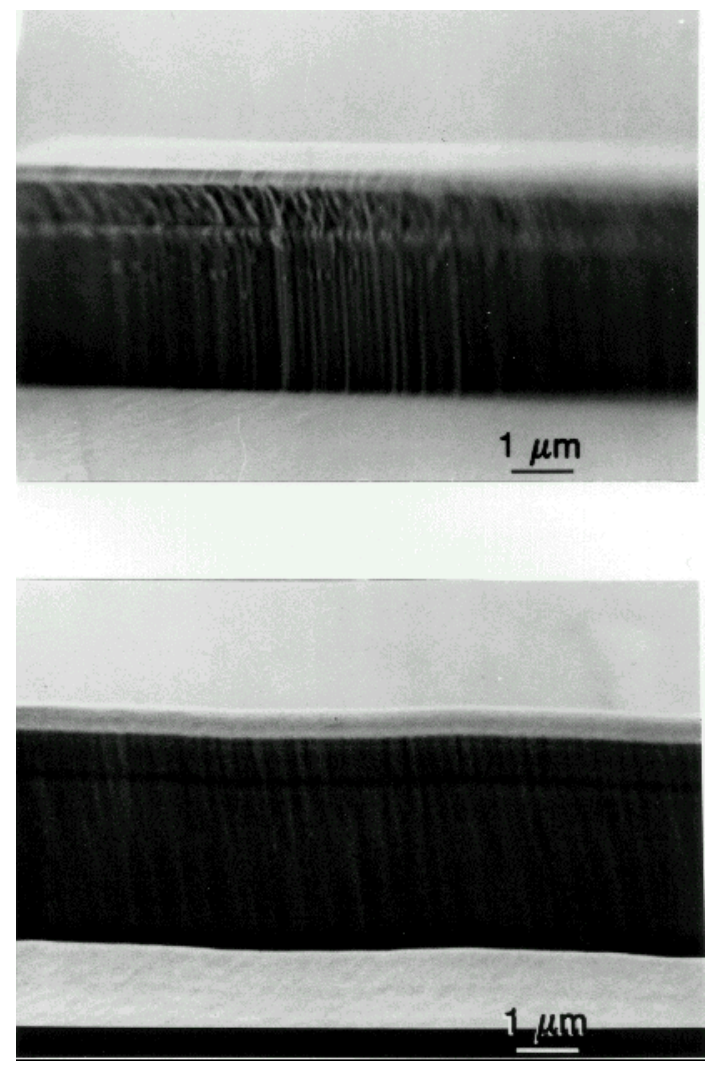

Figure 46. SEM micrographs of features etched into GaN at high (top) or moderate (bottom) ion energy.
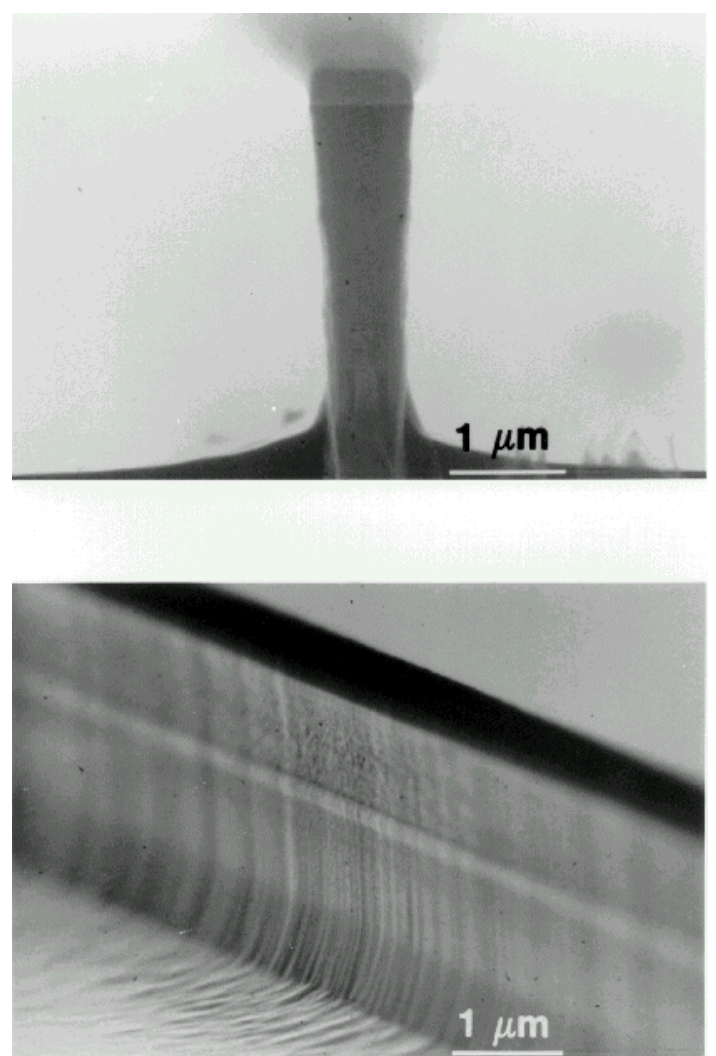

Figure 47. SEM micrographs of dry etched GaN/InGaN/GaN ridge waveguide laser structure.

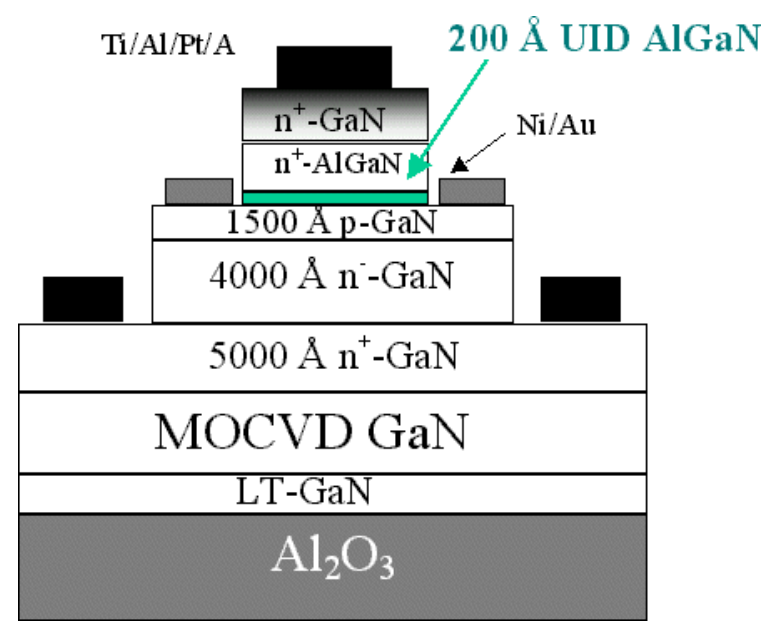

Figure 48. Schematic of MOCVD-grown GaN/AlGaN HBT. 


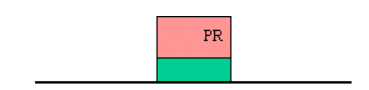

(a) Emitter Mesa Etching

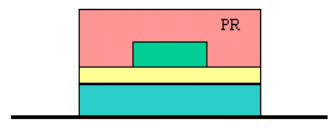

(b) Base Mesa Etching

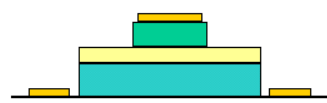

(c) Emitter/Collector Metallization

Figure 49. Schematic process sequence for GaN/AlGaN HBT.

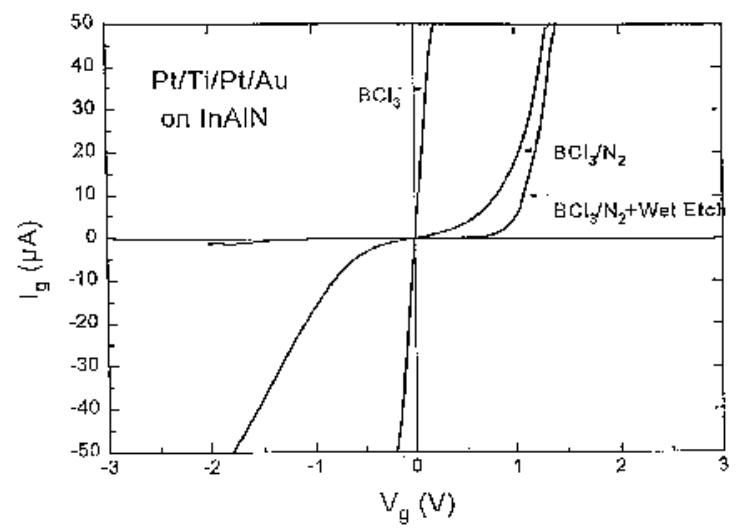

Figure 50. I-V characteristics of Pt/TiPt/Au contacts on InAlN exposed to different ECR plasmas.

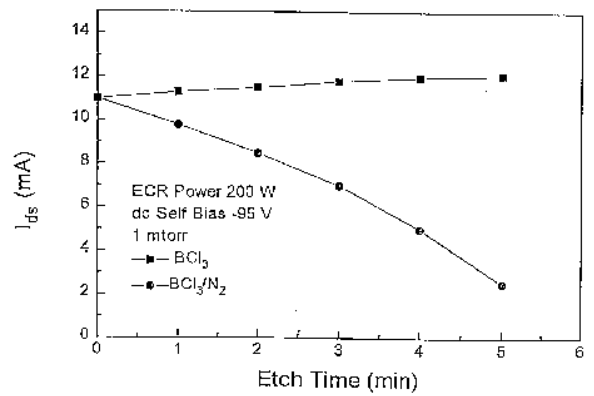

Figure 51. $\mathrm{I}_{\mathrm{DS}}$ values at $5 \mathrm{~V}$ bias for InAlN FETs etched for various times in $\mathrm{BCl}_{3}$ or $\mathrm{BCl}_{3} / \mathrm{N}_{2} \mathrm{ECR}$ plasmas.

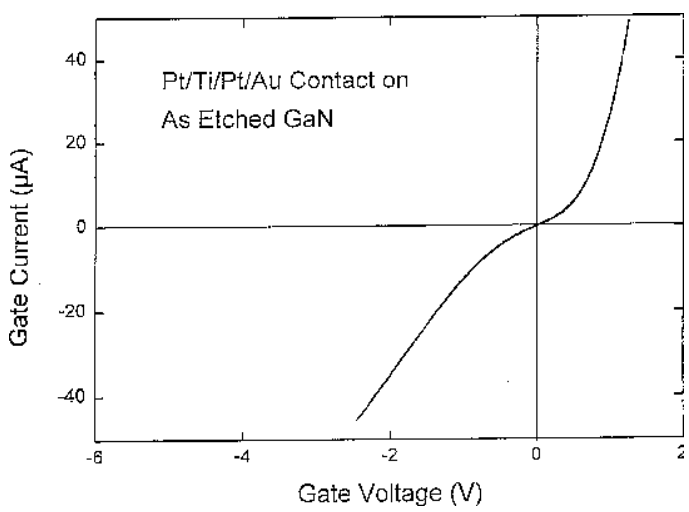

Figure 52. I-V characteristic on $\mathrm{ECR} \mathrm{BCl}_{3}$-etched $\mathrm{GaN}$.

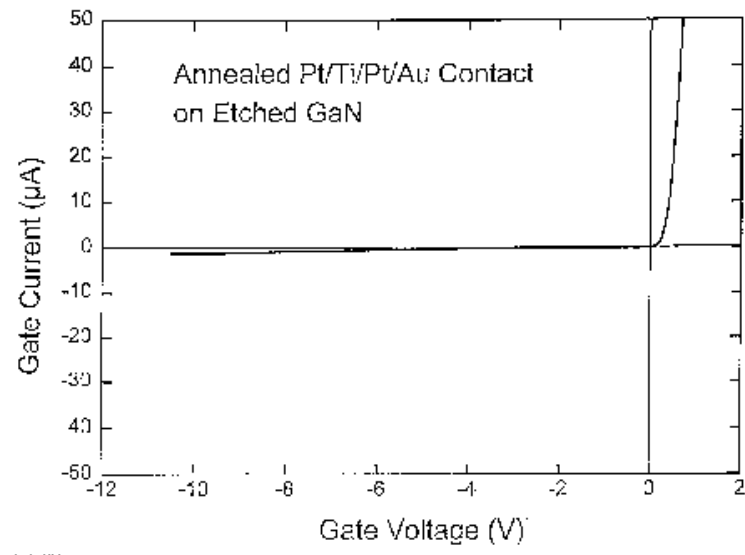

Figure 53. I-V characteristic on $\mathrm{ECR} \mathrm{BCl}_{3}$-etched $\mathrm{GaN}$ annealed at $400^{\circ} \mathrm{C}$ prior to deposition of the gate metal.

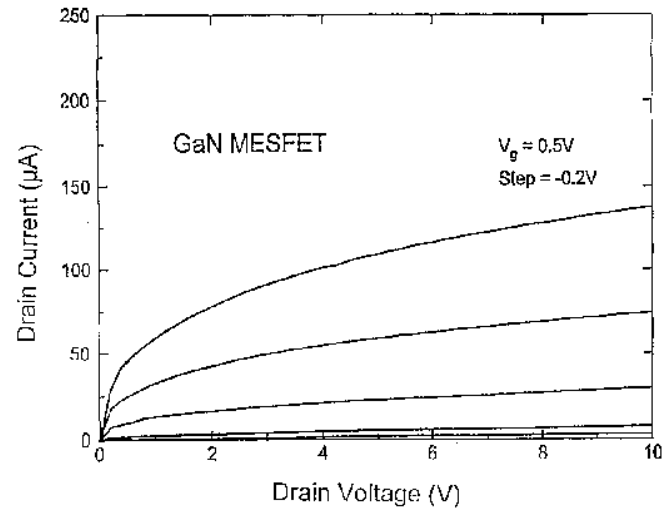

Figure 54. Drain I-V characteristics of a $1 \times 50 \mu \mathrm{m}^{2}$ MESFET. 


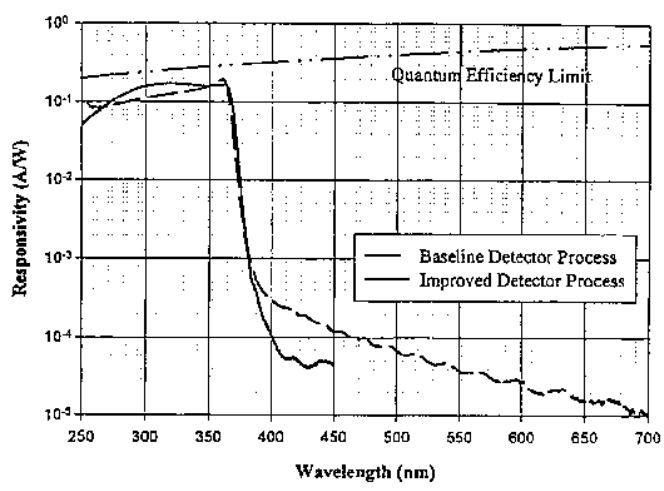

Figure 55. Spectral responsivity for GaN p-i-n UV photodetectors plotted against the maximum theoretical value with no reflection. 


\section{TABLES}

Table I. Boiling points for possible etch products of Group-III nitride films etched in halogen- or $\mathrm{CH}_{4} / \mathrm{H}_{2}$-based plasmas.

\begin{tabular}{|c|c|}
\hline Etch Products & Boiling Points $\left({ }^{\circ} \mathrm{C}\right)$ \\
\hline $\mathrm{AlCl}_{3}$ & 183 \\
\hline $\mathrm{AlF}_{3}$ & na \\
\hline $\mathrm{AlI}_{3}$ & 360 \\
\hline $\mathrm{AlBr}_{3}$ & 263 \\
\hline$\left(\mathrm{CH}_{3}\right)_{3} \mathrm{Al}$ & 126 \\
\hline $\mathrm{GaCl}_{3}$ & 201 \\
\hline $\mathrm{GaF}_{3}$ & 1000 \\
\hline $\mathrm{GaI}_{3}$ & sublimes 345 \\
\hline $\mathrm{GaBr}_{3}$ & 279 \\
\hline$\left(\mathrm{CH}_{3}\right)_{3} \mathrm{Ga}$ & 55.7 \\
\hline $\mathrm{InCl}_{3}$ & 600 \\
\hline $\operatorname{InF}_{3}$ & $>1200$ \\
\hline $\operatorname{InI}_{3}$ & na \\
\hline $\mathrm{InBr}_{3}$ & sublimes \\
\hline$\left(\mathrm{CH}_{3}\right)_{3} \mathrm{In}$ & 134 \\
\hline $\mathrm{NCl}_{3}$ & $<71$ \\
\hline $\mathrm{NF}_{3}$ & -129 \\
\hline $\mathrm{NBr}_{3}$ & na \\
\hline $\mathrm{NI}_{3}$ & explodes \\
\hline $\mathrm{NH}_{3}$ & -33 \\
\hline $\mathrm{N}_{2}$ & -196 \\
\hline$\left(\mathrm{CH}_{3}\right)_{3} \mathrm{~N}$ & -33 \\
\hline
\end{tabular}


Table II. Summary of etch rate results for GaN, AlN and InN with different plasma chemistries in different techniques.

\begin{tabular}{|c|c|c|c|c|c|c|c|c|c|c|}
\hline Gas Chemistry & $\begin{array}{l}\text { Etching } \\
\text { Technique }\end{array}$ & $\begin{array}{l}\text { Etch rate } \\
\text { (nm/min) } \\
\text { at given } \\
\text { bias }\end{array}$ & & & & & & & & \\
\hline & & & GaN & ref & & AlN & ref & & InN & ref \\
\hline $\mathrm{SiCl}_{4} \quad\left[\mathrm{w} / \mathrm{Ar}, \quad \mathrm{SiF}_{4}\right]$ & RIE & 55 & $-400 \mathrm{~V}$ & {$[6]$} & - & - & & - & - & \\
\hline $\mathrm{BCl}_{3}$ & RIE & 105 & $-230 \mathrm{~V}$ & [6] & - & - & & - & - & \\
\hline $\mathrm{HBr} \quad\left[\mathrm{w} / \mathrm{Ar}, \mathrm{H}_{2}\right]$ & RIE & 60 & $-400 \mathrm{~V}$ & [6] & - & - & & - & - & \\
\hline $\mathrm{CHF}_{3}, \mathrm{C}_{2} \mathrm{ClF}_{5}$ & RIE & 45 & $500 \mathrm{~W}$ & {$[5]$} & - & - & & - & - & \\
\hline $\mathrm{SF}_{6}$ & RIE & 17 & $-400 \mathrm{~V}$ & {$[6]$} & - & - & & - & - & \\
\hline $\mathrm{CHF}_{3}, \mathrm{C}_{2} \mathrm{ClF}_{5}$ & RIE & 60 & $-500 \mathrm{~V}$ & [6] & - & - & & - & - & \\
\hline $\mathrm{BCl}_{3} / \mathrm{Ar}$ & ECR & 30 & $-250 \mathrm{~V}$ & [5] & 17 & $-250 \mathrm{~V}$ & [5] & 17 & $-300 \mathrm{~V}$ & [5] \\
\hline $\mathrm{CCl}_{2} \mathrm{~F}_{2} / \mathrm{Ar}$ & ECR & 20 & $-250 \mathrm{~V}$ & [5] & 18 & $-300 \mathrm{~V}$ & [5] & 18 & $-300 \mathrm{~V}$ & {$[5]$} \\
\hline $\mathrm{CH}_{4} / \mathrm{H}_{2} / \mathrm{Ar}$ & ECR & 40 & $-250 \mathrm{~V}$ & {$[5]$} & 2.5 & $-300 \mathrm{~V}$ & {$[5]$} & 10 & $-300 \mathrm{~V}$ & [5] \\
\hline $\mathrm{Cl}_{2} / \mathrm{H}_{2} / \mathrm{Ar}$ & ECR & 200 & $-180 \mathrm{~V}$ & {$[8]$} & 110 & $-150 \mathrm{~V}$ & {$[8]$} & 150 & $-180 \mathrm{~V}$ & [8] \\
\hline $\mathrm{SiCl}_{4} / \mathrm{Ar}$ & ECR & 95 & $-280 \mathrm{~V}$ & [8] & - & - & & - & - & \\
\hline $\mathrm{Hl} / \mathrm{H}_{2}$ & ECR & 110 & $-150 \mathrm{~V}$ & [5] & 120 & $-150 \mathrm{~V}$ & [5] & 100 & $-150 \mathrm{~V}$ & [7] \\
\hline $\mathrm{HBr} / \mathrm{H}_{2}$ & ECR & 70 & $-150 \mathrm{~V}$ & [5] & 65 & $-150 \mathrm{~V}$ & [5] & 17 & $-150 \mathrm{~V}$ & [5] \\
\hline $\mathrm{ICl} / \mathrm{Ar}$ & ECR & 1300 & $-275 \mathrm{~V}$ & [5] & 200 & $-272 \mathrm{~V}$ & [5] & 1150 & $-275 \mathrm{~V}$ & [5] \\
\hline $\mathrm{IBr} / \mathrm{Ar}$ & ECR & 300 & $-170 \mathrm{~V}$ & [12] & 160 & $-170 \mathrm{~V}$ & [5] & 325 & $-170 \mathrm{~V}$ & [12] \\
\hline $\mathrm{BCl}_{3}$ & M-RIE & 350 & $<-100 \mathrm{~V}$ & [10] & 125 & $<-100 \mathrm{~V}$ & [5] & 100 & $<-100 \mathrm{~V}$ & [10] \\
\hline $\mathrm{Cl}_{2} / \mathrm{H}_{2} / \mathrm{Ar}$ & ICP & 688 & $-280 \mathrm{~V}$ & {$[8]$} & - & - & & - & - & \\
\hline $\mathrm{Cl}_{2} / \mathrm{Ar}$ & ICP & 980 & $-450 \mathrm{~V}$ & [8] & 670 & $-450 \mathrm{~V}$ & {$[8]$} & 150 & $-100 \mathrm{~V}$ & {$[8]$} \\
\hline $\mathrm{Cl}_{2} / \mathrm{N}_{2}$ & ICP & 65 & $-100 \mathrm{~V}$ & [8] & 39 & $-100 \mathrm{~V}$ & [8] & 30 & $-100 \mathrm{~V}$ & {$[8]$} \\
\hline $\mathrm{BBr}_{3}$ & ICP & 150 & -380 & [5] & 50 & -200 & [5] & 500 & -380 & [5] \\
\hline $\mathrm{BI}_{3}$ & ICP & 200 & -175 & [5] & 100 & -175 & [5] & 700 & -240 & {$[5]$} \\
\hline Icl & ICP & 30 & -300 & [5] & 30 & -300 & [5] & 600 & -300 & {$[5]$} \\
\hline Ibr & ICP & 20 & -300 & [5] & 30 & -300 & [5] & 600 & -300 & [5] \\
\hline Ar ion & $\begin{array}{l}\text { Ion } \\
\text { milling }\end{array}$ & 110 & $500 \mathrm{eV}$ & [5] & 29 & $500 \mathrm{eV}$ & [5] & 61 & $500 \mathrm{eV}$ & [5] \\
\hline $\mathrm{Cl}_{2}$ [Ar ion $]$ & CAIBE & 210 & $500 \mathrm{eV}$ & [6] & 62 & $500 \mathrm{eV}$ & [6] & - & - & \\
\hline $\mathrm{HCl}[\mathrm{Ar}$ ion] & CAIBE & 190 & $500 \mathrm{eV}$ & {$[6]$} & - & - & & - & - & \\
\hline $\mathrm{Cl}_{2}$ & RIBE & 150 & $500 \mathrm{eV}$ & [5] & - & - & & - & - & \\
\hline $\mathrm{HCl}$ & RIBE & 130 & $500 \mathrm{eV}$ & [5] & - & - & & - & - & \\
\hline $\mathrm{Cl}_{2} / \mathrm{Ar}$ & RIBE & 50 & -400 & [5] & 50 & -400 & [5] & 80 & -400 & [5] \\
\hline $\mathrm{HCl}$ & $\begin{array}{l}\text { Photoassi } \\
\text { sted }\end{array}$ & \begin{tabular}{|l}
$0.04 \AA /$ \\
pulse
\end{tabular} & [6] & - & - & & - & - & & \\
\hline $\mathrm{H}_{2}, \quad \mathrm{Cl}_{2}$ & LE4 & $50-70$ & $1-15 \mathrm{eV}$ & [9] & - & - & & - & - & \\
\hline
\end{tabular}

